University of Zurich

Department of Economics

Working Paper Series

ISSN 1664-7041 (print)

ISSN 1664-705X (online)

Working Paper No. 343

\title{
The Causal Impact of Socio-Emotional Skills Training on Educational Success
}

Giuseppe Sorrenti, Ulf Zölitz, Denis Ribeaud and Manuel Eisner

March 2020 


\title{
The Causal Impact of Socio-Emotional Skills Training on Educational Success*
}

\author{
Giuseppe Sorrenti \\ (University of Amsterdam) \\ Denis Ribeaud \\ (University of Zurich)
}

\author{
(r) Ulf Zölitz \\ (University of Zurich) \\ Manuel Eisner \\ (University of Cambridge)
}

\begin{abstract}
We study the long-term effects of a randomized intervention targeting children's socio-emotional skills. The classroom-based intervention for primary school children has positive impacts that persist for over a decade. Treated children become more likely to complete academic high school and enroll in university. Two mechanisms drive these results. Treated children show fewer ADHD symptoms: they are less impulsive and less disruptive. They also attain higher grades, but they do not score higher on standardized tests. The long-term effects on educational attainment thus appear to be driven by changes in socioemotional skills rather than cognitive skills.
\end{abstract}

Keywords: Socio-emotional skills, randomized intervention, child development, school tracking

JEL classification: C93, I21, I24, I26, J24

\footnotetext{
*We thank Caroline Chuard, Jan Feld, Mark T. Greenberg, Jonathan Guryan, Rahel Jünger, Nicolás Salamanca, Ursina Schaede as well as seminar participants at the NBER children's program meeting, the University College London, the University of Zurich, Royal Holloway-University of London, the University of Konstanz, VATT, the CESifo lunch seminar, the Ski and Labor Seminar, the z-proso Workshop and the briq Workshop on Skills, Preferences and Educational Inequality for helpful discussions and comments. Maximilian Mähr and Jeffrey Yusof provided outstanding research assistance. We gratefully acknowledge financial support from the Jacobs Foundation. Manuel Eisner: University of Cambridge, Institute of Criminology, manuel.eisner@crim.cam.ac.uk. Denis Ribeaud: University of Zurich, Jacobs Center for Productive Youth Development, denis.ribeaud@jacobscenter.uzh.ch. Giuseppe Sorrenti: University of Amsterdam, Amsterdam School of Economics, g.sorrenti@uva.nl. Ulf Zölitz: University of Zurich, Department of Economics and Jacobs Center for Productive Youth Development, IZA, CESifo, CEPR, ulf.zoelitz@econ.uzh.ch. The author order of Sorrenti and Zölitz has been randomized following Debraj 1 ) Robson (2018).
} 


\section{Introduction}

Socio-emotional skills matter. Economists, psychologists, and sociologists agree that socioemotional skills are predictive of major life outcomes like educational attainment, employment, earnings, health, and participation in crime (Barrick and Mount 1991; Heckman and Rubinstein 2001; Noftle et al. 2007; Roberts et al. 2007; Vazsonyi et al. 2007; Almlund et al. 2011). While the predictive power of socio-emotional skills has been established, there is a heated debate about how malleable these skills are. If these skills are indeed malleable, interventions targeting children's socio-emotional skills may change the trajectory of a life and lead to lasting changes in educational attainment and labor market outcomes.

In this paper, we study how a randomized intervention among 8-year-old children in Switzerland affects tracking, high school completion, and university enrollment. The Promoting Alternative Thinking Strategies (PATHS) intervention is a classroom-based socio-emotional learning program for elementary school students that aims to reduce behavioral problems (Greenberg et al. 1995). The intervention consists of weekly lessons and homework assignments embedded in the school curriculum. It lasts for up to two years and is designed to foster selfcontrol, patience, social problem-solving skills, self-esteem, emotional intelligence, as well as academic engagement.

PATHS teaches children to think twice and to look ahead. For example, in one classroom exercise, children learn to make less impulsive choices in difficult situations with the three-part "stoplight approach." First, on the red light, children slow down, take a few deep breaths and explain the problem they face. Next, on the yellow light, children think about solution options, consequences of their actions, and plan a solution to the problem. Finally, on the green light, children execute their plan and evaluate whether it worked. Teachers support children in applying the stoplight approach in role-play and real-life situations occurring in class such as a conflict with 
peers. The children also practice this approach in homework assignments: they describe a schoolrelated social or academic problem, explain solution strategies to parents or classmates, and collect feedback on their solution strategies. The PATHS intervention includes elements of cognitive behavioral therapy. It targets problem-solving and regulatory skills that have been associated with improved externalizing behavior conducive to learning, achievement, and future school success (Izard et al. 2004; Fantuzzo et al. 2007; Roberts 2007; Raver et al. 2011; Deming 2017).

The PATHS intervention was implemented in 2005 in the city of Zurich in Switzerland. Its main goal was to reduce disruptive and aggressive behavior by improving children's socioemotional skills (Eisner, Malti, and Ribeaud 2012). ${ }^{1}$ PATHS was introduced in 28 out of 56 randomly selected public primary schools. Randomization took place at the school level and was stratified within school districts. The intervention was supposed to last for one school year in second grade; however, the program was so popular that over 70 percent of schools accepted the offer to continue with the program for a second year. ${ }^{2}$

To evaluate the long-term effects of the intervention, we follow the treatment and control group over 15 years using the z-proso panel. This panel surveys children, teachers, and primary caregivers on an annual or biannual basis from 2004 until 2018, with the last wave interviewing individuals at age 20. The data include baseline and follow-up measures of children's socioemotional skills, parenting practices, family and household characteristics, as well as administrative and self-reported educational outcomes. The combination of multi-respondent

\footnotetext{
${ }^{1}$ See Eisner et al. (2012), and Malti, Ribeaud, and Eisner (2012), and Averdijk et al. (2016), for a more detailed description.

${ }^{2}$ The experimental design included the Triple $\mathrm{P}$ parenting training program, which was an additional treatment implemented in half of the schools in the PATHS treatment group and in half of the schools in the control group. The Triple P participation rate was only 23 percent (Eisner et al. 2007) and did not affect educational outcomes. This paper focuses on the PATHS intervention. For completeness, we discuss the additional intervention in Section 4 and provide evaluation results in the Appendix.
} 
survey data matched to administrative education records allows us to provide detailed evidence on how treatment effects evolve over time and what skills are affected by the intervention.

Our results show that, four years after the intervention, treated children become 4.4 percentage points more likely to get tracked into academic high school (Gymnasium). ${ }^{3}$ The treatment effect persists and these children become 7.1 percentage points more likely to complete academic high school. This effect is economically significant. It represents a 23 percent increase relative to the mean of the control group. At age 20, twelve years after the intervention, the treatment group is 21 percent more likely to attend university. The size of this effect is one-seventh of the treatment effect of the Abecedarian program for college attendance (Campbell et al. 2014) and one-quarter of the size of the Perry Preschool Program for high school completion (Schweinhart 1993, Heckman et al. 2010a). Our effect size on academic high school attendance is very similar to the treatment effect of the Baloo and You mentoring program (Falk, Kosse, and Pinger 2019).

To investigate how the intervention affected children's educational attainment, we study four potential mechanisms. We evaluate changes in: (1) grades and test scores, (2) socio-emotional skills, (3) children's classroom behavior, and (4) parenting practices.

We find evidence for the first three mechanisms. First, the intervention increases students' grades, but it has no impact on academic high school admission test scores. This result suggests that the treatment effect is more likely to operate through changes in socio-emotional skills rather than through improved cognitive skills. ${ }^{4}$ Second, treated children display less attention deficit and hyperactivity disorder (ADHD) symptoms: they are less impulsive and less disruptive. Treated

\footnotetext{
${ }^{3}$ Ability tracking into secondary school represents a key educational transition in Switzerland. Academic high school (Gymnasium) is the highest secondary school track in Switzerland. Enrollment in university requires a degree from an academic high school. Over 62 percent of OECD countries use a similar school-based tracking system (OECD 2004).

${ }^{4}$ Borghans et al. (2016) show that teacher-assessed grades capture both elements of a child's cognitive and socioemotional skills.
} 
children also display less opposition, defiance, and non-aggressive conduct disorders. Children's anxiety, physical aggression, and prosociality are not affected by the intervention. Third, treated children are less likely to disturb lessons and more likely to focus on the teaching content in class. We do not find that treated children become more likely to complete their homework assignments, which suggests that the treatment mostly affects engagement and attention in the classroom. Fourth, we find little treatment effects on parenting practices.

Taken together, our analysis of the underlying mechanisms paints a consistent picture. The PATHS program reduces children's impulsiveness and fosters their decision-making process. These behavioral changes improve classroom behavior, which is rewarded by higher grades. In the long run, these improvements in grades lead students to enter the academic high school track and enroll in university.

This paper contributes to the literature by connecting studies on long-term effects of childhood interventions to recent evidence on the malleability of socio-emotional skills. ${ }^{5}$ Although a number of existing studies hypothesize that the long-term impact of early childhood interventions are due to changes in socio-emotional skills, the direct empirical evidence for this link is limited. This paper fills that gap.

Figure 1 summarizes related intervention studies and our contribution to this literature. Panel (a) shows childhood intervention programs with long-term evaluations: Campbell et al. (2002) evaluate the Abecedarian preschool program, one of the oldest early childhood interventions, and show that the intervention improved IQ, achievement, and college enrollment.

\footnotetext{
${ }^{5}$ Durlak et al. (2011), Taylor et al. (2017), and Blewitt (2018) conduct a meta-analyses of school-based programs to promote students' social and emotional development and conclude that these programs are generally effective. Socioemotional learning programs are associated with improved attitudes about the self and others, increased prosocial behavior, lower levels of problem behaviors and emotional distress, and improved academic performance.
} 


\section{Figure 1: Related Intervention Studies and Contribution to the Literature}

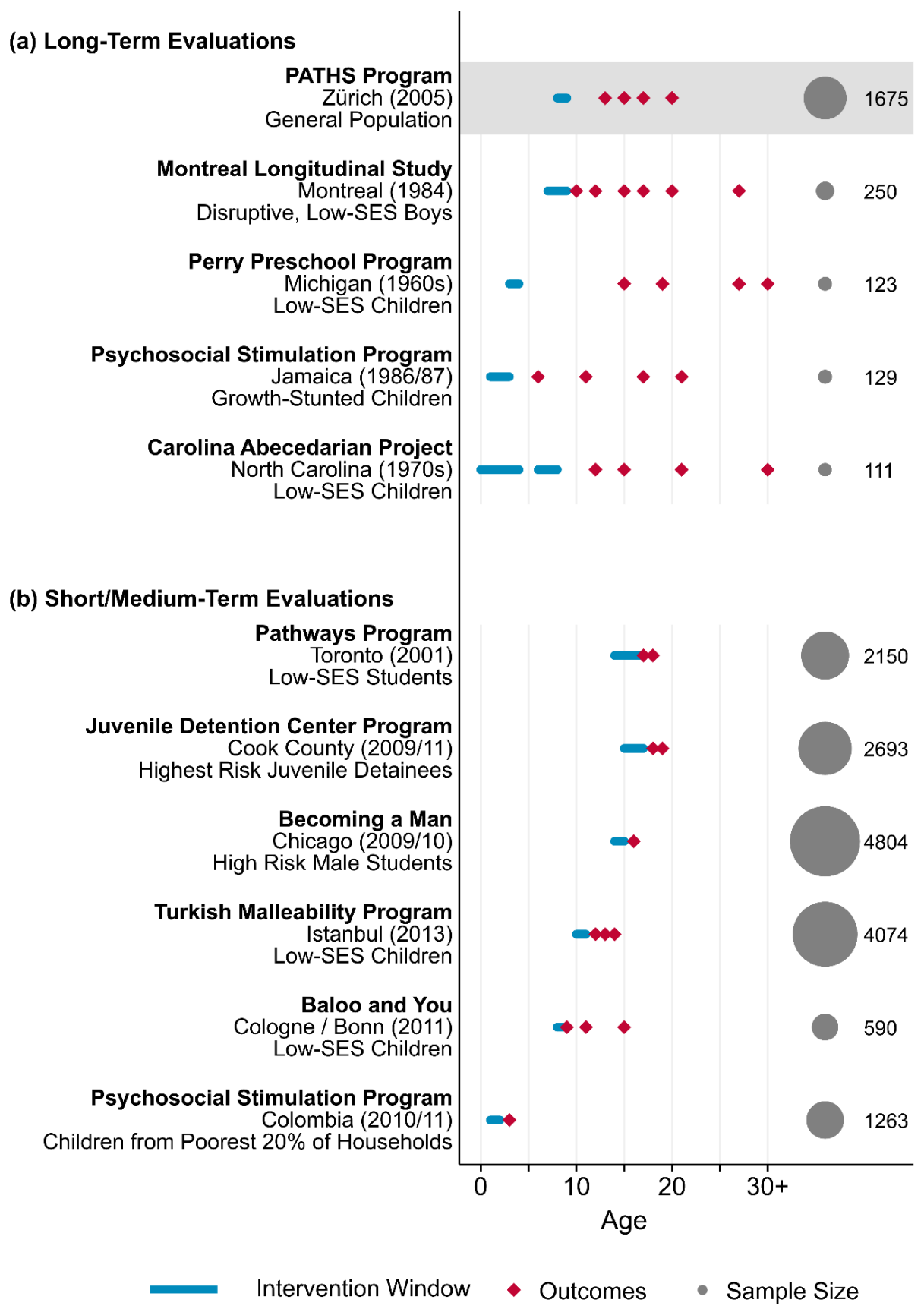

Note: This figure provides an overview of intervention studies in the related literature. Panel (a) shows intervention programs with long-term evaluations. Panel (b) shows programs with short- and medium-term evaluations of interventions targeting socio-emotional skills. Horizontal bars indicate the intervention duration. Red diamonds indicate when post-treatment measures are observed. Sample size refers to the number of students effectively randomized into treatment or control status. "SES" stands for socio-economic status. Information on the Montreal Longitudinal Study is taken from Algan et al. (2016). Information on the Perry Preschool Program is reported in Heckman et al. (2010). Information on the Jamaican Psychosocial Stimulation Program is taken from Gertler et al. (2014). Information on the Carolina Abecedarian Project is reported in Campbell et al. (2014), Information for the Juvenile Detention Center intervention and the Becoming a Man program is reported in Heller et al. (2017). Information for the Pathways program is reported in Oreopoulos et al. (2017). The Turkish Malleability Program refers to the randomized control trials analyzed in Alan and Ertac (2018) and Alan et al. (2019). Sample size and invention periods for the Baloo and You program are taken from Kosse et al. (2020) and Falk et al. (2020). 
Heckman et al. (2010a) and Schweinhart (1993) evaluate the Perry Preschool Program, which aimed to foster the development of disadvantaged children, and show that program participants obtained more schooling, had higher earnings, and committed fewer crimes. ${ }^{6}$ Gertler et al. (2014) analyze long-term effects of the Jamaican Study that contained an intervention aimed at improving mother-child interactions through home visits. They find increases of 25 percent in earnings 20 years after the intervention. Algan et al. (2016) use data from the Montreal Longitudinal Experimental Study, which aimed to improve socio-emotional skills in boys with after-school training sessions. This intervention increased self-control and trust during adolescence and increased educational achievements in early adulthood.

Panel (b) in Figure 1 summarizes more recent interventions explicitly targeting socioemotional skills in children. Alan, Boneva, and Ertac (2019) show that an intervention targeting grit increases students' perseverance and subsequent math test scores two years after the intervention. Alan and Ertac (2018) show that an intervention targeting patience improves selfcontrol and the ability to imagine future selves. These effects lead to more patient intertemporal choices and persist over a three-year period. Cappelen et al. (forthcoming) show that early childhood education affects children's social preferences for fairness and the importance children place on efficiency relative to fairness. Oreopoulos et al. (2017) evaluate a mentoring and tutoring program and find that the program increases high school completion by 35 percent and postsecondary enrollment by more than 60 percent. Kosse et al. (2020) study a mentoring program for primary school children and show that the program persistently increases prosociality. Falk et al. (2020) follow these children over time and show that the program also increases the probability of attending the academic high school track. Heller, et al. (2017) evaluate an intervention in

\footnotetext{
${ }^{6}$ Heckman and Karapakula (2019a and 2019b) follow up on these results and highlight positive long-term effects on cognitive skills, employment, health, and reduced crime, as well as positive intergenerational spillovers.
} 
Chicago similar to PATHS called "Becoming a Man" (BAM). Both programs target emotional awareness, emotion regulation, and behavioral change in the decision-making process of students. ${ }^{7}$

We contribute to the literature in four ways. First, we observe children over a decade after the intervention. This distinguishes us from studies focusing on interventions targeting socioemotional skills, which are limited to outcomes observed a few years after the intervention. Second, in contrast to studies evaluating the long-term consequences of other childhood interventions, we have a substantially larger sample. With 1,675 individuals, we have more statistical power than the Abecedarian Program $(n=111)$, the Perry Preschool Program $(n=123)$, the Jamaican Study $(n=129)$ and the Montreal Longitudinal Study $(n=250)$. Third, while other studies almost exclusively focus on disadvantaged children, we evaluate an intervention that targets children of all backgrounds. Fourth, our detailed survey data allow us to provide evidence on the underlying mechanisms showing which skills and behaviors are affected by the intervention.

\section{The PATHS Training Program}

PATHS is a teacher-led program for primary school children that was developed by Mark T. Greenberg and Carol A. Kusché at the University of Washington for the US context (Kusché and Greenberg 1994). The program teaches systematic coping and decision-making strategies with the aim of fostering children's self-control, emotional understanding, and social problem solving skills (Greenberg et al. 1995).

PATHS focuses on regulatory skills; it aims to foster social skills and improve externalizing behavior (Greenberg et al. 1995, 1998). These behavior changes should improve educational participation, reduce disruptive and aggressive behavior in the classroom, and,

\footnotetext{
7 Both interventions were originally implemented to reduce future aggression and delinquency. The PATHS intervention shows, in contrast to Heller et al. (2017), no impact on aggression and delinquency (Averdijk et al. 2016). This may be due to different environments in Chicago and Zurich. In 2017, for example, the Chicago homicide rate was 28 times higher and the assault rate 48 times higher than in Zurich.
} 
ultimately, reduce violence, delinquency, and crime. Table I, provides an overview of the PATHS curriculum, which targets the following competences: ${ }^{8}$

(1) Self-control, patience

(2) Decision-making strategies, social problem solving

(3) Self-esteem

(4) Emotional intelligence

(5) Fairness and rules

[Table I]

(1) Self-control, patience: PATHS targets self-control and patience through several exercises. Children learn to calm down in stressful situations using breathing techniques. They learn that it is their own responsibility to avoid exploding in anger and losing self-control through the analogy of a balloon that can burst. They role-play situations in which they practice ignoring, interpreting, and handling teasing of other children. They listen to a story of a girl who learned how to control herself by calming down and recognizing her emotions. The children complete some of these exercises at home. For example, children interview their parents about situations in which they had to calm down and write a summary of how their parents managed the situation.

(2) Decision-making strategies, social problem solving: PATHS targets decision-making strategies and social problem solving based on the stoplight approach. To introduce the stoplight approach, the teacher uses the stoplight poster shown in Figure A1 in the Appendix. This approach teaches children systematic decision-making by going through three mental steps before taking

\footnotetext{
${ }^{8}$ Figures A1-A4 in the Appendix provide examples of the teaching material related to the activities summarized in Table I.
} 
action. Each step represents one of phases of the stoplight. The red-light phase is associated with the word "stop." In this phase, children must slow down, take a few deep breaths, and explain the problem they are facing. The yellow-light phase is associated with the word "think." In this phase, children reflect on their solution options, think about the possible consequences of their actions, and make a plan to solve the issue. They also think about how others will respond to their actions. The green-light phase is associated with the word "act." In this phase, children execute their plan and evaluate whether it worked.

After introducing the method in class, the teacher discusses concrete situations in which children can use the approach. Children then apply the stoplight approach in repeated role-play exercises that simulate everyday situations. These exercises involve conflict situations with peers, parents, or teachers, or problems with school assignments. In homework assignments, children describe their problem-solving approach to a specific situation. They also practice the approach at home and explain the three steps to their parents, who receive a separate information leaflet about the benefits of the stoplight approach (Figure A5).

(3) Self-esteem: PATHS aims to increase children's self-esteem by making them aware of their strengths and skills. In one of the lessons, children learn to give and accept compliments from peers and teachers. The teacher explains the concepts of compliments and respect as well as how to express compliments. Children then practice how to give compliments to each other in the classroom. In one homework assignment, children exchange compliments with parents and other family members at home.

In another exercise, the "child of the week" receives special privileges and duties for one week. As part of this exercise, the child acts as the teacher's assistant. At the end of the week, the teacher and classmates prepare a special child-of-the-week certificate with a picture of the child 
and a series of compliments and anecdotes describing what attributes classmates value in the child. While this activity is supposed to foster self-esteem, it also teaches children that privilege comes with responsibilities. They are supposed to learn that being valued by others also requires contributing to the common good.

(4) Emotional intelligence: PATHS targets emotional intelligence by fostering the understanding and expression of feelings. In one lesson, the teacher reads stories and children guess what feelings the protagonist felt. In one homework assignment, children describe their feelings during a recent emotional situation and discuss with their parents how they dealt with their emotions. With this exercise, children learn about themselves and become more aware of how their behavior affects the feelings and perceptions of peers, parents, and teachers. To facilitate the recognition and expression of feelings, children receive "feelings cards." These cards show children expressing different emotions such as happiness, excitement, anger, surprise, sadness, and worry (see Figure A2 in the Appendix). Children first color these cards and then use them to express their current emotional state by placing the corresponding card on their table. In a final step, children reflect on how to demonstrate an emotion. For example, they have to find appropriate verbal responses to feelings like anger or sadness.

(5) Fairness \& rules: Starting with the first PATHS lesson, children discuss the importance of having rules and manners. They discuss with their teachers in class and parents at home which rules should be established in the classroom, at home, and in general everyday life. PATHS also tries to foster children's understanding of fairness by introducing children to principles of fair behavior. In one lesson, children have to identify fair and unfair behavior in different situations. 
In another lesson, the teacher reads a story and the children discuss whether the protagonists' behavior is fair or unfair.

\section{Data and Institutional Background}

This section provides the institutional background of this study. First, we introduce the Zurich Project on Social Development from Childhood to Adulthood (z-proso data collection). Second, we illustrate the main characteristics of the education system in the Canton of Zurich.

\subsection{The z-proso Study}

The data we analyze in the paper come from the z-proso panel study (Malti, Ribeaud, and Eisner 2011; Eisner et al. 2012; Averdijk et al. 2016). The study surveys students, teachers, and primary caregivers $^{9}$ to investigate the life-course of 1,675 children starting primary school in 2004 in Zurich, the largest city in Switzerland. Table II provides an overview of the timing of the surveys and the respondents in eight different waves that took place between 2004 and 2018. By 2018, the study had followed children over a 15 -year period until they were 20 years old. The data include pre-intervention (baseline) and follow-up measures of children's socio-emotional skills, parenting practices, family and household characteristics, and administrative and self-reported educational outcomes. Appendix B1 describes the data collection, informed consent, and ethics approval in greater detail.

[Table II]

\footnotetext{
${ }^{9}$ In most cases the primary caregiver is a child's biological parent. Throughout the paper we use the terms primary caregiver and parents interchangeably.
} 
Two early prevention programs were implemented as part of the z-proso study. The first intervention was PATHS, the school-based social and emotional learning-based program we focus on in this paper (see Section 2). The second intervention was the "Positive Parenting Program" (Triple P). Triple P encourages "positive parenting" by teaching techniques that support desired child behavior, routines that avoid parent-child conflicts, and techniques that help the child plan ahead (Sanders 1999). In this paper, we focus on the PATHS intervention. For completeness, we provide more details on the Triple $\mathrm{P}$ intervention in Section 4 and show its treatment effects in the appendix.

\subsection{Education and Tracking System}

Figure 2 illustrates the school system and educational transitions in the canton of Zurich. Children start primary school at age 7 . At age 12, after six years of primary school, children are tracked into different secondary schools.

The highest school track is academic high school (Gymnasium). Students attend this school for six years and typically graduate when they are 18 years old. It prepares students for university education and allows them to obtain the Matura degree required to enroll in university. Children in the lower track attend one of three secondary high schools called Sekundarschule level A, B, and C. These schools prepare students for vocational education and apprenticeship trainings. Level A leads to white collar jobs and levels B and C lead to blue collar jobs. Students in all three lower tracks attend school for three years and are typically 16 years old upon completion.

Which track the children will attend is determined by their grades in their last year of primary school and their scores on a standardized admission test measuring mathematics and language skills. Grades and test scores receive equal weight. Parents cannot choose the secondary school track and have no direct influence on the tracking outcome. 
Figure 2: School Tracking and Measurement of Educational Outcomes

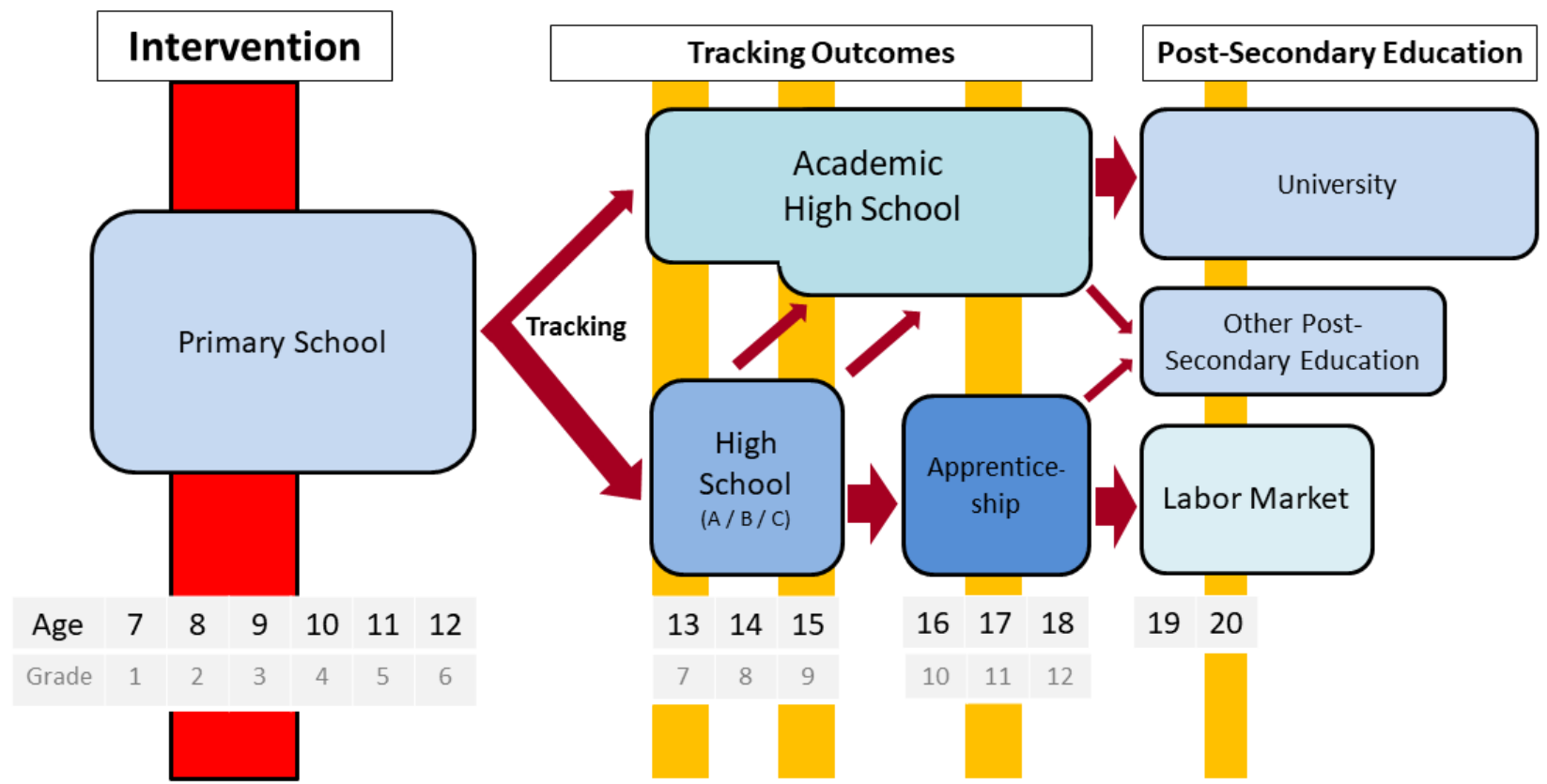

Note: This figure illustrates the structure of the school system in the canton of Zurich. Children attend primary school for six years from ages 7 to 12 (Grade 1 to Grade 6). At the end of primary school, at age 12, children are tracked either into academic high school (Gymnasium) or into regular high school (Sekundarschule). The tracking outcome is exclusively determined by children's grades in the final year of primary school and academic high school admission test scores. Children can either attend academic high school directly starting from Grade 7 (Long-term Gymnasium) or from Grade 9 onwards (Short-term Gymnasium). The non-academic high school track comprises three lower tracks called Sek A, Sek B, and Sek C. Children attending regular high school can also transfer to academic high school after two or three years. The Matura degree obtained upon completion of academic high school is a requirement to enroll in university. Students graduating from regular high school typically start an apprenticeship at age 16. Apprenticeships last two to four years. The red vertical bar indicates the intervention period. The yellow bars indicate the points in time where we observe educational outcomes.

Two additional features characterize the school system in the canton of Zurich. First, after Grade 3, children are reassigned to new classes and teachers if school size permits. Second, children can switch between the different tracks throughout secondary school (see also Figure 2). Students can obtain the Matura degree from an academic high school either through attending long-term academic high school or short-term academic high school. Tracking into long-term academic high school takes place after Grade 6. Tracking into short-term academic high school takes place after Grade 8 or 9. Later transitions are possible if students have sufficiently high grades and pass the standardized admission test. The share of students in the highest track increases by 5-10 percent during the three years of secondary school. 


\section{Experimental Design}

\subsection{Selection of Schools, Randomization, and Definition of Treatment Group}

Selection of participating schools: Zurich consists of seven school districts and has a total of 90 primary schools. In each school district, eight schools were randomly selected to participate in the experiment. All 56 selected schools complied with the request of the City of Zurich's School and Sports Department to participate in the study.

Stratification and Randomization: The 56 participating schools were assigned to 14 strata cells. These cells were constructed by dividing each of the seven school districts into two groups consisting of four similar-sized schools. Within each strata, each school was randomly assigned to one of four treatment groups using a random number generated in Microsoft Excel. Schools with the largest random number in each strata were assigned to the PATHS program (PATHS only). Schools with the second largest number were assigned to the Triple P program (Triple P only). Schools with the third largest number were assigned both to the PATHS and Triple P programs (PATHS \& Triple P). Finally, schools with the lowest number received neither the PATHS nor the Triple P intervention. These schools are the pure control group.

Definition of treatment and control groups: In this paper, we focus on the PATHS intervention and define the treatment group as the group of schools assigned to the one of the two PATHS treatment arms — either PATHS only or PATHS \& Triple P combined. The control group consists of the pure control group and the Triple P-only group. Based on this definition, we have 28 treated and 28 control schools.

We include Triple P schools in the control group because this program had no impact on children's educational careers. It also had no impact on children's problematic behavior or 
educational outcomes (Malti et al 2011; Eisner et al 2012). We provide these results in Table A1 in the Appendix. Triple $\mathrm{P}$ has been shown to be effective for younger children (Doyle, forthcoming). In our setting, however, it suffered from low participation rates. Only 23 percent of parents in the treatment group participated, which makes it challenging to detect any treatment effects.

Given that there are four treatment arms of the original experimental design, we could also estimate effects for each of the three treatment groups separately. In Section 6.2 we show that this approach leads to similar results. Alternatively, we could drop all students that received the Triple P treatment and compare only the pure PATHS with the pure control group. We provide results based on this alternative sample definition in Section 6.2. While we lose about half of our observations with this definition, results remain very similar.

\subsection{Implementation of the Intervention}

In the 2005/06 school year, PATHS was implemented in 28 primary schools in cooperation with the Department of School and Sports of the City of Zurich. Prior to the implementation, the original PATHS material was translated and adjusted to the Swiss context by Rahel Jünger in collaboration with the US developers (Eisner et al. 2007). Rahel Jünger also implemented the program and conducted the teacher training and supervision. This implementation was done independently from the evaluation.

To prepare schools for delivering the PATHS intervention, all teachers in charge of running PATHS lessons participated in a three-day workshop with a PATHS coach. During this workshop the PATHS coach gave teachers an overview of the key concepts, classroom activities, posters, toys, and over 400 pages of materials. During the first year of the program, teachers regularly met their PATHS coach, who gave them feedback and support. PATHS coaches also monitored the 
implementation and observed six PATH lessons for each participating class. After each of these observations, the coach provided suggestions for improvements and graded the quality of the implementation.

The 45-minute PATHS lessons typically took place twice per week. The majority of children received PATHS lessons throughout the entire Grade 2. PATHS lessons replaced the class "Humans and Environment" (Mensch und Umwelt), which teaches children about the environment and organization of Swiss society. To reinforce the practice of PATHS methods, teachers also applied PATHS strategies in lessons not explicitly dedicated to the PATHS curriculum itself. Over the course of Grade 2, children received about 45 hours of PATHS lessons and about 20 hours of PATHS homework assignments (Eisner et al. 2007). Because the majority of teachers, parents, and children highly appreciated PATHS, over 70 percent of schools continued using the program for a second year in Grade 3. The program ended for all children at the end of Grade 3 when classes were reshuffled and students received a new teacher.

Implementing PATHS only cost USD 1,540 per class or USD 67 per student. These costs were for training and materials. The intervention did not lead to increased salary costs as the PATHS curriculum replaced an existing subject. We compare the costs of PATHS to other interventions in Section 8.3.

\subsection{Outcome Variables and Descriptive Statistics}

Outcome variables: We evaluate the long-term effects of the PATHS intervention on educational outcomes. The key outcomes of interest are whether individuals attend and complete the academic high school track (Gymnasium), whether they obtain the Matura degree, which allows them to enroll in any university, and whether they are enrolled in university at age 20. 
We observe students' secondary school tracks at ages 13,15, and 17 from administrative school data provided by the Department of Education of the Canton of Zurich. Some children leave the canton of Zurich and therefore disappear from the administrative data. We therefore complement the administrative records with self-reported tracking outcomes at ages 13,15 , and 17 based on the z-proso survey. ${ }^{10}$ We observe whether students complete academic high school and enroll in university from the wave 8 z-proso survey administered at age 20 .

[Table III]

Table III show that 16 percent of the participants attend academic high school at age 13, right after tracking has taken place. This number increases to 20 percent at age 15 and 26 percent at age $17 .{ }^{11}$ Twenty-seven percent of children complete academic high school, and 17 percent are enrolled in university at age 20 .

Baseline measures: Table III shows characteristics of children and parents measured at the baseline, that is, in the year before the start of the intervention. At this time, children were, on average, seven years old. Forty-eight percent are girls. Our sample comes from a diverse population: only 60 percent are Swiss, only 42 percent were born in Switzerland, and only 49 percent of mothers are Swiss. Seventeen percent of households are single-parent households. About 39 percent of mothers have completed academic high school (Gymnasium), and 16 percent hold a university degree. Fathers are slightly more educated than mothers, with 52 percent having

\footnotetext{
${ }^{10}$ The z-proso study aims to track individuals even after they moved out of the canton or leave the country and has a remarkably low attrition rate. At age 20, we observe self-reported education outcomes for over 70 percent of the original sample $(\mathrm{n}=1,675)$.

${ }^{11}$ The proportion of students in academic high school increases over time due to students' switching to Gymnasium from lower tracks during different stages of secondary school.
} 
completed Gymnasium or other types of higher education and 25 percent holding a university degree. The average family household income is USD 86,000 per year; 38 percent of families are entitled to financial aid, and 18 percent report financial problems at the baseline.

Our data contain detailed baseline measures of child behavior assessed through the Social Behavior Questionnaire (SBQ) (Tremblay et al. 1991; Murray et al. 2019). The SBQ covers the following domains: ADHD symptoms (disruptiveness and impulsiveness), opposition and defiance, non-aggressive conduct disorder, anxiety and depressivity, aggression, and prosociality. At the baseline, SBQ measures are available from teacher, parent, and child reports. The data also contain measures of parenting practices assessed through the Alabama Parenting Questionnaire (APQ) (Shelton, Frick, and Wootton 1996). The APQ includes the following domains: corporal punishment, inconsistent discipline, parental supervision, parental involvement, and positive parenting.

\section{Empirical Strategy}

This section introduces our empirical model and provides evidence on the balance between the treatment and control groups.

\subsection{Empirical Model}

Our goal is to estimate the treatment effect of the PATHS intervention on educational outcomes. Equation (1) shows our main empirical model:

$$
Y_{i}=\beta_{1} \text { PATHS }_{\mathrm{i}}+X_{i}^{\prime} \gamma+\theta+\varepsilon_{i},
$$


where $Y_{i}$ is the outcome of interest of individual $i$ (attendance of academic high school at ages 13, 15 , and 17, academic high school completion, and university enrollment at age 20). PATHS is an indicator showing whether the individual was randomly assigned to the PATHS training program. $\beta_{1}$ is the parameter of interest. It captures the treatment effect of participating in the PATHS program. Vector $X_{i}$ contains baseline control variables. These differ depending on the specification. In our most complete specification, we include pre-treatment measures of child characteristics, household characteristics, and child socio-emotional skills. Child characteristics include age, gender, and Swiss citizenship. Household characteristics include household income, mother's age at the baseline, mother's education, father's education, and indicator variables for whether the mother was born in Switzerland and whether she has Swiss citizenship, whether the household is single-headed, whether the household reports receiving financial aid, and whether the household reports financial problems. For a child's socio-emotional skills, we rely on SBQ measures reported by the teacher and the primary caregiver. These include ADHD symptoms (disruptiveness and impulsiveness), anxiety and depressivity, aggression, prosociality, nonaggressive externalizing problem behavior, non-aggressive conduct disorder, and opposition and defiance. The model always includes strata fixed effects $\theta$ for the level at which randomization took place. $\varepsilon_{i}$ represents the error term of the model.

We estimate Equation (1) using linear probability models and cluster standard errors at the school level. We additionally provide $p$-values based on randomization inference with 10,000 repetitions following Young (2018).

\subsection{Balancing Tests}

The identifying assumption of our empirical strategy relies on the random assignment of children to the treatment status. To verify this assumption, we test whether baseline characteristics predict 
treatment status. In particular, we regress treatment status on each of the pre-treatment characteristics separately. We use all available characteristics on child and family demographics and measures for socio-emotional skills, and we estimate a total of 56 regressions.

Table IV summarizes the balancing tests. Column (1) shows the number of statistically significant coefficients we obtain when regressing the indicator for treatment status (PATHS) on baseline characteristics. Column (2) shows the number of coefficients we would expect to find statistically significant due to chance variation. Overall, Table IV suggests that the randomization was successfully implemented: the number of significant coefficients is similar to the expected number of significant coefficients under random assignment.

\section{[Tables IV and V]}

Table V provides a closer look at unbalanced variables by reporting point estimates from all 56 balancing regressions. The analysis reveals a substantial and significant imbalance $(p<0.01)$ in fathers' education levels between the treatment and the control group. Given that parental education is a key determinant of children's educational outcomes, this imbalance deserves careful consideration. Children receiving the PATHS intervention come from families with, on average, less educated parents. Treated children are about ten percentage points less likely to have a father that holds at least an academic high school degree. This imbalance in fathers' education levels will make it harder for us to identify effects of the intervention if the treatment affects children's educational outcomes positively. Without accounting for this imbalance, we would underestimate treatment effects of the PATHS training program. To assess how much this imbalance affects our results, we will provide results from three empirical specifications. The first specification does not control for parental education. The treatment effect estimate in this model will be downward biased 
due to the imbalance in parental education. The second specification accounts for this imbalance by controlling for parental education. As a final test, we estimate a specification with a full set of baseline control variables to test the sensitivity of our findings to including a large set of additional pre-treatment characteristics. ${ }^{12}$

\section{Results}

In this section, we provide the main results of our analysis on the impact of the PATHS curriculum on educational careers. We also test whether these results are driven by selective attrition and estimate treatment effects for different subgroups.

\subsection{Main Results}

Table VI shows estimates of the PATHS treatment effect on education trajectories. The outcome variables in columns (1) to (3) are indicator variables for attendance of academic high school at ages 13, 15, and 17. The outcome variables in columns (4) and (5) are indicator variables for academic high school completion and university enrollment at age 20, respectively. Panel A reports results without control variables. Panel B reports results with additional controls for parental education to account for the imbalance between treatment and control groups at the baseline. We refer to this set of controls as randomization controls. Panel $\mathrm{C}$ reports results including randomization controls and a large set of additional baseline control variables.

\section{[Table VI]}

\footnotetext{
12 These additional pre-treatment characteristics include mother's age, child's age, household income, as well as indicators for whether the mother is a Swiss national, whether the mother was born in Switzerland, whether the child is a Swiss national, whether the child is female, whether the child has been raised in a single-parent household, whether the household has financial problems, and whether the household receives financial aid.
} 
Panel A of Table VI provides estimates of the effect of the PATHS program from specifications without baseline controls. Despite having less-educated parents, children who attended the PATHS program appear to do better than children in the control group. While not statistically significant, the point estimates are positive for all outcomes. For example, treated children are 3.3 percentage points more likely to attend academic high school at age 17 and 2.3 percentage points more likely to have completed academic high school at age 20.

Panel B shows estimates that account for the imbalance in parental education at the baseline. In these specifications, we see positive and statistically significant treatment effects for all educational outcomes. The point estimates show that the PATHS program increases children's likelihood of attending an academic high school by 2.3 percentage points at age 13, by 4.1 percentage points at age 15 , and by 6 percentage points at age 17 . This effect increases with student age because PATHS students are more likely to transition to the academic track from lower-track schools. These effects translate into higher graduation grades. Attending PATHS increases children's likelihood of completing academic high school by 5.1 percentage points by age 20 . This effect represents a 20 percent increase over the completion rate of the control group. Finally, we also see that attending PATHS increases children's likelihood of enrolling in university by 3.6 percentage points (21 percent).

Panel C of Table VI shows results including controls for parental education and a large set of additional baseline control variables. These additional controls are child characteristics, household characteristics, and child's socio-emotional skills. More specifically, we control for age and gender of the child, the Swiss citizenship of the child, household income, age of the mother, indicator variables for the mother having Swiss citizenship and being born in Switzerland, singleparent household status, receipt of financial aid, financial problems reported by the household, as well as baseline measures of a child's socio-emotional skills covering ADHD symptoms, anxiety 
and depressivity, non-aggressive externalizing problem behavior, non-aggressive conduct disorder and opposition and defiance. Differences in the point estimates between the models with and without extra control variables provide information on the extent to which correlated unobservables affect the relationship between the treatment effect and education outcomes. If the estimates remain similar despite including this large set of observable characteristics, results are likely robust to factors not included in the estimations (Altonji, Elder, and Taber 2005).

Panel $\mathrm{C}$ shows that the results are robust to including a large set of additional baseline control variables that also substantially increase the R-squared. For these specifications, we have smaller samples due to missing values in our control variables. However, for each outcome, point estimates in the model with randomization controls (Panel B) and the full set of controls (Panel C) are not statistically different from each other. Point estimates in these specifications show that PATHS increases children's likelihood of completing academic high school by 7.1 percentage points (23 percent) and increases their likelihood of enrolling in university by 4 percentage points (21 percent).

Figure 3 summarizes how the treatment effect evolves over time and provides a comparison between the models with randomization controls (Panel a) and the model that includes the full set of baseline control variables (Panel b). The similarity of results between the two panels points to the robustness of our findings: Our estimates are not sensitive to including a large set of control variables. $^{13,14}$

\footnotetext{
${ }^{13} \mathrm{We}$ also investigate whether the treatment affects other outcomes at age 20. Figure A6 in the Appendix shows that treated individuals are more likely to be enrolled in education or vocational training and less likely to be searching for vocational training or other further education. Conditional on not being in education or training, treated individuals are more likely to be employed full-time. We do not find that the intervention affects the probability of having no educational degree or the probability of being unemployed. Given that individuals are only 20 years old, it is probably too early to provide conclusive evidence on their labor market outcomes.

${ }^{14}$ In Appendix B3 we investigate whether the treatment effect creates a potential mismatch between students and high schools. We find no evidence that marginal students who got pushed into academic high school by the treatment perform relatively worse in the more challenging school track.
} 
Figure 3: Main Results - Treatment Effects on Educational Outcomes

(a) Randomization Controls

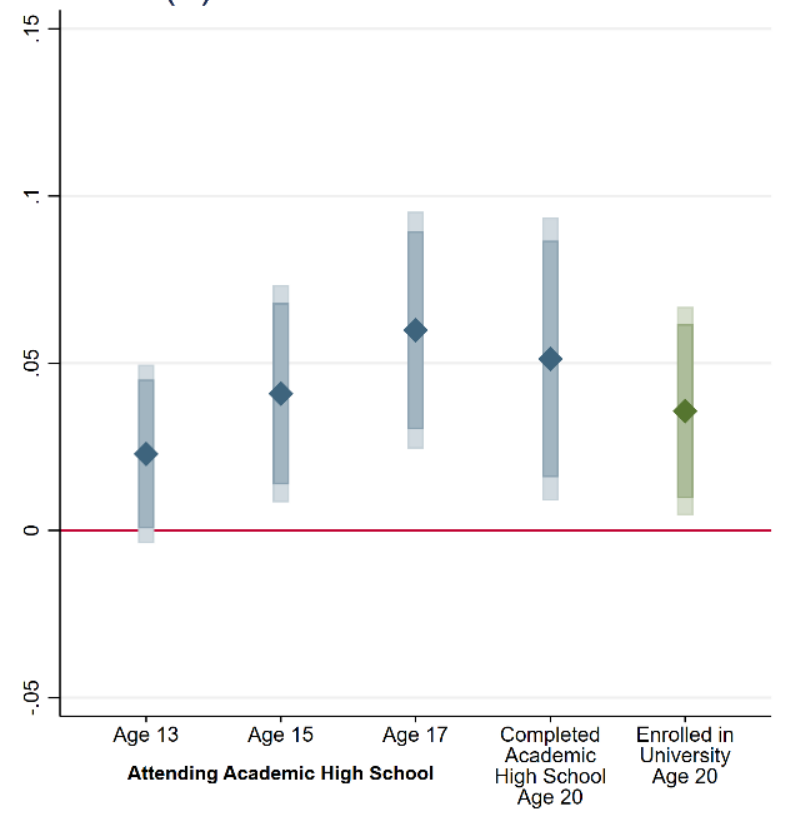

(b) Full Set of Controls

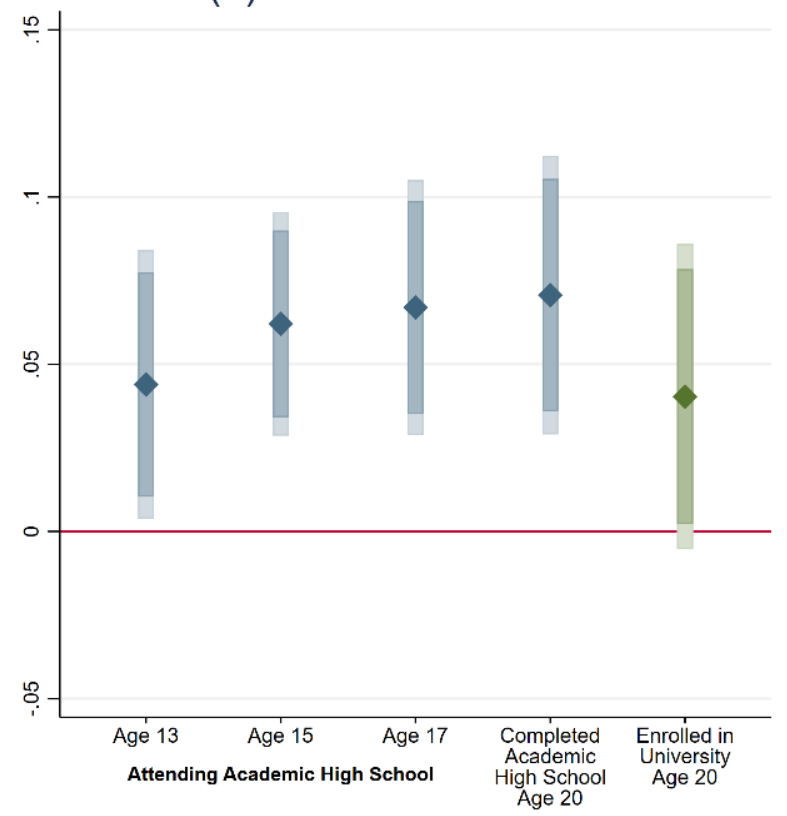

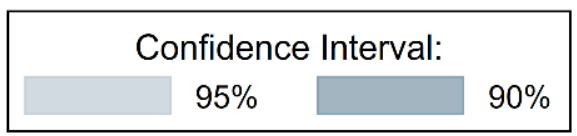

Note: This figure is based on estimates shown in Table VI and shows the treatment effect of the PATHS intervention on the probability of attending academic high school at age 13,15, and 17 as well as on the probability of completing academic high school and being enrolled in university at age 20. All dependent variables are indicator variables and all specifications are estimated using linear probability models. All models include strata fixed effects for the level of randomization. In Panel (a), we include randomization controls for mother and father education level and indicator variables for missing education level. In Panel (b), we include controls for baseline child, parental, and household characteristics and baseline child SBQ measures. Child controls include age and gender of the child and having Swiss citizenship. Household controls include household income, age of the mother, indicator variables for the mother having Swiss citizenship and being born in Switzerland, an indicator for mother and father education level, indicator variables for missing education level, and indicator variables for single-parent household, household that received financial aid, and household that experienced financial problems. Controls for baseline child SBQ measures include measures for anxiety and depressivity, ADHD, non-aggressive externalizing problem behavior, non-aggressive conduct disorder, opposition and defiance, prosociality, and three measures of aggressive behavior. Each point estimate is shown with the respective 90 and 95 percent confidence intervals calculated based on standard errors clustered at the school level.

Overall, we observe large and economically significant effects. In the average class in our sample, five out of 28 children attend university at age 20 . The size of the treatment effect implies that one additional child — six instead of five children-will attend university due to the intervention. The size of our treatment effect for attending academic high school (a 20 percent increase) is very similar to the treatment effect of the mentoring program Baloo and You on the 
same outcomes in Germany (a 23 percent increase; Falk, Kosse, and Pinger 2019). The effect size we find is equivalent to one-seventh of treatment effect of the Abecedarian program on college attendance (Campbell et al. 2014) and about one-quarter of the size of the Perry Preschool Program on high school completion (Heckman et al. 2010a). We discuss our effect sizes and how they compare to other childhood interventions in Section 8.

\subsection{Robustness Analysis}

In this section, we test the robustness of our results in three ways. First, we test whether our conclusions remain the same if we compute $p$-values based on randomization inference. Second, we estimate specifications using the three separate treatment groups based on the original experimental design. Third, we test whether selective attrition drives our results.

Randomization inference: In the main analysis, we cluster standard errors at the school level, resulting in 56 clusters. As a robustness test, we compute $p$-values based on randomization inference using 10,000 random permutations. With this procedure we account for possible bias in standard errors due to a small number of clusters. Table VI shows that $p$-values based on randomization inference lead to the same overall conclusions.

Three separate treatment groups: Our baseline analysis compares individuals exposed to PATHS (treatment) to individuals who were not exposed to PATHS (control). However, some individuals in the treatment and control groups were also exposed to the Triple P program. In Table A1 in the appendix we show estimates of being assigned to each of the three treatment arms of the original experiment (PATHS only, PATHS + Triple P, Triple P only) compared to the nointervention group (pure control). This table shows that the PATHS treatment effect remains 
similar to the effect in Table VI and that the Triple $\mathrm{P}$ intervention has no significant effect on educational outcomes. The lack of effects for Triple P is consistent with Eisner et al. (2012), who show that the intervention had no short-term effects on either parenting practices or child problem behavior.

Selective attrition: To test for selective attrition, we estimate the effect of attending the PATHS program on the probability of observing an individual in our estimation sample at four different points in time: at ages $13,15,17$, and $20 .{ }^{15}$ More specifically, we regress an indicator showing whether we observe the individual in our sample at a given time on a PATHS treatment dummy. Table A3 shows that the treatment does not affect the probability of being observed in the sample at different points in time. The PATHS coefficients are small and not statistically significant in all specifications. Selective attrition does not appear to drive our results. ${ }^{16}$

\subsection{Dosage and Heterogeneous Treatment Effects}

In this section, we shed light on dosage effects of the intervention and test whether there are larger treatment effects for children who were exposed to the program for a longer period. We also estimate heterogeneous treatment effects to investigate who benefits the most from the PATHS training program.

\footnotetext{
${ }^{15}$ Data are missing at ages 13,15, and 17 when individuals move out of the canton of Zurich and refuse to participate in the survey. Outcomes for academic high school completion and university enrollment are based on self-reported information and are only available for those individuals participating in the wave 8 survey.

${ }_{16}$ Although we do not find any evidence of selective attrition, we also replicate our main results following Wooldridge's (2007) inverse probability weighting in Appendix Table A4. We first model attrition for each outcome variable as a function of the initial assignment to a specific treatment condition and the full set of control variables used in the baseline analysis. Then, we predict from these models to compute individual weights. In the estimation, we then weight each observation with the inverse of this probability to account for the probability of being observed in a specific administrative register or survey wave of the data collection. Appendix Table A4 shows that all main results remain similar when using inverse probability weighting.
} 


\section{Figure 4: Dosage Effects - Two vs. One Year of Treatment}

(a) Randomization Controls

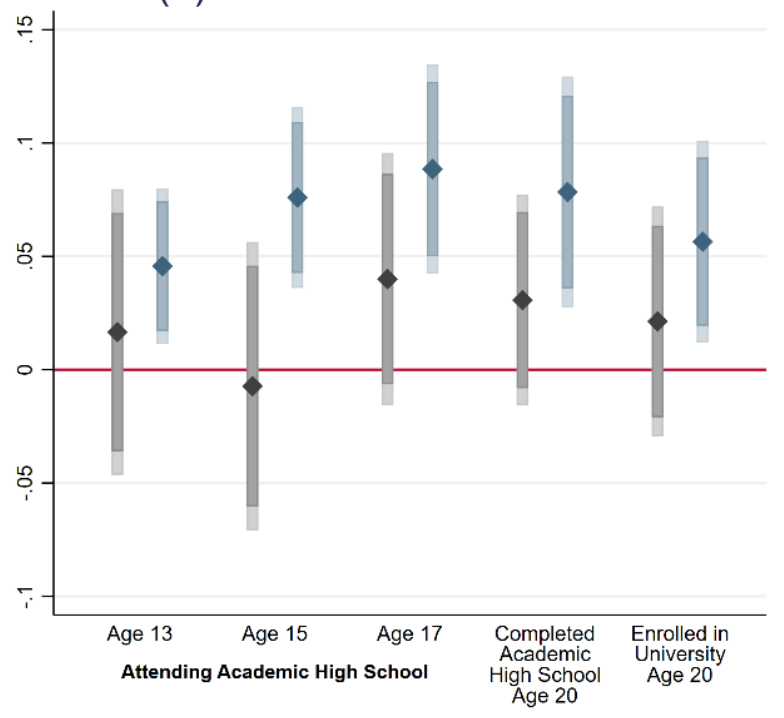

(b) Full Set of Controls

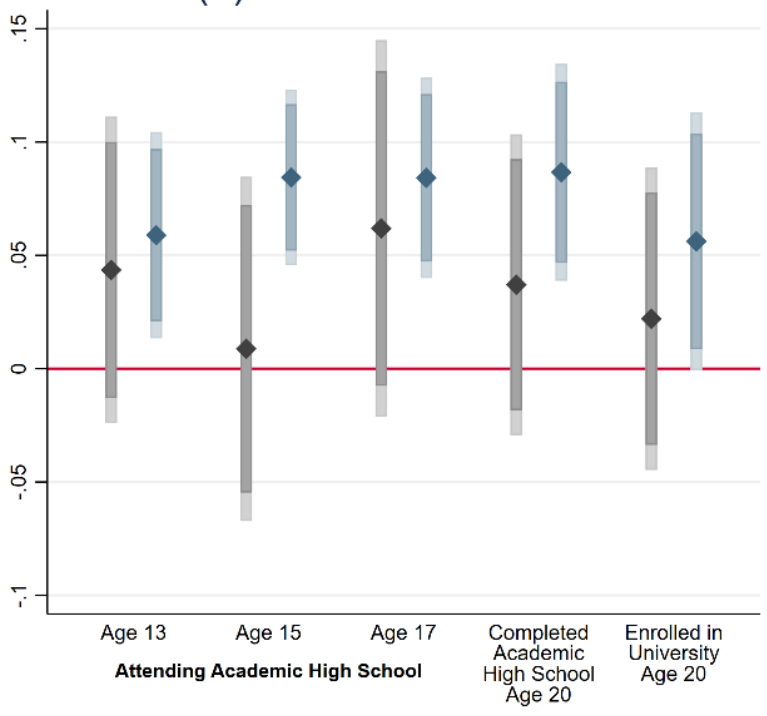

\begin{tabular}{|ll|}
\hline \multicolumn{2}{|c|}{ Confidence Interval: } \\
\hline One-Year Treatment: & Two-Year Treatment: \\
$95 \%$ & $95 \%$ \\
$90 \%$ & $90 \%$ \\
\hline
\end{tabular}

Note: This figure is based on estimates shown in Table A5 and shows the treatment effect of the PATHS intervention for one versus two years on the probability of attending academic high school at ages 13, 15, and 17 as well as on the probability of completing academic high school and being enrolled in university at age 20. Treatment effects are separately shown for children who received the treatment for one (PATHS 1 Year) or two (PATHS 2 Years) years. All dependent variables are indicator variables and all specifications are estimated using linear probability models. All models include strata fixed effects for the level of randomization. In Panel (a), we include randomization controls for mother and father education level and indicator variables for missing education level. In Panel (b), we include controls for baseline child, parental, and household characteristics and baseline child SBQ measures. Child controls include age and gender of the child and having Swiss citizenship. Household controls include household income, age of the mother, indicator variables for the mother having Swiss citizenship and being born in Switzerland, an indicator for mother and father education level, indicator variables for missing education level, and indicator variables for singleparent household, household that received financial aid, and household that experienced financial problems. Controls for baseline child SBQ measures include measures for anxiety and depressivity, ADHD, non-aggressive externalizing problem behavior, non-aggressive conduct disorder, opposition and defiance, prosociality, and three measures of aggressive behavior. Each point estimate is shown with the respective 90 and 95 percent confidence intervals calculated based on standard errors clustered at the school level.

Over 70 percent of schools in the treatment group accepted the offer to continue with the program for a second year based on the perception of teachers and school principals that the program was effective. It appears likely that teachers who continued the program were either more successful in the implementation or had students who were more responsive to the program. 
Whether a student receives the PATHS intervention for one or two years is therefore endogenous and we cannot interpret any dosage estimates causally. Nevertheless, we can estimate if longer exposure to the PATHS training program is correlated with better outcomes.

Figure 4 shows that treatment effect for children treated for two years is approximately twice as large as the effect for children treated for one year. Although we cannot disentangle whether this effect is causal or reflects selection bias, it is encouraging to see that children exposed to the program for a longer time benefit more.

Figure 5: Heterogeneous Treatment Effects

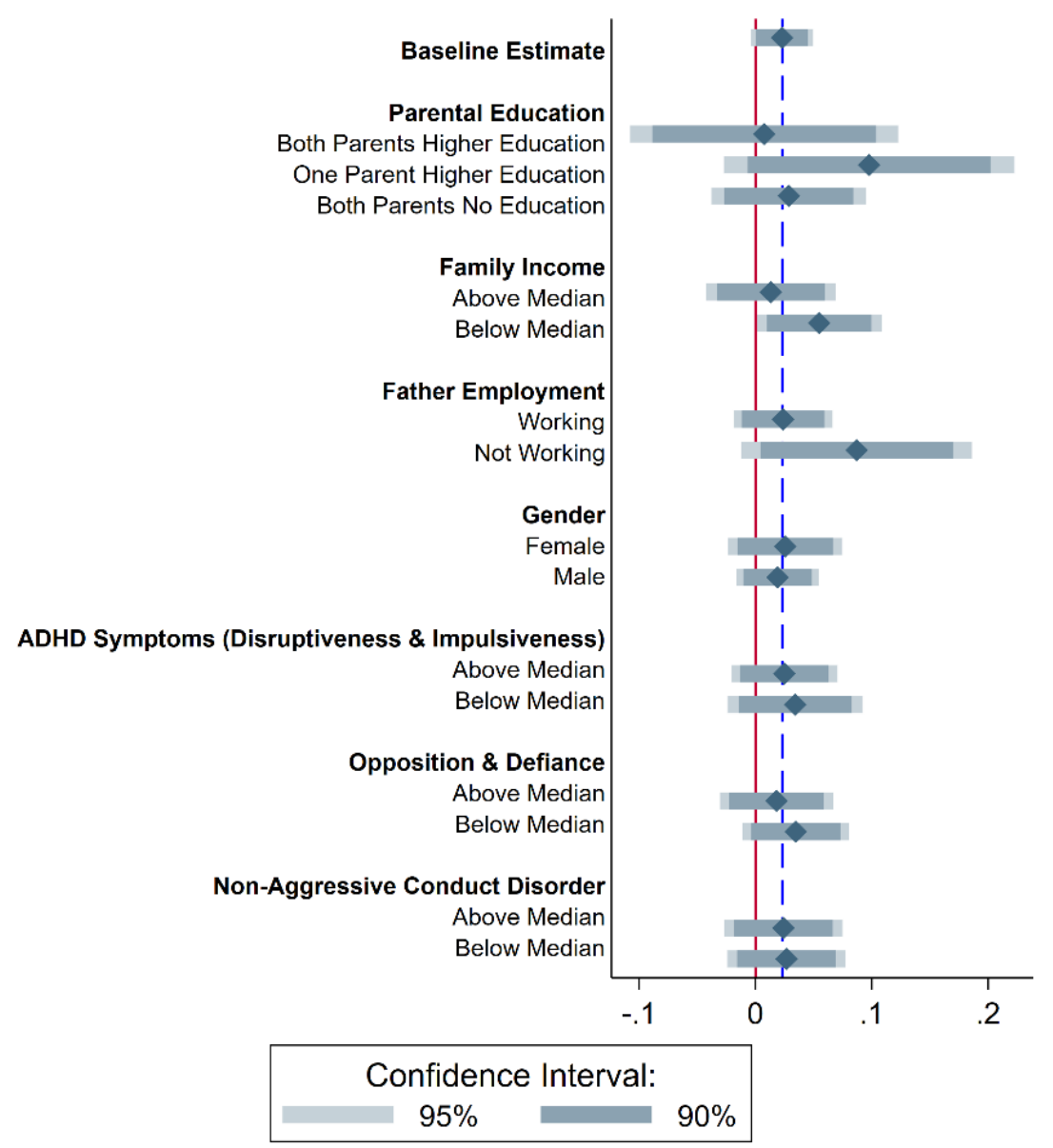

Note: This figure shows heterogeneous treatment effects for the initial tracking outcome by parental education, family income, father's employment status, child gender, as well as on baseline child SBQ measure for ADHD symptoms (disruptiveness and impulsiveness), opposition and defiance, and non-aggressive conduct disorder. Estimates are based on models in Table VI, Panel B and include randomization controls. The dashed line indicates the overall treatment effect shown in Table VI, Panel B, column (1). Each point estimate is shown with the respective 90 and 95 percent confidence intervals calculated based on standard errors clustered at the school level. 
Figure 5 shows heterogeneous treatment effects for the impact of PATHS on initial tracking into academic high school at age 13. In the regressions underlying the figure, we interact the treatment variable with an indicator for the respective subgroup shown on the y-axis. We estimate heterogeneous effects for the following dimensions: parental education, family income, fathers' employment status, child's gender, and child's baseline socio-emotional skills including ADHD symptoms, opposition and defiance, and non-aggressive conduct disorder. We see little evidence of heterogeneous treatments effects. None of the treatment effects differ significantly by subgroup. Figure A7 in the Appendix replicates this analysis for the effect of PATHS on academic high school completion. This analysis leads to similar conclusions.

\section{Mechanisms}

In this section, we study four possible mechanisms underlying the effect of the PATHS training program on educational trajectories. First, we analyze whether PATHS affected the two elements that determine the tracking outcome: primary school grades and academic high school admission test scores. Second, we study whether PATHS affected children's socio-emotional developmentthe main target of the intervention. Third, as some of the PATHS activities involve parent-child interactions, we test whether the intervention affected parenting practices. Fourth, we investigate whether PATHS affected school-related behavior like classroom disruption and homework completion. We also conduct a mediation analysis providing suggestive evidence on how much of the treatment effect can be explained by these mechanisms.

\subsection{Effects on Grades and Admission Test Scores}

Primary school grades are given on a scale of 1-6 and are based on tests and the subjective assessments of the primary school teacher. The standardized high school admission test is graded 
on that same 1-6 scale and covers mathematics, reading comprehension, and writing. The test is evaluated by an external high school teacher who typically does not know the child. Students' tracking outcomes are determined by their average primary school grades and their admission test scores. Both performance measures have equal weight and students with a minimum of 4.5 out of six are admitted to academic high school. ${ }^{17}$

We estimate the effect of PATHS on grades and admission test scores using specifications with randomization controls and specifications with the full set of controls. To simplify the interpretation of the results, we standardized both outcome variables to have means of zero and a standard deviations of one.

Panel (a) of Figure 6 shows that the PATHS program increases children's grades by 20 percent of a standard deviation. ${ }^{18}$ Panel (b) of Figure 6 shows the treatment effect on the admission test scores. Point estimates on these test scores are lower; they range between 5 and 10 percent of a standard deviation. While these coefficients are imprecisely estimated and not statistically significant, we cannot rule out that the treatment had a small positive impact on the standardized admission test.

Taken together, our results suggest that the intervention raises grades but has only a limited impact on admission test scores. While test scores mainly capture dimensions of children's cognitive skills, grades are more likely to also reflect differences in classroom behavior, aptitude, and engagement. ${ }^{19}$ One plausible interpretation for the effects is that treated children display better

\footnotetext{
${ }^{17}$ Participation in the academic high school admission test is voluntary and there is some suggestive evidence that the treatment increases children's probability of taking the test (see Table A6 in Appendix). Children who do not take the test cannot attend academic high school. To account for the fact that we only observe a subsample of children, we reweigh our observations in Table VI and Figure 6 using inverse probability weighting.

${ }^{18}$ Grades are likely determined on a curve within schools and might therefore not be comparable across schools. Given that all students within a school have the same treatment status, any within-school curving would lead to an underestimation of treatment effects on (uncurved) grades.

${ }^{19}$ Borghans et al. (2016) show that grades capture students' cognitive skills but also reflect behavioral differences and differences in personality and socio-emotional skills.
} 
classroom behavior that is rewarded with higher grades by the teacher. Our results suggest that long-term intervention effects are more likely to operate through changes in socio-emotional skills rather than cognitive skills.

\section{Figure 6: Treatment Effects on Grades and Admission Test Scores}

(a) Grades in Primary School

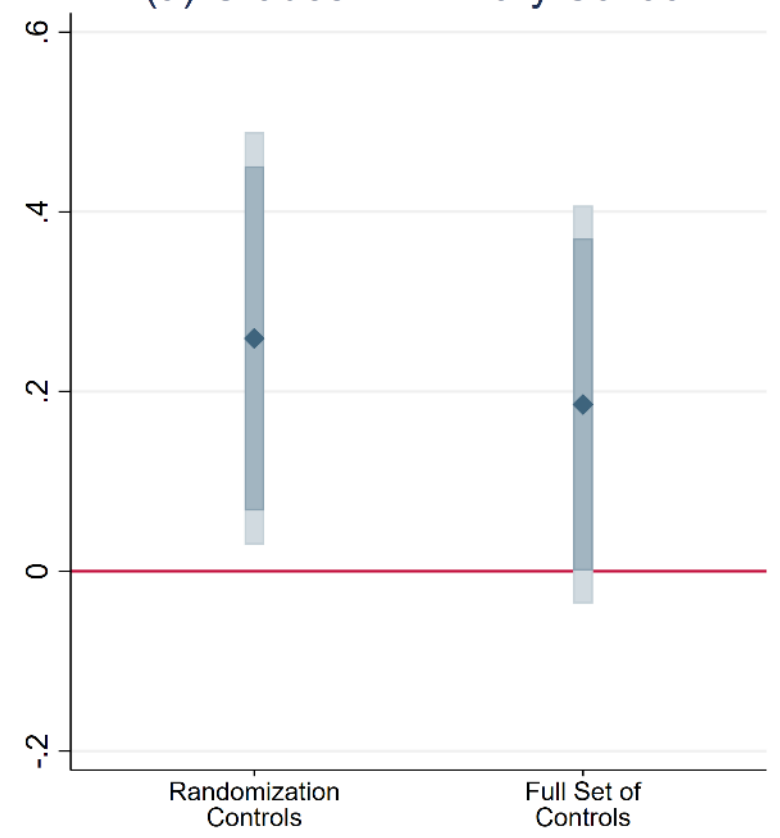

(b) Admission Test Scores

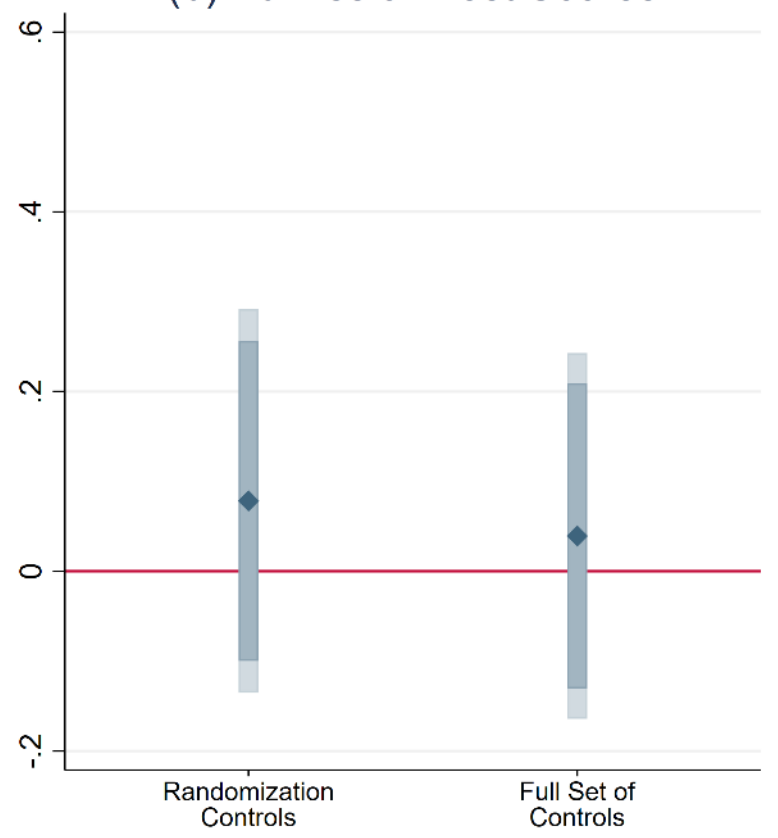

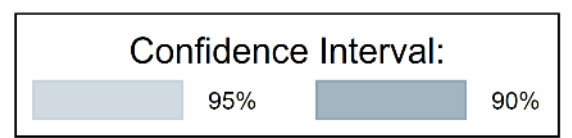

Note: This figure shows the treatment effect of the PATHS intervention on grades and test scores. The dependent variable in Panel (a) is a student's standardized grades in Grade 6. The dependent variable in Panel (b) is the test score in the centralized admission test for academic high school. Admission to academic high school is possible after Grade 6,8 , and 9. Estimates for admission test scores are based on the score obtained from the first time taking the test. Grades in primary school correspond to the teacher-given grades obtained before taking the admission test. All regressions are based on inverse probability weighting, with weights constructed by regressing an indicator for whether we observe the respective outcome on the full set of controls. We winsorize at the first two percentiles to avoid negative weights. Each point estimate is shown with the respective 90 and 95 percent confidence intervals calculated based on standard errors clustered at the school level. 


\subsection{Effects on Socio-Emotional Skills}

PATHS aims to foster regulatory behavior, smart decision-making, and emotional understanding.

Given these primary goals, we investigate changes in children's socio-emotional development as possible mechanisms of the long-term effects of PATHS on educational trajectories.

We measure children's socio-emotional development with the Social Behavior Questionnaire (SBQ), which teachers and parents answer. This questionnaire includes the following six domains: (1) ADHD symptoms (disruptiveness and impulsiveness), (2) opposition and defiance, (3) non-aggressive conduct disorder, (4) anxiety and depressivity, (5) aggression, and (6) prosociality. Each of these domains is measured with up to ten subitems that ask about the prevalence of a specific behavior. ${ }^{20}$ For every survey wave, we combine all available responses from teachers and parents. We do this by first computing the sum of standardized answers to each subitem domain, then take the average of teacher and parent reports and standardize again to obtain measures with a mean of zero and a standard deviation of one.

Figure 7 shows the PATHS treatment effect on ADHD symptoms and opposition and defiance. Panel (a) of Figure 7 shows the evolution of the PATHS treatment effect on ADHD symptoms (disruptiveness and impulsiveness) over time. PATHS causes children to become more impulsive and disruptive during the intervention period and persistently less impulsive and disruptive after the intervention is completed.

Seeing more behavioral problems during the intervention is, at first sight, surprising. This effect goes against the aim of the intervention. One explanation is that the intervention made teachers and parents more aware of what appropriate child behavior should look like. This possibly

\footnotetext{
20 Table B1 in the Appendix provides an overview of the items used in the Social Behavior Questionnaire that constitute the six different SBQ domains. Answers are recorded on a 5-point Likert scale ranging from (1) "never" to (5) "very often."
} 


\section{Figure 7: Dynamic Treatment Effects on Socio-Emotional Skills I}

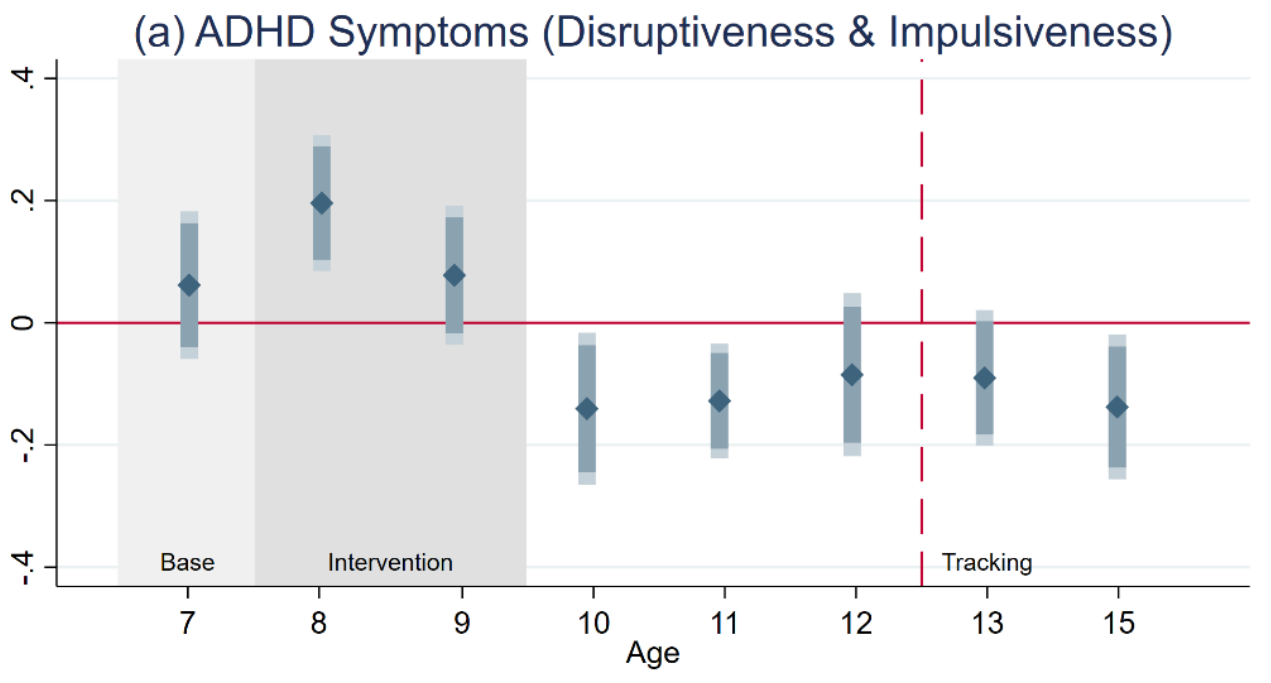

(b) Opposition \& Defiance

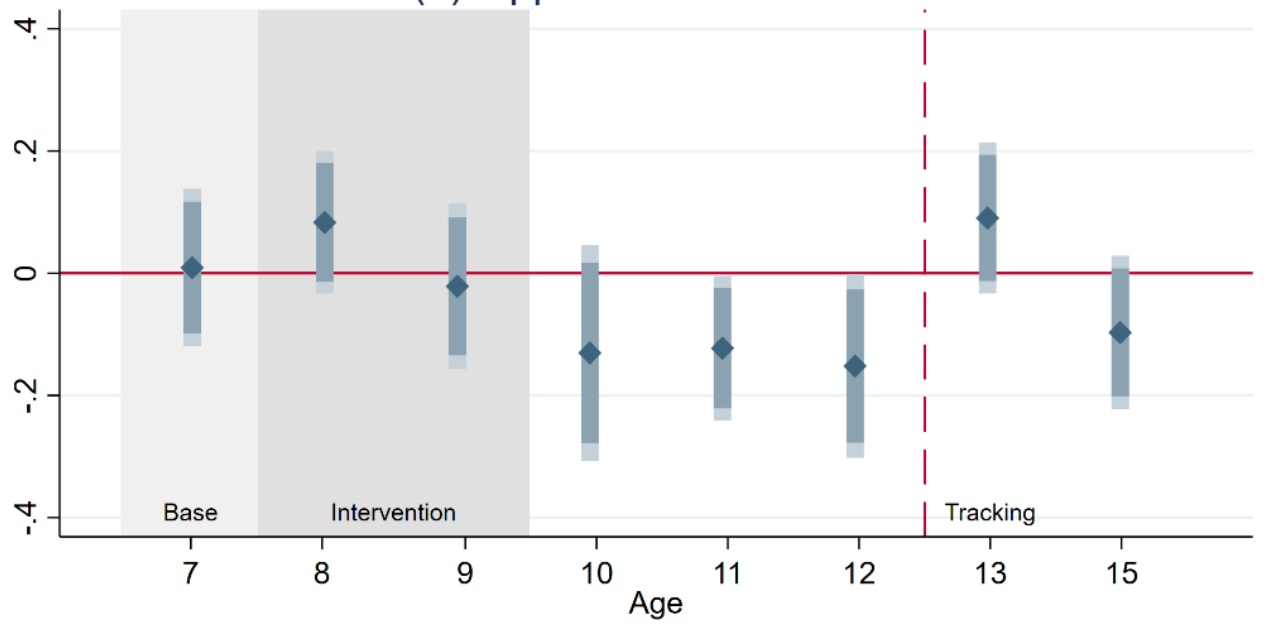

Confidence Interval:

$95 \% \quad 90 \%$

Note: This figure shows the treatment effect of the PATHS intervention on children's socio-emotional skills from ages 7 through 15. The dependent variable in Panel (a) is ADHD symptoms (disruptiveness and impulsiveness). The dependent variable in Panel (b) is opposition and defiance. All dependent variables are indices standardized to mean zero and a standard deviation of one. All models include strata fixed effects for the level of randomization. All models include controls for baseline child, parental, and household characteristics and baseline child SBQ measures. To provide evidence on balance across the treatment and the control groups, we do not include individual controls in the estimation of the treatment effect at age 7. For each SBQ measure, we combine measures from teacher and parent reports by taking the average of the two standardized indices and standardize the resulting index again. For measures at ages $10,12,13$, and 15 , we rely solely on teacher reports, as there are no parent surveys at these times. Details on the SBQ items and construct validity are provided in Appendix B2. Shaded areas indicate the baseline and the intervention periods. The dashed vertical line shows the time when tracking into secondary schools takes place. Each point estimate is shown with the respective 90 and 95 percent confidence intervals calculated based on standard errors clustered at the school level. 
increased awareness may have made them more critical in the short-run. Consistent with this interpretation, the PATHS developers provide anecdotal evidence showing that teachers raise their expectations about children's appropriate behavior during the intervention.

After the intervention, starting from age 10, we see that PATHS reduces ADHD symptoms by making children less disruptive and impulsive. At age 10, children were also reassigned to new classes and new teachers who were not involved in the intervention. From this age, our measures therefore likely reflect child behavior and development more objectively. The treatment effect persists until primary school completion, when children are 12 years old, and remains visible at ages 13 and $15 .^{21}$

Panel (b) of Figure 7 shows the PATHS treatment effect on opposition and defiance. Opposition and defiance capture behaviors like telling lies, cheating, or ignoring teachers' instructions. The overall picture is similar to the treatment effect for ADHD symptoms. PATHS increases opposition and defiance during the intervention and decreases those behaviors after the intervention is completed. The treatment effects fade out after children transition to secondary school.

Figure 8 shows the effects of PATHS on non-aggressive conduct behavior (Panel a), anxiety and depressivity (Panel b), aggression (Panel c), and prosociality (Panel d). PATHS reduces children's non-aggressive conduct disorders such as lying, stealing, or destroying other children's belongings after the intervention. This effect remains visible until age 11 and fades out afterward. Anxiety, aggression, and prosociality do not appear to be systematically affected by the intervention.

\footnotetext{
${ }^{21}$ Appendix Figure A8 reports separate effects for disruptiveness (Panel (a)) and impulsiveness (Panel (b)). The figure shows that the overall picture is similar for both traits, but perhaps more pronounced for disruptiveness.
} 


\section{Figure 8: Dynamic Treatment Effects on Socio-Emotional Skills II}

(a) Non-Aggressive Conduct Disorder

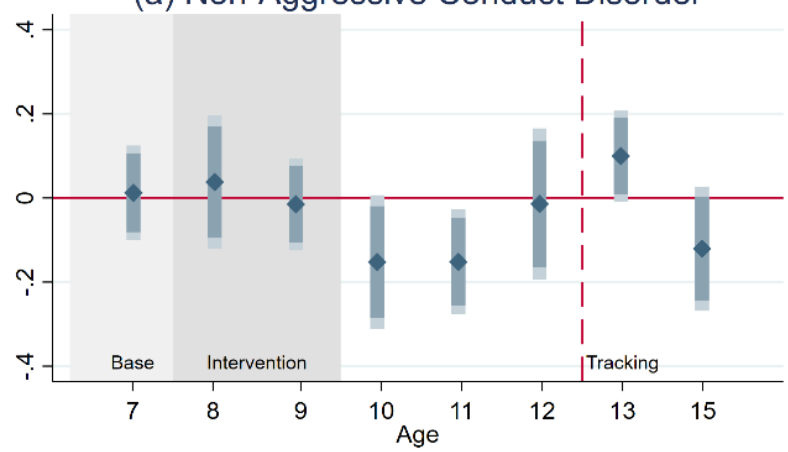

(c) Aggression

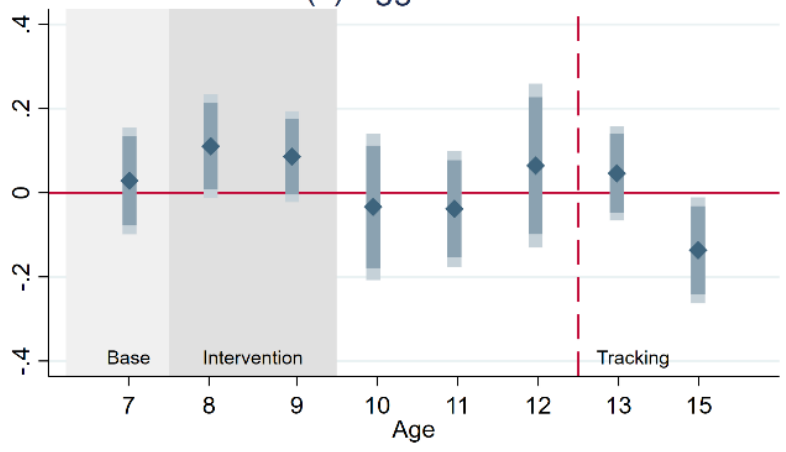

(b) Anxiety \& Depressivity

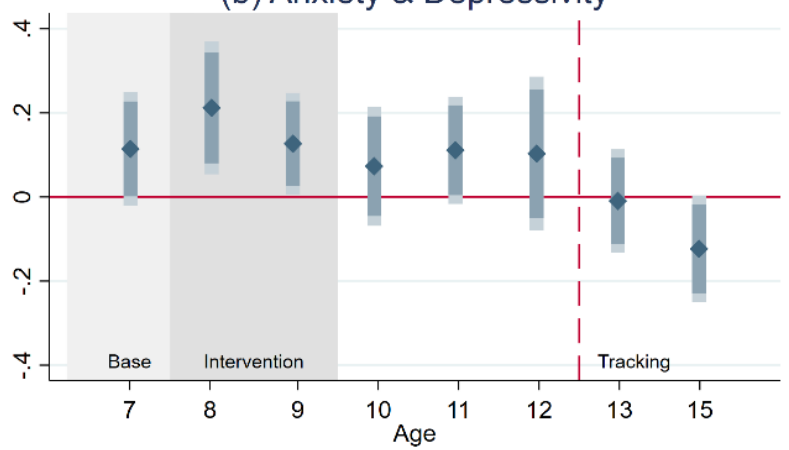

(d) Prosociality

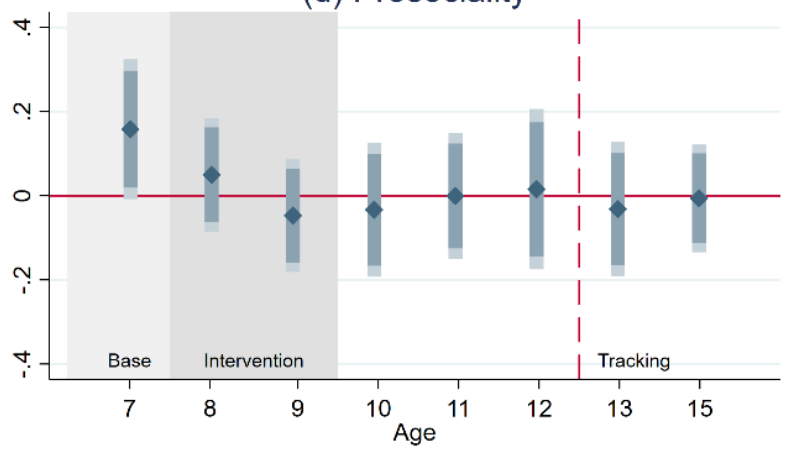

Confidence Interval:

$95 \%$

Note: This figure shows the treatment effect of the PATHS intervention on children's socio-emotional skills from ages 7 through 15 . The dependent variables are non-aggressive conduct disorder (Panel (a)), anxiety and depressivity (Panel (b)), aggression (Panel (c)), and prosociality (Panel (d)). All dependent variables are indices standardized to mean zero and a standard deviation of one. All models include strata fixed effects for the level of randomization. All models include controls for baseline child, parental, and household characteristics and baseline child SBQ measures. To provide evidence on balance across the treatment and the control groups, we do not include individual controls in the estimation of the treatment effect at age 7. For each SBQ measure, we combine measures from teacher and parent reports by taking the average of the two standardized indices and standardize the resulting index again. For measures at ages $10,12,13$, and 15, we rely solely on teacher reports, as there are no parent surveys at these times. Details on the SBQ items and construct validity are provided in Appendix B2. Shaded areas indicate the baseline and the intervention period. The dashed vertical line shows the time when tracking into secondary schools takes place. Each point estimate is shown with the respective 90 and 95 percent confidence intervals calculated based on standard errors clustered at the school level.

\subsection{Effects on Parenting Practices}

The PATHS training program includes information leaflets for parents and has a substantial homework component. In these homework assignments, children discuss the curriculum with their 
parents. The PATHS program therefore may affect parent-child interactions or trigger adjustments in parenting practices. ${ }^{22}$

We analyze parenting practices using the Alabama Parenting Questionnaire (APQ) that captures the following five domains: (1) corporal punishment, (2) parental control and supervision, (3) inconsistent discipline, (4) parental involvement, and (5) positive parenting. Each domain is measured with up to ten questions answered by the primary caregiver on a 5-point Likert scale ranging from "never" to "always." 23 To facilitate comparisons, we standardize each subdomain to have a mean of zero and a standard deviation of one.

Figure 9 shows the evolution of the PATHS treatment effect on parenting practices over time. Parents seem to respond to the intervention with less corporal punishment during and right after the intervention period. When the child is 11 years old, PATHS appears to reduce parents' hitting and smacking their children by 8.4 percent of a standard deviation. We see no effect on other parenting practices.

The treatment effect on corporal punishment could be driven by three factors. First, children exposed to the PATHS program might improve their behavior thereby reducing the "need" for parental corrective actions. Second, parents might become less impulsive and stop hitting their kids. Third, parents might feel pressured to report reductions in corporal punishment, as the PATHS program stresses the importance of non-violent social interactions. Given that information on smacking, slapping, and hitting is self-reported, how to interpret the effect on corporal punishment remains ambiguous.

\footnotetext{
22 Parenting styles and practices may shape child preferences and behavior with effects on children's education performance and choices (Doepke and Zilibotti 2017; Doepke, Sorrenti, and Zilibotti 2019). Adjustments in parenting practices therefore represent a possible mechanism for the observed PATHS treatment effects on educational outcomes.

${ }^{23}$ Appendix Table B3 provides an overview on the survey items used to measure parenting practices. Items remain the same across surveys conducted in different years.
} 


\section{Figure 9: Dynamic Treatment Effects on Parenting Practices}

(a) Corporal Punishment

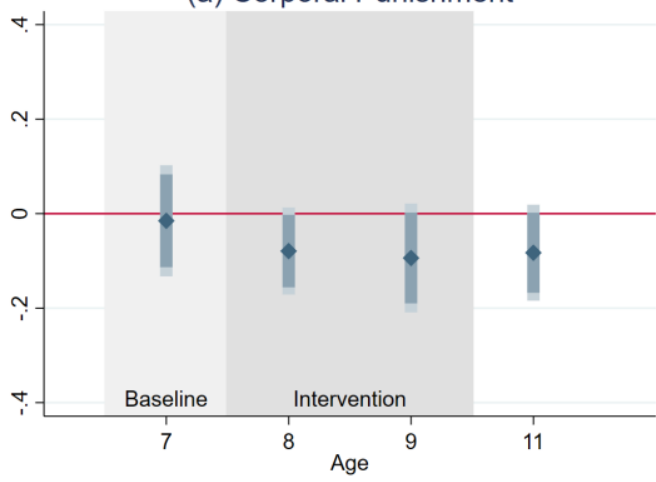

(c) Inconsistent Discipline

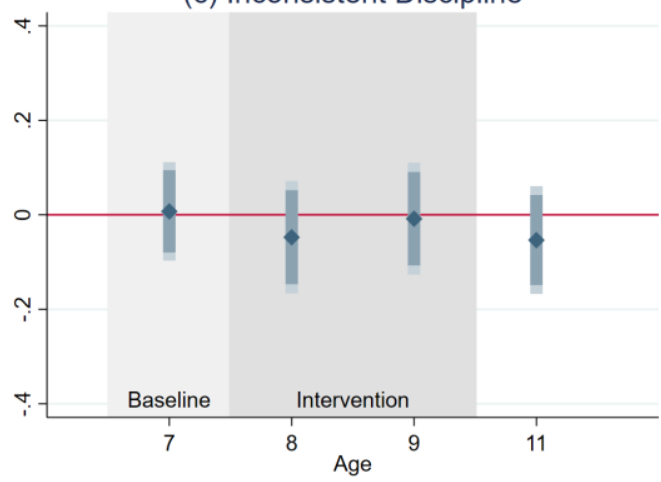

(e) Positive Parenting

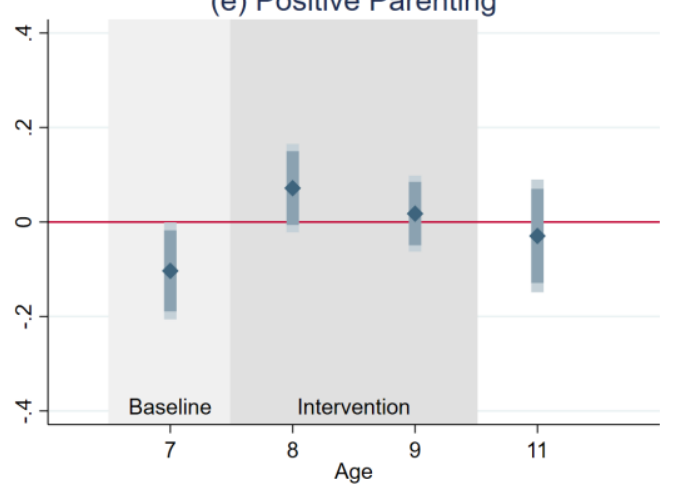

(b) Parental Control \& Supervision

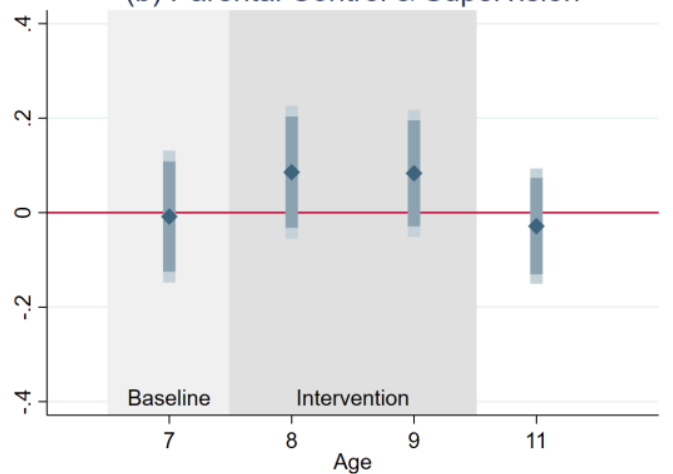

(d) Parental Involvement

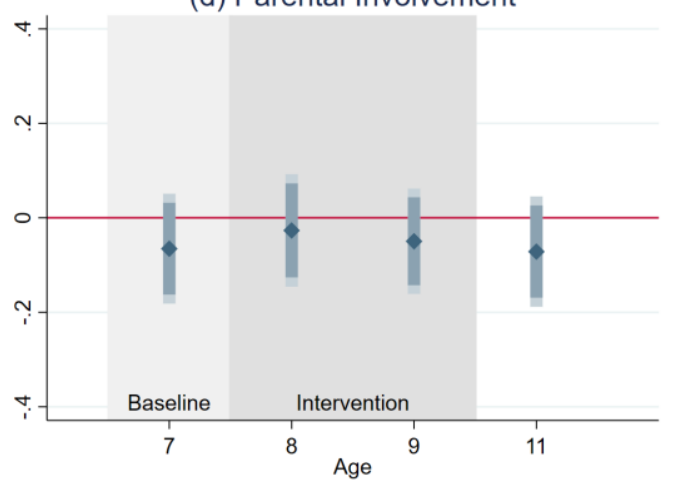

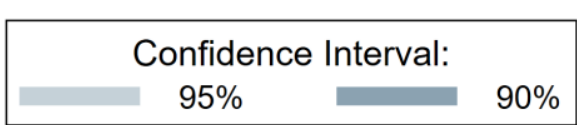

Note: This figure shows the treatment effect of the PATHS intervention on parenting practices from ages 7 through 11. The dependent variables are corporal punishment (Panel (a)), parental control \& supervision (Panel (b)), inconsistent discipline (Panel (c)), parental involvement (Panel (d)), and positive parenting (Panel (e)). All dependent variables are indices standardized to mean zero and a standard deviation of one. All models include strata fixed effects for the level of randomization. All models include controls for baseline child, parental, and household characteristics and baseline child SBQ measures. To provide evidence on balance across the treatment and the control groups, we do not include individual controls in the estimation of the treatment effect at age 7. Shaded areas indicate the baseline and the intervention periods. The dashed vertical line shows the time when tracking into secondary schools takes place. Each point estimate is shown with the respective 90 and 95 percent confidence intervals calculated based on standard errors clustered at the school level. 


\subsection{Effect on Behavior in Class}

In this section, we look at possible intervention effects on school-related behavior. We have measures on school related-behavior for four different domains: (1) disturbing lessons, (2) being busy with other things during classes, (3) impertinent school behavior, and (4) neglecting homework. We observe these outcomes starting from Grade 4, after children are reassigned to new classes and evaluated by a new teacher. Each domain is measured through a 5-point Likert scale ranging from "never" to "very often." To facilitate comparisons, we standardize each subdomain to have a mean of zero and a standard deviation of one.

Figure 10: Dynamic Treatment Effects on Behavior in Class

(a) Disturbs Lessons

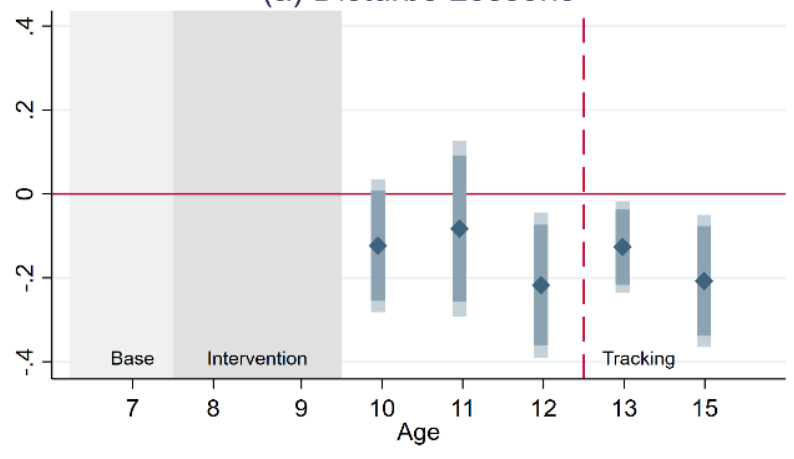

(c) Impertinent Conduct at School

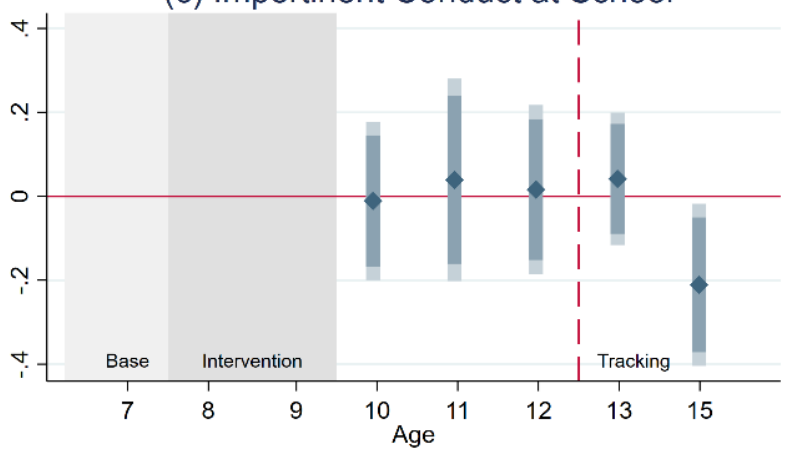

(b) Busy with Other Things in Class

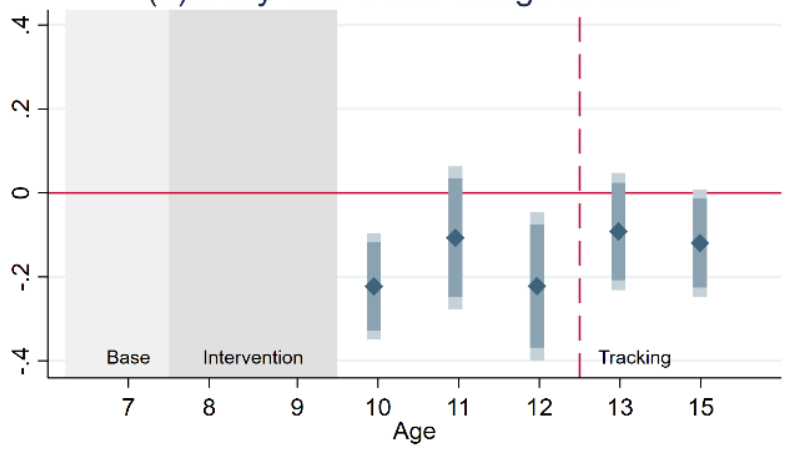

(d) Neglects Homework

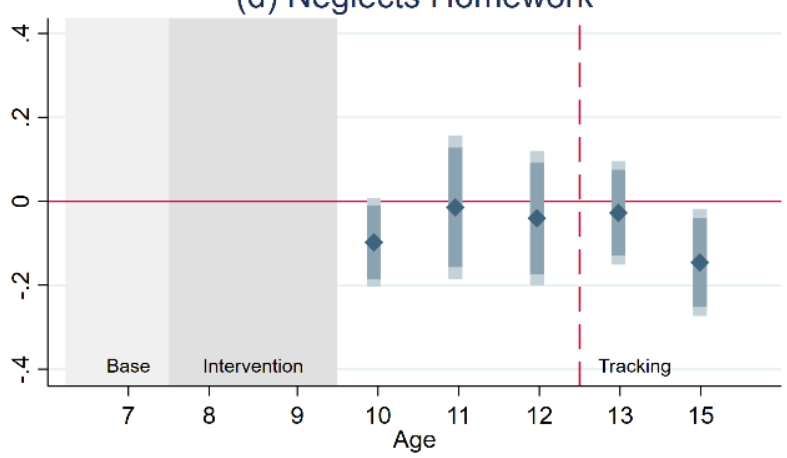

Confidence Interval: $95 \%$ $90 \%$ 
Note: This figure shows the treatment effect of the PATHS intervention on children's behavior at school from ages 10 through 15. The dependent variables are disturbing the lesson (Panel (a)), being busy with other things in class (Panel (b)), impertinent conduct at school (Panel (c)), and neglecting homework (Panel (d)). All dependent variables are indices standardized to mean zero and a standard deviation of one. All models include strata fixed effects for the level of randomization. All models include controls for baseline child, parental, and household characteristics and baseline child SBQ measures. Measures are taken from teacher reports. Shaded areas indicate the baseline and the intervention periods. The dashed vertical line shows the time when tracking into secondary schools takes place. Each point estimate is shown with the respective 90 and 95 percent confidence intervals calculated based on standard errors clustered at the school level.

Figure 10 shows results for school-related behavior. PATHS reduces children's likelihood of disturbing lessons by 12.4 percent at age 10 . The effect persists throughout secondary education. We see a similar pattern for children's ability to focus. Treatment effects are largest immediately after the intervention at age 10 with an effect equivalent to a reduction of 20.4 percent of a standard deviation. The effect remains visible after children are tracked. We find no significant treatment effects for impertinent conduct at school or neglecting homework.

\subsection{Mediation Analysis}

In this section, we perform a mediation analysis in the spirit of Gelbach (2016). This analysis provides insights on the relative importance of different mechanisms (mediators) in shaping the PATHS treatment effect on the education outcomes. This analysis allows us to quantify the proportion of the treatment effect mediated by all our proposed mechanisms and to separate the contribution of each single mechanism to the estimated treatment effect.

The results of the mediation analysis should be interpreted with caution. Imai, Keele, and Tingley (2010) show to be able to interpret this type of analysis causally one needs to make strong assumptions about the source of variation of the mediators. Despite these limitations, we believe that this analysis is helpful to see whether the mechanism we study explain treatment effects. 
We perform the mediation analysis for the following education outcomes: attendance of academic high school at ages 13,15, and 17, academic high school completion, and university enrollment at age 20. As possible mediators, we focus on socio-emotional skills, parenting practices and classroom behavior. ${ }^{24}$ We assume that the PATHS treatment has both direct and indirect effects on education outcomes. The indirect effects run through treatment effects of the intervention on socio-emotional skills, parenting practices, and classroom behavior. The results of the mediation analysis will give us an estimate of the importance of these indirect effects.

Panel (a) of Figure 11 shows the results of the mediation analysis. ${ }^{25}$ Each horizontal bar represents a specific outcome of interest. Colored areas within the bars illustrate the contribution of each mediator to the overall treatment effect. The grey area stands for the unexplained share of the treatment effect. The mediation analysis highlights that our candidate mechanisms explain about 20-26 percent of the treatment effect. Among the mechanisms we study, socio-emotional skills appear as the most important mediator of the PATHS treatment effect. For example, socioemotional skills explain about 25 percent of the PATHS treatment effect on university attendance at age 20. The contribution of parenting practices and classroom behavior are smaller and less stable across different outcomes, suggesting that these are not important mechanisms.

\footnotetext{
${ }^{24}$ The set of mediators includes all variables analyzed as potential mechanisms in Sections 7 except grades and test scores because these variables are only available for a subsample of students that sit the standardized academic high school admission test. For the sake of readability, we aggregate all candidate mechanisms into three domains: (1) socio-emotional skills, (2) parenting practices, (3) and classroom behavior. Given the longitudinal nature of our data, we only consider measures obtained after the intervention and before the educational outcome is measured. In cases in which we have multiple observations for the same mediator, we construct a summary index using the covariance weighting procedure discussed in Anderson (2008).

${ }^{25}$ We perform the mediation analysis by decomposing the treatment effect obtained from estimates of the unconditional outcome equation $Y_{i}=\beta_{1}$ PATHS $_{\mathrm{i}}+X_{i}^{\prime} \gamma+\theta+\varepsilon_{i}$ (Equation 1) in the following way:

$\frac{d Y}{d P A T H S}=\sum \frac{\partial Y}{\partial M} \frac{\partial M}{\partial P A T H S}+R$, where $Y$ is the outcome, PATHS is the treatment indicator, $M$ is a vector of $k$ mediators, and $R$ is the unexplained part of the treatment effect. We estimate two additional specifications. First, we estimate the conditional outcome equation augmented with the vector $M: Y_{i}=\beta_{2}$ PATHS $_{\mathrm{i}}+M_{i} \varphi+X_{i}^{\prime} \gamma+\theta+\epsilon_{i}$. Second, we separately estimate the treatment effect of the intervention on each mediator $j \in k: M_{i}^{j}=\beta_{3}^{j}$ PATHS $_{\mathrm{i}}+X_{i}^{\prime} \gamma+\theta+v_{i}$. The contribution of each mediator $j \in k$ is then computed as the ratio $\frac{\varphi^{j} \times \beta_{3}^{j}}{\beta_{1}}$. The unexplained part, $R$, results from $R=1-\sum_{j=1}^{k} \frac{\varphi^{j} \times \beta_{3}^{j}}{\beta_{1}}$.
} 


\section{Figure 11: Mediation Analysis}

(a) Mediation Analysis

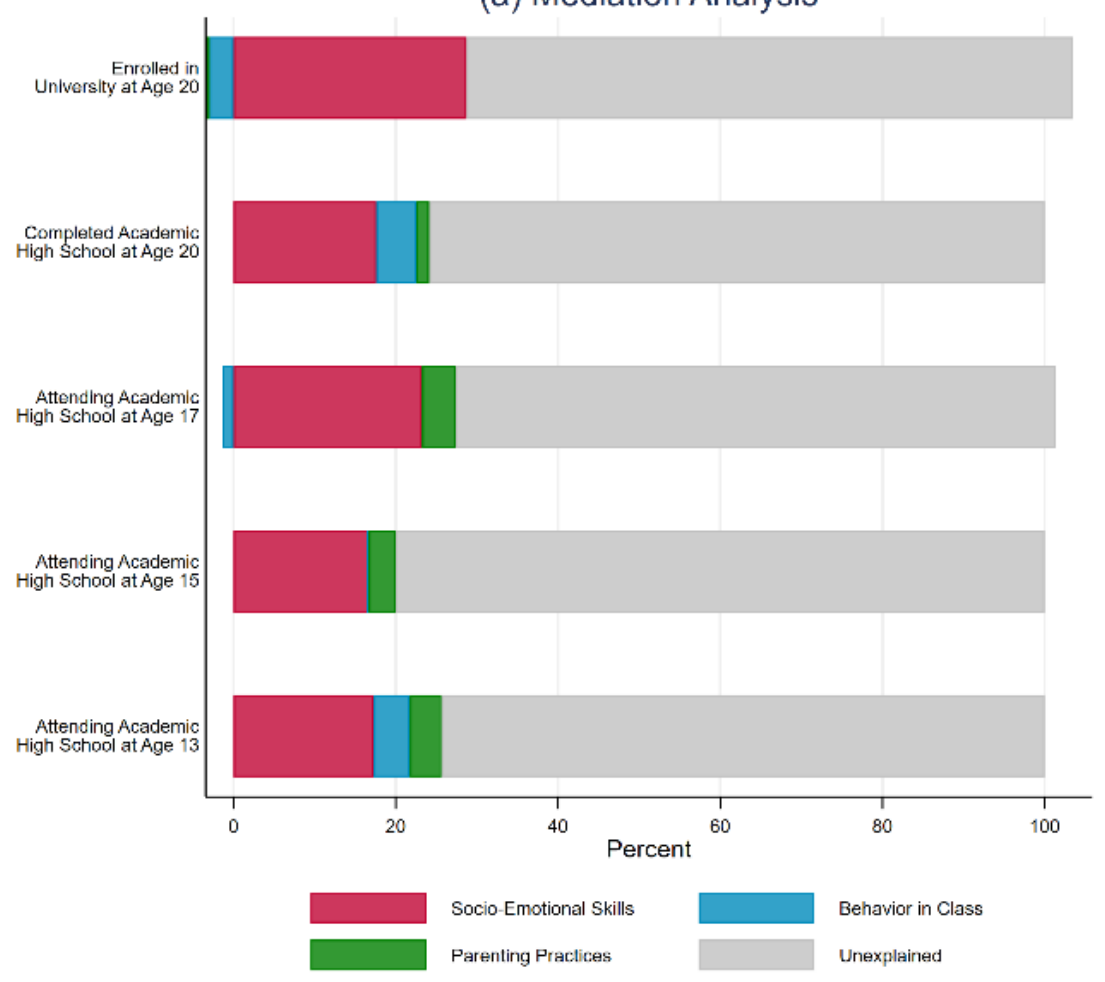

(b) Breakdown of Socio-Emotional Skills

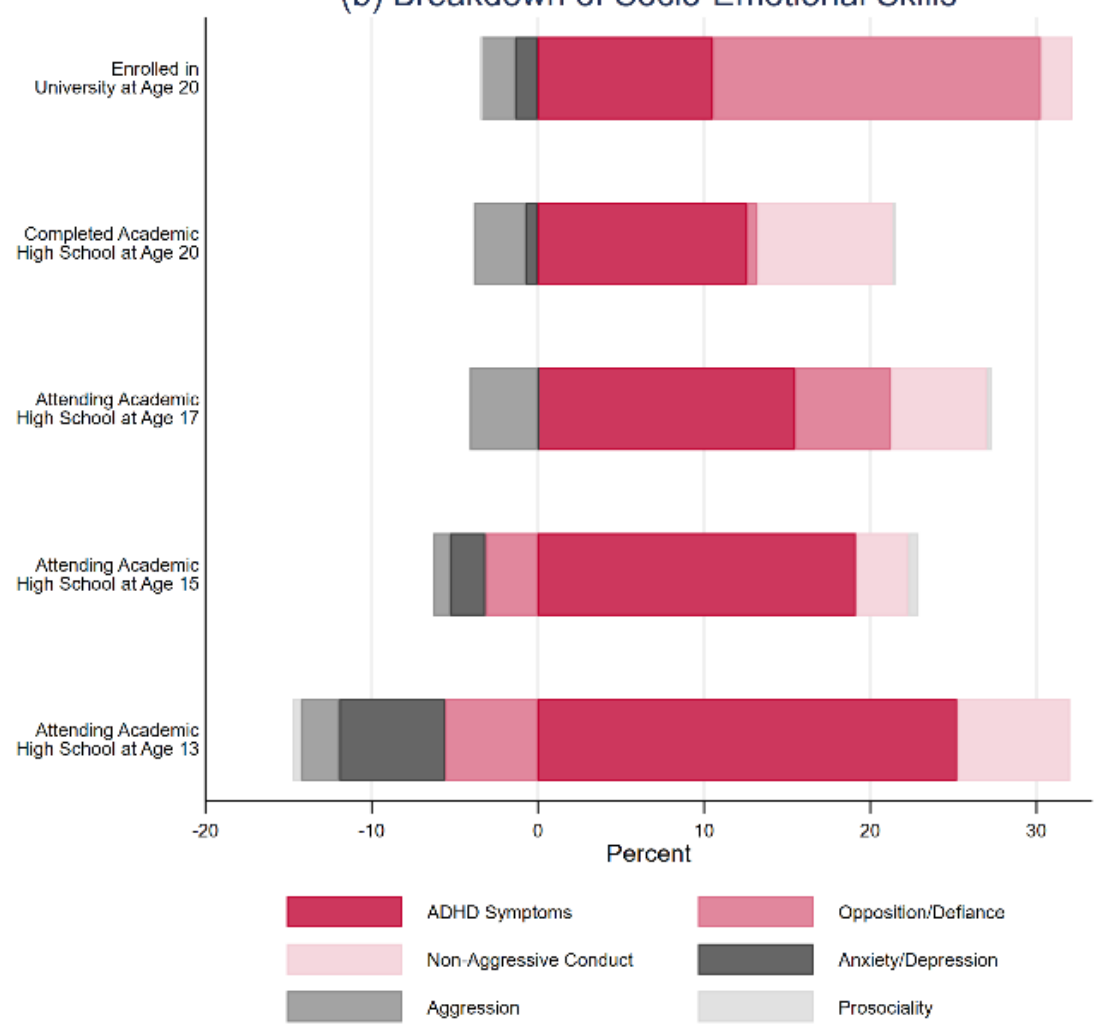

Note: This figure shows the results of our mediation analysis. Panel (a) shows the decomposition of the overall treatment effect. In Panel (a) we include socioemotional skills, parenting practices, and behavior in class as mediators. Panel (b) shows the decomposition of socio-emotional skills. We decompose the treatment effect obtained from the unconditional outcome equation $Y_{i}=\beta_{1}$ PATHS $_{\mathrm{i}}+X_{i}^{\prime} \gamma+\theta+\varepsilon_{i}$ shown in Equation (1) in the following way: $\frac{d Y}{d P A T H S}=\sum \frac{\partial Y}{\partial M} \frac{\partial M}{\partial P A T H S}+$ $R$, where $Y$ is the outcome, PATHS is the treatment indicator, $M$ is a vector of $k$ mediators (comprised of the variables included in socio-emotional skills, parenting practices, and behavior in class), and $R$ is the unexplained part of the treatment effect. We estimate two additional specifications. First, we estimate the conditional outcome equation augmented with the vector $M: Y_{i}=\beta_{2}$ PATHS $_{i}+M_{i} \varphi+X_{i}^{\prime} \gamma+\theta+\epsilon_{i}$. Second, we separately estimate the treatment effect of the intervention on each mediator $j \in k: M_{i}^{j}=\beta_{3}^{j} \mathrm{PATHS}_{\mathrm{i}}+X_{i}^{\prime} \gamma+\theta+v_{i}$. Given the longitudinal nature of our data, for all mediators we only consider measures obtained posttreatment and before the education outcome is measured. In case of multiple observations for the same mediator, we construct a summary index using the covariance weighting procedure discussed in Anderson (2008). The contribution of each mediator $j \in k$ is then computed as the ratio $\frac{\varphi^{j} \times \beta_{3}^{j}}{\beta_{1}}$, which is shown in the color-coded bars. The unexplained part, $R$, results from $R=1-\sum_{j=1}^{k} \frac{\varphi^{j} \times \beta_{3}^{j}}{\beta_{1}}$. 
Given the important mediating role of socio-emotional skills, we investigate the contribution of each of the following six separate skills: opposition and defiance, non-aggressive conduct disorder, anxiety and depressivity, aggression, and prosociality and ADHD symptoms. Panel (b) of Figure 11 shows the results of this mediation analysis. The main mediator is reduction of ADHD symptoms. This variable explains up to 25 percent of the PATHS treatment effect on educational outcomes. The relative importance of its mediating role is similar across outcomes and does not depend on the children's age. Non-aggressive conduct disorders and opposition/defiance are also relevant mediators, but quantitatively less important. Their mediating role is also less stable over time. The remaining socio-emotional skills seem to have a negligible role as mediators (prosociality) or have a negative load as mediators (anxiety and aggression).

Taken together, the mediation analysis described in this section suggests that the PATHS treatment effect on educational outcomes is driven by treatment-induced improvements in children's socio-emotional skills, in particular, by reductions in ADHD symptoms - impulsiveness and disruptiveness.

\section{Comparison of Costs, Benefits, and Previous Evaluations}

In this section, we contextualize the main results of this study. We start with the discussion of other randomized control trials (RCTs) that evaluated the PATHS program. These studies focus on the short-term effects of PATHS on behavioral outcomes and do not analyze the long-term impacts. We then compare the size of the treatment effects and the cost of PATHS to related childhood interventions.

\subsection{Previous Evaluations of PATHS}

A few studies have evaluated the short-term effects of PATHS in settings where the program was randomly assigned. These studies suggest that PATHS improves socio-emotional skills, improves 
academic performance, and reduces aggressive behavior. Greenberg et al. (1995) show that PATHS increases vocabulary and emotional intelligence of second and third grade children in the United States. Schonfeld et al. (2015) find similar results and show that PATHS improves reading and math proficiency in primary school. This effect, however, disappears two years after the intervention. Crean and Johnson (2013) examine the effect of PATHS on US elementary school students' aggressive behavior and find lower levels of aggressive behavior for treated students. The effect persists over two years after the intervention. Kam, Greenberg and Kusché (2004) evaluate PATHS in a sample of children with special needs living in the United States. They find positive effects on externalizing and internalizing behavior and reduced self-reported depressivity three years after the intervention. Riggs et al. (2006) that show that PATHS fosters inhibitory control and leads to less disruptive behavior. While some of the results of previous evaluations are consistent with our evidence on underlying mechanisms, we find no evidence that the intervention reduced physical aggression in our setting.

\subsection{Comparison of Effect Size and Costs of Similar Interventions}

In this section, we benchmark our intervention to similar interventions affecting educational outcomes and targeting child development. Figure 12 illustrates differences in effect sizes across studies. In our setting, PATHS increases children's probability of completing academic high school by 23 percent. This effect size is comparable to effects of other interventions. The Montreal Longitudinal Study social skills training program increases the probability of completing high school by 13 to 18 percent (Boisjoli et al. (2007); Algan et al. 2016). The Becoming a Man intervention forecasts treatment effects of 12 to 19 percent on high school completion (Heller et al. 2017). The Pathways mentoring and tutoring program increases high school completion by 35 percent (Oreopoulos et al. 2017). The Baloo and You mentoring program increases the probability 
of getting tracked into academic high school by 20 percent (Falk et al., 2020). While Baloo and You and PATHS differ in their content, both interventions are similarly long (as measured in contact hours), target similarly aged children, and have almost identical treatment effects.

The effect of PATHS is substantially smaller than effects of US preschool programs. The PATHS effect is about one-quarter of the effect size of the Perry preschool program on high school completion (Barnett 1995; Heckman et al. 2010a) and about one-seventh of the effect of the Abecedarian program on college attendance (Campbell et al. 2014). These studies might find larger effects because they focus on disadvantaged populations.

We complement our effect size comparison with a comparison of costs. This comparison is difficult because information on costs is sometimes missing and sometimes, like in the case of teacher salaries, very context dependent. Therefore, the following analysis should be interpreted with caution.

Figure 13 shows the costs of interventions for which this information is available. The total intervention cost per child refers to all costs over the intervention period, excluding evaluation costs. These costs are in nominal USD. The implementation of PATHS in Zurich cost USD 1,540 per class and USD 67 per child. The main cost of implementing PATHS stems from the teachers' training and the material for PATHS activities, for example, teaching folders, posters, books, and feeling cards. The Baloo and You intervention costs USD 1,266 per child (Baldauf, and Péron, 2015). The Becoming a Man intervention costs USD 1,475 per child (Heller at al. 2017). The socioemotional skills and parenting training implemented as part of the Montreal Longitudinal Study costs USD 4,750 per child (Algan et al. 2016). The Pathways mentoring and tutoring program costs USD 10,100 per child (Oreopoulos et al. 2017). In light of their substantial treatment effects, all these interventions seem cost-effective. However, PATHS stands out as remarkably low-cost. 


\section{Figure 12: Effect Size Comparison to Other Interventions}

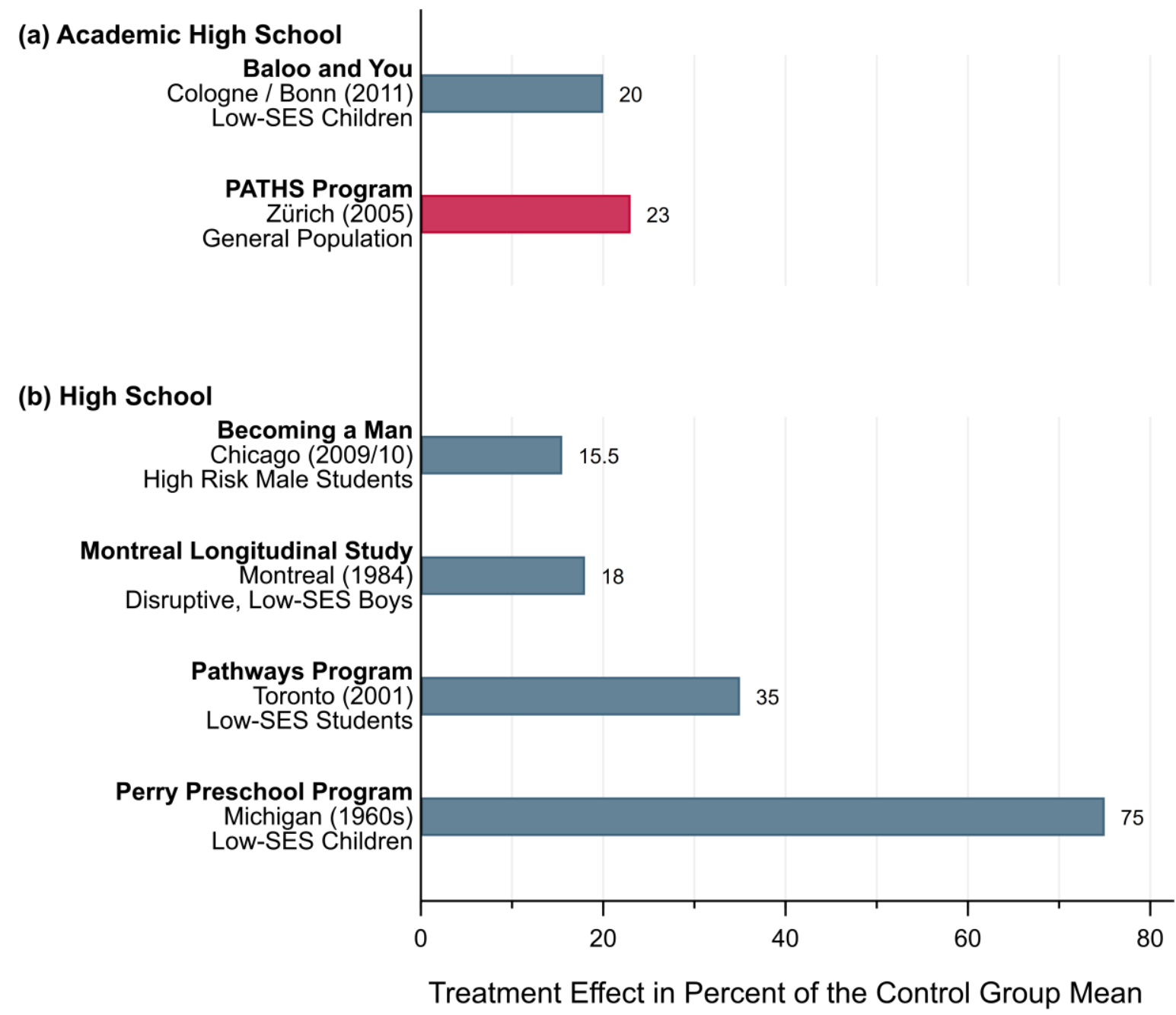

Note: This figure shows treatment effect sizes for (academic) high school completion of different interventions in the related literature. The figure distinguishes between academic high school completion in Germany and Switzerland (Panel (a)) and high school completion in the United States and Canada (Panel (b)). The effect size for the Baloo and You program is reported in Falk et al. (2020). The effect size of the Perry Preschool Program is reported in Heckman et al. (2010). The intervention effect size of the Montreal Longitudinal Study is reported in Algan et al. (2016). The effect size for the Becoming a Man intervention represents the midpoint of the range of 12 to 19 percent as provided in Heller et al. (2017). The effect size of the Pathways program is reported in Oreopoulos et al (2017).

PATHS is also substantially less expensive than early childhood education programs like the Perry Preschool Program or the Abecedarian project. The Perry Preschool Program costs USD 10,000 per child (Web-Appendix of Heckman et al. 2010b). The Abecedarian program costs USD 13,400 per child (Campbell et al. 2014). These striking cost differences reflect that the Perry 
Preschool Program and the Abecedarian program are high-intensity interventions targeted at particularly disadvantaged populations.

To summarize, the comparison of effect sizes and costs suggests that PATHS is a low-cost intervention with substantial positive impacts. Our results suggest that embedding socio-emotional skills training programs as a general part of the standard primary school curriculum is a good investment.

\section{Figure 13: Cost Comparison with Other Interventions}

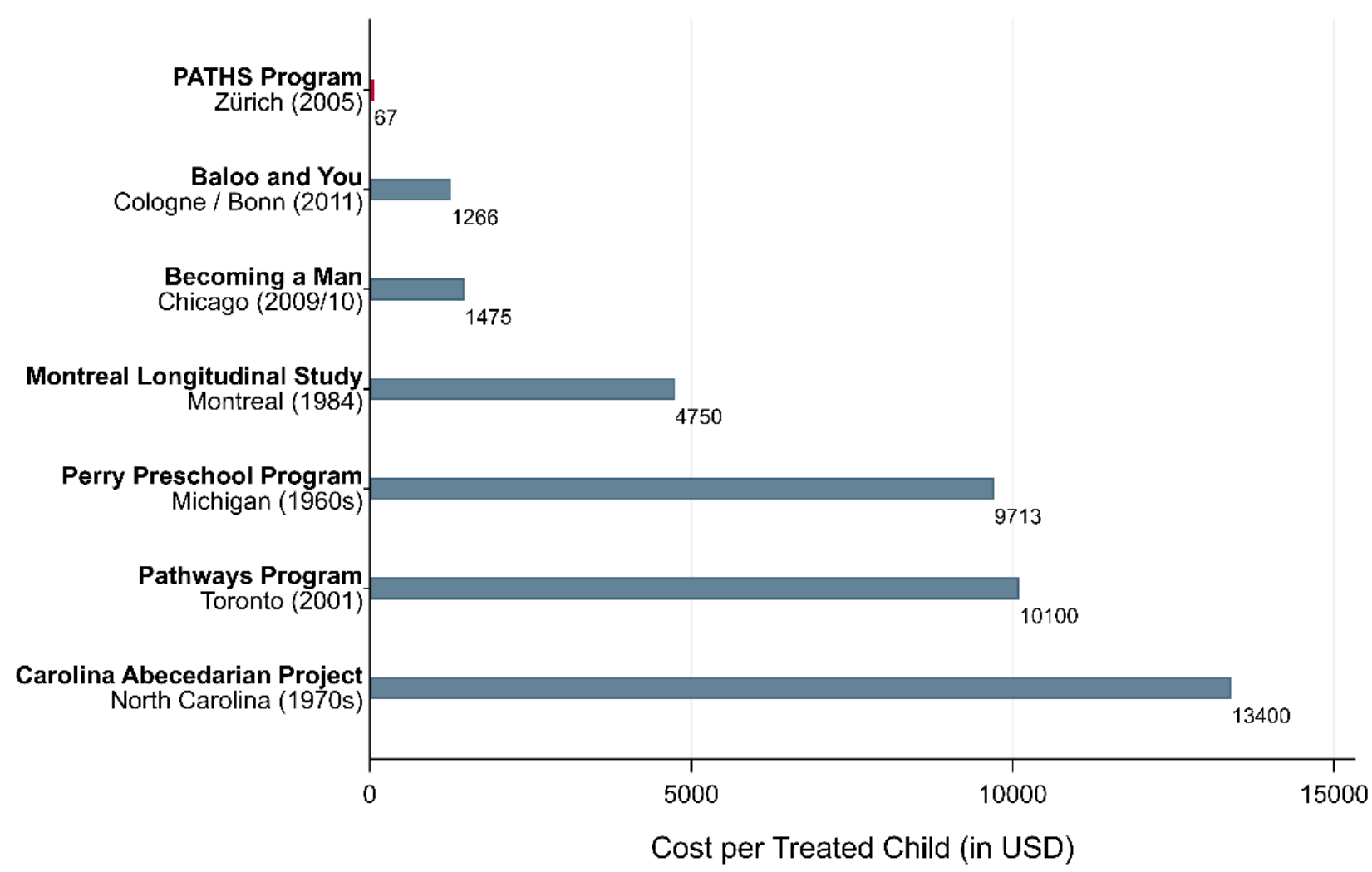

Note: This figure shows the cost per treated child of different interventions in the related literature. Cost estimates for the Becoming a Man, the Montreal Longitudinal Study, and the Carolina Abecedarian Projects intervention are taken from Heller at al. (2017), Algan et al. (2016), and Campell (2014), respectively. Costs of the Perry Preschool Program are taken from the web appendix of Heckman et al. (2011). Cost estimates of the Baloo and You intervention in Germany are based on Baldauf and Péron (2015). Costs of the Pathways program are reported in Oreopoulos et al (2017). 


\section{Conclusion}

This paper provides experimental evidence that fostering socio-emotional skills in primary school children has persistent positive effects on educational careers. We provide evidence on the PATHS program, a teacher-run intervention that lasts for up to two years in primary school. The intervention increases the probability of completing academic high school and enrolling in university twelve years after the end of the intervention.

Our results on underlying mechanisms suggest that the PATHS treatment effect is mainly driven by changes in some of the socio-emotional skills targeted by the intervention. Treated children become less impulsive, less disruptive, and display less opposition to teachers and parents. In class, treated children become less likely to disturb lessons and more likely to focus on the teaching content. Although we find that treated children have better grades, we find no evidence that standardized test scores are affected by the intervention. Long-term effects thus seem more likely to operate through changes in socio-emotional skills rather than cognitive skills.

This paper has two main limitations. The first limitation concerns the general equilibrium effects of the intervention. It is not clear whether we would observe the same treatment effects on tracking if the entire population were treated. Academic high schools have capacity constraints and there is a strong belief in Switzerland that these schools should remain selective. It is therefore unclear whether a nationwide roll-out of the program would persistently increase overall university enrollment. The second limitation concerns the external validity of our results outside the Swiss context. While over 60 percent of OECD countries use tracking policies similar to Switzerland's, it is unclear how much of the long-term effects we document are due to children being tracked only three years after the intervention. Despite these limitations, we think that the reduction in ADHD symptoms, and improvements in classroom behavior and other socio-emotional skills are valuable by themselves. Students, parents, and teachers benefit from these changes independently of 
whether they lead students to a higher secondary school track. We hope that future studies will provide evidence on the labor market returns caused by the changes in socio-emotional skills we document in this paper.

Taken together, the results of this study raise an interesting question. Would it be possible to teach children socio-emotional skills with a subject that is explicitly dedicated to it, similar to the way math and reading are taught? While it has been shown that teachers have lasting impacts on behavior (Chetty el al. 2011, Jackson 2018), there is no school subject explicitly designed to foster socio-emotional skills. The results of this study suggest that primary schools are a promising place to institutionalize the training of socio-emotional skills. 


\section{References}

Alan, S., Boneva, and T., Ertac, S. (2019), "Ever Failed, Try Again, Succeed Better: Results from a Randomized Educational Intervention on Grit," Quarterly Journal of Economics, 134(3), $1121-1162$.

Alan, S., and Ertac, S. (2018), "Fostering Patience in the Classroom: Results from a Randomized Educational Intervention,” Journal of Political Economy, 126 (5), 1865-1911.

Algan Y., Beasley E., Tremblay R. E., and Vitaro, F. (2016), “The Impact of Non-Cognitive Skills Training on Academic and Nonacademic Trajectories: From Childhood to Early Adulthood," Unpublished Manuscript.

Almlund, M., Duckworth, A. L., Heckman, J., and Kautz, T. (2011), "Personality Psychology and Economics," in Handbook of the Economics of Education vol. 4, E. A. Hanushek, S. J. Machin, and L. Woessmann, eds. (Elsevier, 2016), 1-181.

Altonji, J. G., Elder, T. E., and Taber, C. R. (2005), "Selection on Observed and Unobserved Variables: Assessing the Effectiveness of Catholic Schools," Journal of Political Economy, 113(1), 151-184.

Anderson, M. L. (2008), "Multiple Inference and Gender Differences in the Effects of Early Intervention: A Reevaluation of the Abecedarian, Perry Preschool, and Early Training Projects," Journal of the American Statistical Association, 103(484), 1481-1495.

Averdijk, M., Zirk-Sadowski, J., Ribeaud, D., and Eisner, M. (2016), “Long-Term Effects of Two Childhood Psychosocial Interventions on Adolescent Delinquency, Substance Use, and Antisocial Behavior: A Cluster Randomized Controlled Trial," Journal of Experimental Criminology, 12(1), 21-47.

Baldauf, V., and Péron, C. (2015), "Was Bringt's? SROI-Analyse des Mentoring-Programms Balu und du. Technical Report," URL: https://www.eleven.ngo/content/2-blog/86-was-bringts-sroianalyse-des-mentoring-programms-balu-und-du-liegt-vor/sroi-bericht-bud-final-

17feb2015.pdf (visited on 26 November 2019).

Barnett, W. S. (1995), "Long-Term Effects of Early Childhood Programs on Cognitive and School Outcomes," Future of Children, 25-50.

Barrick, M. R., and Mount, M. K. (1991), “The Big Five Personality Dimensions and Job Performance: A Meta-Analysis," Personnel Psychology, 44(1), 1-26. 
Boisjoli, R., Vitaro, F., Lacourse, É., Barker, E. D., and Tremblay, R. E. (2007), "Impact and Clinical Significance of a Preventive Intervention for Disruptive Boys: 15-year Follow-Up," British Journal of Psychiatry, 191(5), 415-419.

Blewitt, C., Fuller-Tyszkiewicz, M., Nolan, A., Bergmeier, H., Vicary, D., Huang, T., McCabe, P., McKay, T., and Skouteris, H. (2018), "Social and Emotional Learning Associated With Universal Curriculum-Based Interventions in Early Childhood Education and Care Centers: A Systematic Review and Meta-Analysis”, JAMA Network Open, 1(8), e185727.

Borghans, L., Golsteyn, B. H., Heckman, J. J., and Humphries, J. E. (2016), "What Grades and Achievement Tests Measure," Proceedings of the National Academy of Sciences, 113(47), 13354-13359.

Campbell, F. A., Conti, G., Heckman, J. J., Moon, S. H., Pinto, R., Pungello, E., and Pan, Y. (2014), "Early Childhood Investments Substantially Boost Adult Health,” Science, 343(6178), 14781485.

Campbell, F. A., Ramey, C. T., Pungello, E., Sparling, J., and Miller-Johnson, S. (2002), "Early Childhood Education: Young Adult Outcomes from the Abecedarian Project," Applied Developmental Science, 6(1), 42-57.

Cappelen, A., List, J. A., Samek, A., and Tungodden, B. (Forthcoming), "The Effect of Early Education on Social Preferences," Journal of Political Economy.

Chetty, R., Friedman, J. N., Hilger, N., Saez, E., Schanzenbach, D. W., and Yagan, D. (2011), "How Does Your Kindergarten Classroom Affect Your Earnings? Evidence from Project STAR," Quarterly Journal of Economics, 126(4), 1593-1660.

Crean, H. F., and Johnson, D. B. (2013), "Promoting Alternative Thinking Strategies (PATHS) and Elementary School Aged Children's Aggression: Results from a Cluster Randomized Trial,” American Journal of Community Psychology, 52(1-2), 56-72.

Deming, D. J. (2017), “The Growing Importance of Social Skills in the Labor Market,” Quarterly Journal of Economics, 132(4), 1593-1640.

Doepke, M., and Zilibotti, F. (2017), "Parenting with Style: Altruism and Paternalism in Intergenerational Preference Transmission,” Econometrica, 85(5), 1331-1371.

Doepke, M., Sorrenti, G., and Zilibotti, F. (2019), "The Economics of Parenting," Annual Review of Economics, 11, 55-84.

Doyle, O. (Forthcoming), "The First 2,000 Days and Child Skills," Journal of Political Economy. 
Durlak, J. A., Weissberg, R. P., Dymnicki, A. B., Taylor, R. D., and Schellinger, K. B. (2011), “The Impact of Enhancing Students' Social and Emotional Learning: A Meta-Analysis of School-Based Universal Interventions," Child Development, 82(1), 405-432.

Eisner, M., Nagin, D., Ribeaud, D., and Malti, T. (2012), "Effects of a Universal Parenting Program for Highly Adherent Parents: A Propensity Score Matching Approach," Prevention Science, 13(3), 252-266.

Eisner, M., Malti, T., and Ribeaud, D. (2011), "Large-Scale Criminological Field Experiments. The Zurich Project on the Social Development of Children," in SAGE Handbook of Criminological Research Methods, D. Gadd, S. Karstedt, and S. F. Messner eds. (London: Sage Publications), 410-424.

Eisner, M., Ribeaud, D., Jünger, R., and Meidert, U. (2007), Frühprävention von Gewalt und Aggression. Ergebnisse des Zürcher Präventions-und Interventionsprojektes an Schulen (Zürich, Chur).

Falk A., Kosse F., Pinger P., and Schildberg-Hörisch H. (2020), “(In)Equality of Opportunity, Mentoring, and Critical Educational Decisions," Unpublished Manuscript.

Fantuzzo, J., Bulotsky-Shearer, R., McDermott, P., McWayne, C., Frye, D., and Perlman, S. (2007), "Investigation of Dimensions of Social-Emotional Classroom Behavior and School Readiness for Low-Income Urban Preschool Children,” School Psychology Review, 36(1), 4462.

Gelbach, J. B. (2016), "When Do Covariates Matter? And Which Ones, and How Much?" Journal of Labor Economics, 34(2), 509-543.

Gertler, P., Heckman, J., Pinto, R., Zanolini, A., Vermeersch, C., Walker, S., Chang, S. M., and Grantham-McGregor, S. M. (2014), "Labor Market Returns to an Early Childhood Stimulation Intervention in Jamaica," Science, 344(6187), 998-1001.

Grantham-McGregor, S. M., Walker, S. P., Chang, S. M., and Powell, C. A. (1997), "Effects of Early Childhood Supplementation With and Without Stimulation on Later Development in Stunted Jamaican Children,” American Journal of Clinical Nutrition, 66(2), 247-253.

Greenberg, M. T., and Kusche, C. A. (1993), Promoting Social and Emotional Development in Deaf Children: The PATHS Project (University of Washington Press, 1993). 
Greenberg, M. T., Kusché, C. A., Cook, E. T., and Quamma, J. P. (1995), "Promoting Emotional Competence in School-Aged Children: The Effects of the PATHS Curriculum," Development and Psychopathology, 7(1), 117-136.

Greenberg, M. T., Kusché, C. A., Mihalic, S. F., and Elliott, D. (1998), Blueprints for Violence Prevention: Book Ten: Promoting Alternative Thinking Strategies (Boulder, CO: Center for the Prevention of Violence).

Heckman, J. J., and Karapakula, G. (2019a). Intergenerational and Intragenerational Externalities of the Perry Preschool Project. National Bureau of Economic Research WP 25889.

Heckman, J. J., and Karapakula, G. (2019b), "The Perry Preschoolers at Late Midlife: A Study in Design-Specific Inference,” National Bureau of Economic Research Working Paper.

Heckman, J., Moon, S. H., Pinto, R., Savelyev, P., and Yavitz, A. (2010a), “Analyzing Social Experiments as Implemented: A Reexamination of the Evidence from the High Scope Perry Preschool Program," Quantitative Economics, 1(1), 1-46.

Heckman, J. J., Moon, S. H., Pinto, R., Savelyev, P. A., and Yavitz, A. (2010b), "The Rate of Return to the High Scope Perry Preschool Program," Journal of Public Economics, 94(1-2), $114-128$.

Heckman, J. J., and Rubinstein, Y. (2001), “The Importance of Noncognitive Skills: Lessons from the GED Testing Program," American Economic Review, 91(2), 145-149.

Heller, S. B., Shah, A. K., Guryan, J., Ludwig, J., Mullainathan, S., and Pollack, H. A. (2017), "Thinking, Fast and Slow? Some Field Experiments to Reduce Crime and Dropout in Chicago," Quarterly Journal of Economics, 132(1), 1-54.

Imai, K., Keele, L., and Tingley, D. (2010), “A General Approach to Causal Mediation Analysis,” Psychological Methods, 15(4), 309-344.

Izard, C. E., Trentacosta, C. J., King, K. A., and Mostow, A. J. (2004), “An Emotion-Based Prevention Program for Head Start Children,” Early Education \& Development, 15(4), 407422.

Jackson, C. K. (2018), "What Do Test Scores Miss? The Importance of Teacher Effects on NonTest Score Outcomes,” Journal of Political Economy, 126(5), 2072-2107.

Kam, C. M., Greenberg, M. T., and Kusché, C. A. (2004), "Sustained Effects of the PATHS Curriculum on the Social and Psychological Adjustment of Children in Special Education," Journal of Emotional and Behavioral Disorders, 12(2), 66-78. 
Kosse, F., Deckers, T., Pinger, P. R., Schildberg-Hörisch, H., and Falk, A. (2020), “The Formation of Prosociality: Causal Evidence on the Role of Social Environment," Journal of Political Economy, 128(2), 434-467.

Kusché, C. A. and Greenberg M. T. (1994). The PATHS Curriculum. Seattle: Developmental Research and Programs.

Malti, T., Ribeaud, D., and Eisner, M. P. (2011), “The Effectiveness of Two Universal Preventive Interventions in Reducing Children's Externalizing Behavior: A Cluster Randomized Controlled Trial," Journal of Clinical Child \& Adolescent Psychology, 40(5), 677-692.

Malti, T., Ribeaud, D., and Eisner, M. (2012), "Effectiveness of a Universal School-Based Social Competence Program: The Role of Child Characteristics and Economic Factors," International Journal of Conflict and Violence, 6(2), 249-259.

Murray, A. L., Booth, T., Eisner, M., Ribeaud, D., McKenzie, K., and Murray, G. (2019), “An Analysis of Response Shifts in Teacher Reports Associated with the Use of a Universal SchoolBased Intervention to Reduce Externalizing Behavior," Prevention Science, 20(8), 1265-1273. Murray, A., Eisner, M., Obsuth, I., and Ribeaud, D. (2019), "Evaluating Longitudinal Invariance in Dimensions of Mental Health Across Adolescence: An Analysis of the Social Behavior Questionnaire," Assessment, 26(7), 1234-1245.

Noftle, E. E., \& Robins, R. W. (2007), "Personality Predictors of Academic Outcomes: Big Five Correlates of GPA and SAT Scores,” Journal of Personality and Social Psychology, 93(1), 116.

OECD (2004), "Learning for Tomorrow's World: First Results from PISA 2003," OECD Publishing.

Oreopoulos, P., Brown, R. S., \& Lavecchia, A. M. (2017), Pathways to Education: An Integrated Approach to Helping At-Risk High School Students. Journal of Political Economy, 125(4), 947-984.

Raver, C. C., Jones, S. M., Li-Grining, C., Zhai, F., Bub, K., and Pressler, E. (2011), CSRP's Impact on Low-Income Preschoolers' Preacademic Skills: Self-Regulation as a Mediating Mechanism," Child Development, 82(1), 362-378.

Ray, D., (r) Robson, A. (2018), “Certified Random: A New Order for Coauthorship,” American Economic Review, 108(2), 489-520. 
Roberts, B. W., Kuncel, N. R., Shiner, R., Caspi, A., and Goldberg, L. R. (2007), “The Power of Personality: The Comparative Validity of Personality Traits, Socioeconomic Status, and Cognitive Ability for Predicting Important Life Outcomes," Perspectives on Psychological Science, 2(4), 313-345.

Riggs, N. R., Greenberg, M. T., Kusché, C. A., and Pentz, M. A. (2006), “The Mediational Role of Neurocognition in the Behavioral Outcomes of a Social-Emotional Prevention Program in Elementary School Students: Effects of the PATHS Curriculum," Prevention Science, 7(1), 91-102.

Sanders, M. R. (1999), “Triple P-Positive Parenting Program: Towards an Empirically Validated Multilevel Parenting and Family Support Strategy for the Prevention of Behaviour and Emotional Problems in Children," Clinical Child and Family Psychology Review, 2, 71-89.

Schonfeld, D. J., Adams, R. E., Fredstrom, B. K., Weissberg, R. P., Gilman, R., Voyce, C., Tomlin, R., and Speese-Linehan, D. (2015), "Cluster-Randomized Trial Demonstrating Impact on Academic Achievement of Elementary Social-Emotional Learning," School Psychology Quarterly, 30(3), 406-420.

Schweinhart, L. J. (1993), "Significant Benefits: The High/Scope Perry Preschool Study through Age 2," in Monographs of the High/Scope Educational Research Foundation vol. 10, L. J. Schweinhart, and D. P. Weikart, eds. (Ypsilanti: MI, 1993).

Shelton, K. K., Frick, P. J., and Wootton, J. (1996), “Assessment of Parenting Practices in Families of Elementary School-Age Children,” Journal of Clinical Child Psychology, 25(3), 317329.

Taylor, R. D., Oberle, E., Durlak, J. A., and Weissberg, R. P. (2017), "Promoting Positive Youth Development Through School-Based Social and Emotional Learning Interventions: A Meta-Analysis of Follow-Up Effects," Child Development, 88(4), 1156-1171

Tremblay, R. E., Loeber, R., Gagnon, C., Charlebois, P., Larivée, S., and LeBlanc, M. (1991), "Disruptive Boys with Stable and Unstable High Fighting Behavior Patterns During Junior Elementary School," Journal of Abnormal Child Psychology, 19(3), 285-300.

Vazsonyi, A. T., Pickering, L. E., Junger, M., and Hessing, D. (2001), “An Empirical Test of a General Theory of Crime: A Four-Nation Comparative Study of Self-Control and the Prediction of Deviance," Journal of Research in Crime and Delinquency, 38(2), 91-131. 
Wooldridge, J. M. (2007), "Inverse Probability Weighted Estimation for General Missing Data Problems," Journal of Econometrics, 141(2), 1281-1301.

Young, A. (2018), "Channeling Fisher: Randomization Tests and the Statistical Insignificance of Seemingly Significant Experimental Results," Quarterly Journal of Economics, 134(2), 557598. 


\section{Tables}

Table I: PATHS Activities

\begin{tabular}{|c|c|c|c|}
\hline \multirow{2}{*}{$\begin{array}{l}\text { Activity } \\
\text { Category }\end{array}$} & \multicolumn{3}{|c|}{ Example Activities } \\
\hline & Class Activity: & Homework: & Parental Involvement: \\
\hline $\begin{array}{l}\text { Self-Control; } \\
\text { Patience }\end{array}$ & $\begin{array}{l}\text { Calming down: Teacher discusses various } \\
\text { methods to calm down with class. Teacher } \\
\text { reads aloud story of a girl that learned how to } \\
\text { control herself. } \\
\text { Teasing: Children learn to ignore people that } \\
\text { tease in a mean way. Children make role-plays } \\
\text { to learn how to interpret and handle teasing. }\end{array}$ & $\begin{array}{l}\text { Calming down: Children } \\
\text { write what their parents do, } \\
\text { when they have a problem } \\
\text { or want to calm down. }\end{array}$ & $\begin{array}{l}\text { Calming down: Children } \\
\text { ask their parents about } \\
\text { situations where they had to } \\
\text { calm down and had to think } \\
\text { about a possible solution. }\end{array}$ \\
\hline $\begin{array}{l}\text { Social } \\
\text { Problem } \\
\text { Solving }\end{array}$ & $\begin{array}{l}\text { Control signals: Children learn the three steps } \\
\text { of problem solving: } \\
\text { 1. Calm down and express own feelings. } \\
\text { 2. Think about possible solutions and their } \\
\text { consequences. } \\
\text { 3. Try your plan and evaluate it. } \\
\text { Children make role-plays to practice the } \\
\text { problem solving steps. } \\
\text { Problem pot: If children have problems, they } \\
\text { can write them down and put them in the } \\
\text { problem pot. The class will then try to solve } \\
\text { these problems with the help of the control } \\
\text { signals and role-playing. } \\
\text { Generosity: Class plans a project to somehow } \\
\text { help others (e.g. raise money or clean up } \\
\text { neighborhood) }\end{array}$ & $\begin{array}{l}\text { Control signals: Children } \\
\text { have to make their own } \\
\text { control signals. } \\
\text { Generosity: Children } \\
\text { should do something good } \\
\text { to a person and draw/write } \\
\text { about it. }\end{array}$ & $\begin{array}{l}\text { Control signals: Parents } \\
\text { receive an explanation } \\
\text { about when and how they } \\
\text { could use the control } \\
\text { signals. }\end{array}$ \\
\hline Self-Esteem & $\begin{array}{l}\text { Child-of-the-week: In each PATHS lecture a } \\
\text { child is randomly picked to be the teacher's } \\
\text { assistant during the lecture. Further, the other } \\
\text { children make a list of compliments for the } \\
\text { child-of-the-week. Before that, the children } \\
\text { learn about how to compliment another person. }\end{array}$ & $\begin{array}{l}\text { Compliments: Children } \\
\text { have to give compliments to } \\
\text { other members of their } \\
\text { families and reflect on how } \\
\text { they felt giving } \\
\text { compliments and how the } \\
\text { other person reacted. }\end{array}$ & $\begin{array}{l}\text { Child-of-the-week/ } \\
\text { compliments: Parents are } \\
\text { informed that their child is } \\
\text { the child-of-the-week. They } \\
\text { go through the list of } \\
\text { compliments with their } \\
\text { child and add compliments. }\end{array}$ \\
\hline $\begin{array}{l}\text { Emotional } \\
\text { Intelligence }\end{array}$ & $\begin{array}{l}\text { Emotions: Children get introduced to and } \\
\text { discuss various emotions. Teacher tells a story } \\
\text { about or shows picture of people, and children } \\
\text { have to guess how the person in the story/in the } \\
\text { picture felt in this situation. Child choses an } \\
\text { emotion and the other children try to mimic the } \\
\text { emotion. }\end{array}$ & $\begin{array}{l}\text { Emotions: Children draw a } \\
\text { picture or write about a } \\
\text { situation in which they felt } \\
\text { a certain emotion. }\end{array}$ & $\begin{array}{l}\text { Emotions/appropriate } \\
\text { behavior: Children ask } \\
\text { their parents or other adults } \\
\text { to tell them about a } \\
\text { situation in which they felt } \\
\text { a certain emotion and how } \\
\text { they behaved. }\end{array}$ \\
\hline
\end{tabular}




\section{Table I: PATHS Activities (continued)}

\begin{tabular}{|c|c|c|c|}
\hline $\begin{array}{l}\text { Emotional } \\
\text { Intelligence } \\
\text { (Continued) }\end{array}$ & $\begin{array}{l}\text { Feelings cards: Children receive cards } \\
\text { with faces expressing different } \\
\text { emotions. Children can place a card on } \\
\text { their table to express their current } \\
\text { emotional state. } \\
\text { Appropriate behavior: Children are } \\
\text { given drawings of children behaving out } \\
\text { of an emotion (e.g. anger). They then } \\
\text { have to color the drawings in which they } \\
\text { think the behavior is appropriate. }\end{array}$ & & \\
\hline $\begin{array}{l}\text { Fairness } \\
\text { Rules }\end{array}$ & $\begin{array}{l}\text { Classroom rules: Children discuss with } \\
\text { teacher why rules are useful and } \\
\text { establish a set of rules for their } \\
\text { classroom. } \\
\text { Making friends: Teacher reads aloud } \\
\text { story to class about two children } \\
\text { becoming friends. After, discussion and } \\
\text { role-play about friendship and making } \\
\text { friends. } \\
\text { Listening to others: In groups, children } \\
\text { learn to listen to each other to gather } \\
\text { information about the members of their } \\
\text { group. } \\
\text { Manners: Classroom discussion about } \\
\text { good/bad manners and why good } \\
\text { manners are important. Children gather } \\
\text { polite phrases and expressions. Teacher } \\
\text { reads a story and children have to decide } \\
\text { in each situation whether the teacher } \\
\text { reads the polite or impolite version. } \\
\text { Afterwards, children reenact the } \\
\text { situation. } \\
\text { Fairness: Teacher introduces poster } \\
\text { with principles of fair behavior. } \\
\text { Children hear stories/get worksheet with } \\
\text { different situations and discuss in groups } \\
\text { whether the displayed behavior is fair or } \\
\text { not. Children establish ideas on how to } \\
\text { make fair decisions (e.g. coin toss). } \\
\text { Reconciliation: Children gather ideas } \\
\text { and make a list of ways to reconcile. }\end{array}$ & $\begin{array}{l}\text { Rules at home: Children have } \\
\text { to establish a list with the rules } \\
\text { that apply in their home. }\end{array}$ & $\begin{array}{l}\text { Rules: Children have to } \\
\text { interview their parents } \\
\text { about the rules that applied } \\
\text { in their home when they } \\
\text { were children themselves. } \\
\text { Manners: Parents should } \\
\text { discuss with children } \\
\text { good/bad manners and } \\
\text { how they feel when the } \\
\text { child shows bad manners } \\
\text { at home. }\end{array}$ \\
\hline
\end{tabular}

Note: This table provides an overview of the main themes of the PATHS curriculum. Besides classroom activities, children also received homework, which may have involved parents. All major themes of the PATHS curriculum were accompanied with an information leaflet for parents explaining the current theme and providing suggestions on how to support children with the current curricular activities. 
Table II: Overview of the z-proso Study Survey Waves

\begin{tabular}{lcccccccccc}
\hline Year & $2004 / 5$ & 2006 & 2007 & 2008 & 2009 & 2010 & 2011 & 2013 & 2015 & 2018 \\
Wave & 1 & 2 & 3 & 4.1 & 4.2 & 4.3 & 5 & 6 & 7 & 8 \\
Age & 7 & 8 & 9 & 10 & 11 & 12 & 13 & 15 & 17 & 20 \\
Grade & 2 & 3 & 4 & 5 & 6 & 7 & 8 & 10 & $(12)$ & - \\
\hline & & & & & & & & & & \\
Respondents: & $\checkmark$ & $\checkmark$ & $\checkmark$ & $\checkmark$ & $\checkmark$ & $\checkmark$ & $\checkmark$ & $\checkmark$ & $(\checkmark)$ & $\mathbf{x}$ \\
Teacher & $\checkmark$ & $\checkmark$ & $\checkmark$ & $\mathbf{x}$ & $\checkmark$ & $\mathbf{x}$ & $\checkmark$ & $\checkmark$ & $\checkmark$ & $\checkmark$ \\
Child & $\checkmark$ & $\checkmark$ & $\checkmark$ & $\mathbf{x}$ & $\checkmark$ & $\mathbf{x}$ & $\mathbf{x}$ & $\mathbf{x}$ & $\mathbf{x}$ & $\mathbf{x}$ \\
Parent & $\checkmark$ &
\end{tabular}

Note: The table shows the timing and respondents of the different survey waves of the z-proso study. Age refers to the median child age in the respective survey wave. The table also shows which respondents took part in the respective survey wave. In wave 1 , parents had already been surveyed in 2004. In our analysis, we do not use teacher assessments at age 17 since individuals outside academic high school do not have a regular school teacher that could provide a valid assessment at this age. 
Table III: Descriptive Statistics

\begin{tabular}{|c|c|c|c|c|c|}
\hline & $\begin{array}{l}(1) \\
\mathrm{N}\end{array}$ & $\begin{array}{c}(2) \\
\text { Mean } \\
\end{array}$ & $\begin{array}{l}(3) \\
\text { SD } \\
\end{array}$ & $\begin{array}{c}(4) \\
\text { Min }\end{array}$ & $\begin{array}{c}(5) \\
\text { Max } \\
\end{array}$ \\
\hline \multicolumn{6}{|l|}{ Educational Outcomes: } \\
\hline Attending Academic High School Age 13 & 1,589 & 0.157 & 0.364 & 0 & 1 \\
\hline Attending Academic High School Age 15 & 1,535 & 0.202 & 0.402 & 0 & 1 \\
\hline Attending Academic High School Age 17 & 1,305 & 0.261 & 0.439 & 0 & 1 \\
\hline Completed Academic High School Age 20 & 1,185 & 0.270 & 0.444 & 0 & 1 \\
\hline Enrolled in University Age 20 & 1,178 & 0.167 & 0.373 & 0 & 1 \\
\hline In Education or Training Age 20 & 1,178 & 0.565 & 0.496 & 0 & 1 \\
\hline \multicolumn{6}{|l|}{ Baseline Child Characteristics: } \\
\hline Age in 2005 & 1,238 & 7.033 & 0.396 & 5.699 & 8.494 \\
\hline Swiss Citizenship & 1,238 & 0.599 & 0.490 & 0 & 1 \\
\hline Female & 1,675 & 0.481 & 0.500 & 0 & 1 \\
\hline \multicolumn{6}{|l|}{ Baseline Child Socio-Emotional Skills (Teacher Report): } \\
\hline ADHD Symptoms (Disruptiveness and Impulsiveness) & 1,348 & 1.246 & 0.989 & 0 & 4 \\
\hline Opposition \& Defiance & 1,348 & 0.541 & 0.815 & 0 & 4 \\
\hline Non-Aggressive Conduct Disorder & 1,348 & 0.217 & 0.405 & 0 & 2.500 \\
\hline Anxiety \& Depressivity & 1,348 & 0.871 & 0.762 & 0 & 4 \\
\hline Aggression & 1,348 & 0.588 & 0.684 & 0 & 4 \\
\hline Prosociality & 1,348 & 2.171 & 0.824 & 0 & 4 \\
\hline \multicolumn{6}{|l|}{ Baseline Child Socio-Emotional Skills (Parent Report): } \\
\hline ADHD Symptoms (Disruptiveness and Impulsiveness) & 1,229 & 1.212 & 0.646 & 0 & 3.778 \\
\hline Opposition \& Defiance & 1,229 & 0.966 & 0.621 & 0 & 2.750 \\
\hline Non-Aggressive Conduct Disorder & 1,229 & 0.296 & 0.326 & 0 & 2.800 \\
\hline Anxiety \& Depressivity & 1,229 & 0.704 & 0.464 & 0 & 2.556 \\
\hline Aggression & 1,229 & 0.601 & 0.423 & 0 & 2.750 \\
\hline Prosociality & 1,229 & 2.577 & 0.528 & 0.600 & 4 \\
\hline \multicolumn{6}{|l|}{ Baseline Parenting Practices (Parent Report): } \\
\hline Corporal Punishment & 1,229 & 0.454 & 0.489 & 0 & 2.667 \\
\hline Inconsistent Discipline & 1,229 & 1.188 & 0.598 & 0 & 3.200 \\
\hline Parental Control \& Supervision & 1,229 & 3.686 & 0.328 & 2 & 4 \\
\hline Parental Involvement & 1,229 & 3.189 & 0.422 & 1.500 & 4 \\
\hline Positive Parenting & 1,229 & 3.215 & 0.514 & 1.200 & 4 \\
\hline \multicolumn{6}{|l|}{ Baseline Household Characteristics: } \\
\hline Mother Completed at least Gymnasium Degree & 1,215 & 0.393 & 0.489 & 0 & 1 \\
\hline Father Completed at least Gymnasium Degree & 1,015 & 0.518 & 0.500 & 0 & 1 \\
\hline Mother Holds University Degree & 1,215 & 0.160 & 0.367 & 0 & 1 \\
\hline Father Holds University Degree & 1,015 & 0.249 & 0.433 & 0 & 1 \\
\hline Single Parent Household & 1,230 & 0.172 & 0.378 & 0 & 1 \\
\hline Age Mother in 2005 & 1,218 & 37.020 & 5.375 & 23 & 53 \\
\hline Mother Swiss Citizenship & 1,663 & 0.486 & 0.500 & 0 & 1 \\
\hline Mother Born in Switzerland & 1,219 & 0.423 & 0.494 & 0 & 1 \\
\hline Family Receives Financial Aid & 1,213 & 0.380 & 0.486 & 0 & 1 \\
\hline Family Reports Financial Problems & 1,216 & 0.178 & 0.382 & 0 & 1 \\
\hline Household Income (in 1000 USDs) & 1,132 & 86.310 & 48.710 & 12 & 270 \\
\hline
\end{tabular}

Note: This table shows descriptive statistics for the variables used our analysis. SD stands for standard deviation. 
Table IV: Summary Table for Balancing of Baseline Characteristics

\begin{tabular}{lcc}
\hline & $\begin{array}{c}(1) \\
\text { Number of } \\
\text { Balancing Tests }\end{array}$ & $\begin{array}{c}(2) \\
\text { Expectation under Random } \\
\text { Assignment }\end{array}$ \\
\hline $\begin{array}{l}\text { Total Number of Balancing Tests } \\
\text { Number of Tests Significant with } \mathrm{p}<0.01\end{array}$ & 56 & 0.560 \\
Number of Tests Significant with $\mathrm{p}<0.05$ & 2 & 2.800 \\
Number of Tests Significant with $\mathrm{p}<0.1$ & 5 & 5.600 \\
\hline
\end{tabular}

Note: This table summarizes the results of our balancing tests. To test random assignment, we regress treatment status on baseline characteristics. We run a separate linear probability model for each baseline characteristic. Table V shows a detailed list of all baseline characteristics and individual point estimates. All regressions include strata fixed effects for the level of randomization. Standard errors are clustered at the school level. Column (1) reports the total number of balancing tests and the number of statistically significant tests for different levels of significance. Column (2) reports the number of coefficients we would expect to be statistically significant due to chance under random assignment. 
Table V: Balancing Tests of Baseline Characteristics

\begin{tabular}{|c|c|c|c|c|c|c|c|}
\hline & (1) & & (2) & & (3) & & (4) \\
\hline $\begin{array}{l}\text { Child and Household } \\
\text { Characteristics }\end{array}$ & PATHS Treatment & SBQ (Parent Report) & $\begin{array}{l}\text { PATHS } \\
\text { Treatment }\end{array}$ & SBQ (Teacher Report) & $\begin{array}{l}\text { PATHS } \\
\text { Treatment }\end{array}$ & SBQ (Child Report) & $\begin{array}{l}\text { PATHS } \\
\text { Treatment }\end{array}$ \\
\hline Age & $\begin{array}{l}-0.013 \\
(0.042)\end{array}$ & Prosocial Behavior & $\begin{array}{c}0.004 \\
(0.013)\end{array}$ & Prosocial Behavior & $\begin{array}{r}0.057 * * \\
(0.028)\end{array}$ & Prosocial Behavior & $\begin{array}{l}-0.004 \\
(0.016)\end{array}$ \\
\hline Female & $\begin{array}{l}0.037 * \\
(0.020)\end{array}$ & Anxiety \& Depressivity & $\begin{array}{c}0.009 \\
(0.014)\end{array}$ & Anxiety \& Depressivity & $\begin{array}{c}0.035 \\
(0.021)\end{array}$ & Anxiety \& Depressivity & $\begin{array}{c}0.009 \\
(0.013)\end{array}$ \\
\hline Swiss Citizenship & $\begin{array}{c}0.036 \\
(0.045)\end{array}$ & $\begin{array}{l}\text { ADHD Symptoms } \\
\text { (Disruptiveness and } \\
\text { Impulsiveness) }\end{array}$ & $\begin{array}{l}-0.004 \\
(0.012)\end{array}$ & $\begin{array}{l}\text { ADHD Symptoms } \\
\text { (Disruptiveness and Impulsiveness) }\end{array}$ & $\begin{array}{c}0.035 \\
(0.021)\end{array}$ & $\begin{array}{l}\text { ADHD Symptoms } \\
\text { (Disruptiveness and } \\
\text { Impulsiveness) }\end{array}$ & $\begin{array}{c}0.014 \\
(0.014)\end{array}$ \\
\hline Mother University & $\begin{array}{l}-0.049 \\
(0.045)\end{array}$ & Opposition \& Defiance & $\begin{array}{l}-0.022^{*} \\
(0.013)\end{array}$ & Opposition \& Defiance & $\begin{array}{c}0.029 \\
(0.024)\end{array}$ & Opposition \& Defiance & $\begin{array}{c}0.013 \\
(0.013)\end{array}$ \\
\hline Father University & $\begin{array}{l}-0.073 \\
(0.044)\end{array}$ & $\begin{array}{l}\text { Non-Aggressive Conduct } \\
\text { Disorder }\end{array}$ & $\begin{array}{l}0.000 \\
(0.012)\end{array}$ & Non-Aggressive Conduct Disorder & $\begin{array}{l}0.008 \\
(0.019)\end{array}$ & $\begin{array}{l}\text { Non-Aggressive Conduct } \\
\text { Disorder }\end{array}$ & $\begin{array}{l}-0.009 \\
(0.011)\end{array}$ \\
\hline Mother Gymnasium & $\begin{array}{l}-0.049 \\
(0.035)\end{array}$ & $\begin{array}{l}\text { Non-Aggressive Externalizing } \\
\text { Problem Behavior }\end{array}$ & $\begin{array}{l}-0.015 \\
(0.013)\end{array}$ & $\begin{array}{l}\text { Non-Aggressive Externalizing } \\
\text { Problem Behavior }\end{array}$ & $\begin{array}{l}0.020 \\
(0.022)\end{array}$ & $\begin{array}{l}\text { Non-Aggressive Externalizing } \\
\text { Problem Behavior }\end{array}$ & $\begin{array}{l}0.005 \\
(0.012)\end{array}$ \\
\hline Father Gymnasium & $\begin{array}{c}-0.099 * * * \\
(0.033)\end{array}$ & Indirect Aggression & $\begin{array}{c}0.016 \\
(0.013)\end{array}$ & Indirect Aggression & $\begin{array}{c}0.029 \\
(0.020)\end{array}$ & Indirect Aggression & $\begin{array}{c}0.022 \\
(0.015)\end{array}$ \\
\hline Single Parent Household & $\begin{array}{c}0.004 \\
(0.031)\end{array}$ & Physical Aggression & $\begin{array}{l}-0.006 \\
(0.015)\end{array}$ & Reactive Aggression & $\begin{array}{c}0.018 \\
(0.026)\end{array}$ & Reactive Aggression & $\begin{array}{c}0.003 \\
(0.013)\end{array}$ \\
\hline Age Mother & $\begin{array}{l}0.003 \\
(0.003)\end{array}$ & $\begin{array}{l}\text { Proactive Aggression \& } \\
\text { Dominance }\end{array}$ & $\begin{array}{l}-0.008 \\
(0.013)\end{array}$ & Physical Aggression & $\begin{array}{c}0.001 \\
(0.021)\end{array}$ & Physical Aggression & $\begin{array}{c}0.009 \\
(0.014)\end{array}$ \\
\hline $\begin{array}{l}\text { Mother Swiss } \\
\text { Citizenship }\end{array}$ & $\begin{array}{l}0.029 \\
(0.039)\end{array}$ & Reactive Aggression & $\begin{array}{c}0.001 \\
(0.012)\end{array}$ & Proactive Aggression \& Dominance & $\begin{array}{c}0.029 \\
(0.021)\end{array}$ & $\begin{array}{l}\text { Proactive Aggression \& } \\
\text { Dominance }\end{array}$ & $\begin{array}{l}0.023^{*} \\
(0.012)\end{array}$ \\
\hline $\begin{array}{l}\text { Mother Born in } \\
\text { Switzerland }\end{array}$ & $\begin{array}{l}0.018 \\
(0.036)\end{array}$ & Overall Aggression & $\begin{array}{l}-0.005 \\
(0.014)\end{array}$ & Overall Aggression & $\begin{array}{c}0.017 \\
(0.023)\end{array}$ & Overall Aggression & $\begin{array}{l}0.013 \\
(0.014)\end{array}$ \\
\hline HH Financial Aid & $\begin{array}{l}-0.031 \\
(0.028)\end{array}$ & Overall Externalizing Behavior & $\begin{array}{l}-0.009 \\
(0.013)\end{array}$ & Overall Externalizing Behavior & $\begin{array}{c}0.029 \\
(0.024)\end{array}$ & Overall Externalizing Behavior & $\begin{array}{c}0.013 \\
(0.014)\end{array}$ \\
\hline HH Financial Problems & $\begin{array}{l}-0.009 \\
(0.043)\end{array}$ & Overall Behavior Score 1 & $\begin{array}{l}-0.002 \\
(0.014)\end{array}$ & Overall Behavior Score 1 & $\begin{array}{c}0.017 \\
(0.025)\end{array}$ & Overall Behavior Score 1 & $\begin{array}{c}0.017 \\
(0.015)\end{array}$ \\
\hline HH Income & $\begin{array}{c}0.000 \\
(0.000)\end{array}$ & Overall Behavior Score 2 & $\begin{array}{l}-0.010 \\
(0.014)\end{array}$ & Overall Behavior Score 2 & $\begin{array}{l}-0.011 \\
(0.024)\end{array}$ & Overall Behavior Score 2 & $\begin{array}{c}0.010 \\
(0.015)\end{array}$ \\
\hline
\end{tabular}

Note: This table shows the coefficients from 56 separate OLS regressions testing whether a characteristic predicts treatment status. In each regression, the treatment indicator PATHS is regressed on one baseline variable. Baseline variables include all available child, parental, and household characteristics and baseline child SBQ measures. All models include strata fixed effects for the level of randomization. Robust standard errors clustered at the school level are in parentheses. *** $\mathrm{p}<0.01, * * \mathrm{p}<0.05, * \mathrm{p}<0.1$ 
Table VI: Treatment Effect on Educational Outcomes

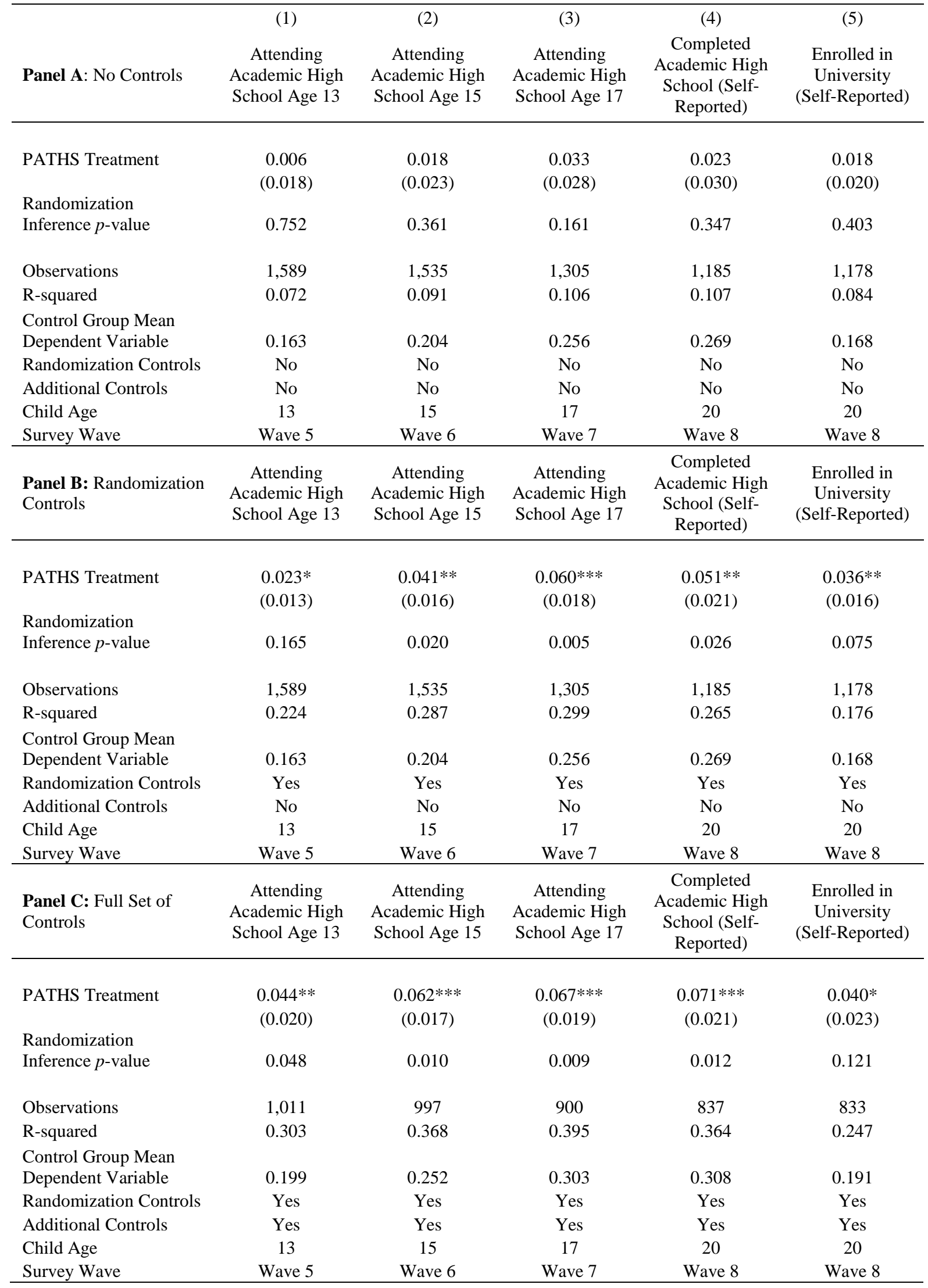

Note: This table shows the treatment effect of the PATHS intervention on the probability of attending academic high school at ages 13, 15, and 17 as well as on the probability of completing academic high school and being enrolled in university at age 20. All dependent variables are indicator variables and all specifications are estimated using linear 
probability models. All models include strata fixed effects for the level of randomization. In Panel A, we do not include any controls for baseline characteristics. In Panel B, we include randomization controls for mother and father education level and indicator variables for missing education level. In Panel C, we include controls for baseline child, parental, and household characteristics and baseline child SBQ measures. Child controls include age and gender of the child and having Swiss citizenship. Household controls include household income, age of the mother, indicator variables for the mother having Swiss citizenship and being born in Switzerland, an indicator for mother and father education level, indicator variables for missing education level, and indicator variables for single-parent household, household that received financial aid, and household that experienced financial problems. Controls for baseline child SBQ measures include measures for anxiety and depressivity, ADHD, non-aggressive externalizing problem behavior, non-aggressive conduct disorder, opposition and defiance, prosociality, and three measures of aggressive behavior. The table also shows $p$-values based on randomization inference with 10,000 replications. Robust standard errors clustered at the school level are in parentheses. $* * * \mathrm{p}<0.01, * * \mathrm{p}<0.05, * \mathrm{p}<0.1$ 


\section{Appendix A1: Supplementary Tables and Figures}

Table A1: Main Results with Separate Treatment Arms

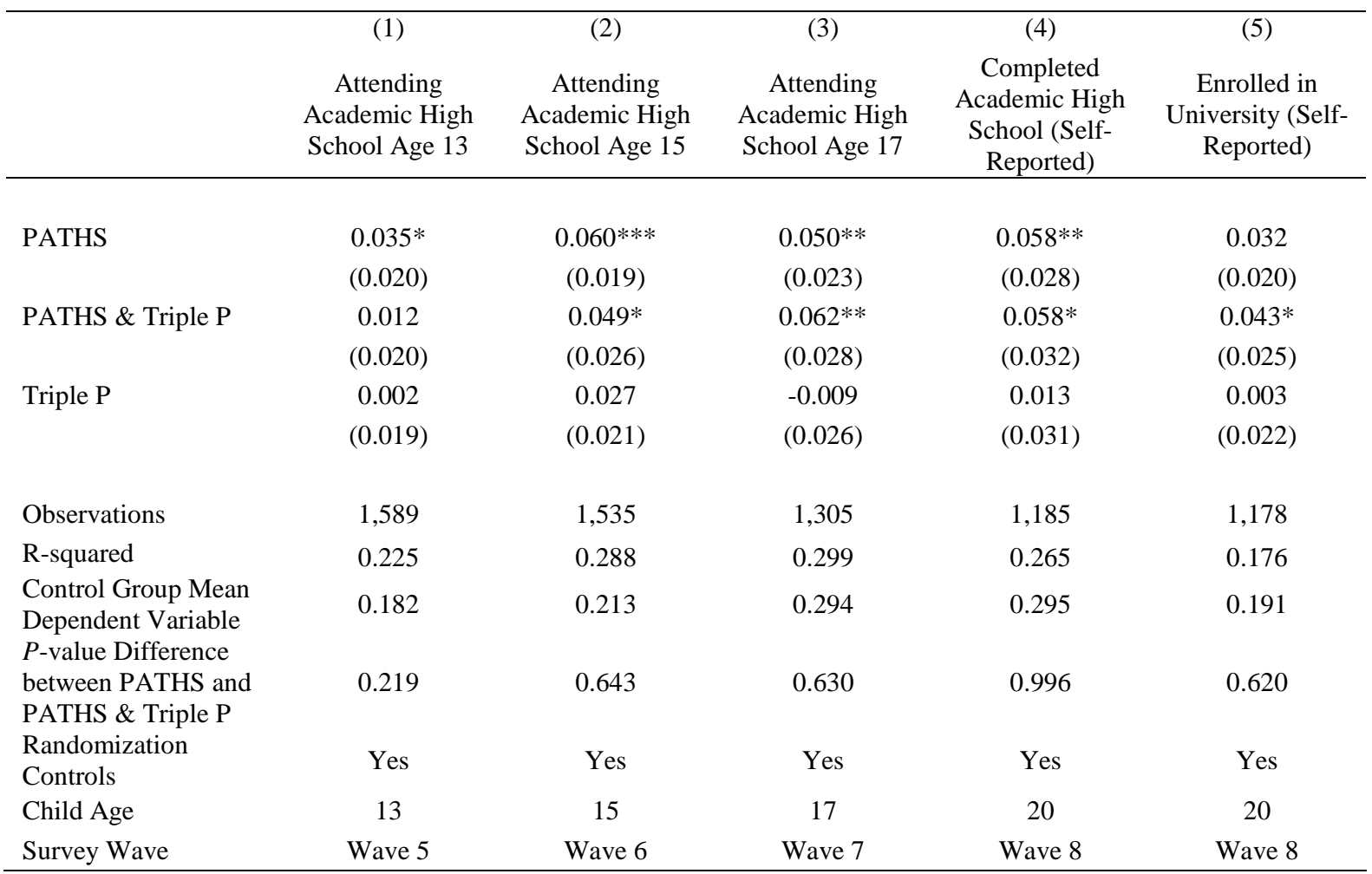

Note: This table shows the treatment effect of the PATHS intervention on the probability of attending academic high school at ages 13,15, and 17 as well as on the probability of completing academic high school and being enrolled in university at age 20 . All dependent variables are indicator variables and all specifications are estimated using linear probability models. We estimate separate effects for all separate intervention arms: PATHS, Triple $\mathrm{P}$, and the combined treatment PATHS \& Triple P. We report $p$-values of testing the difference between the PATHS and the PATHS \& Triple P coefficients. All models include strata fixed effects for the level of randomization. In Panel A, we do not include any controls for baseline characteristics. In Panel B, we include randomization controls for mother and father education level and indicator variables for missing education level. In Panel C, we include controls for baseline child, parental, and household characteristics and baseline child SBQ measures. Child controls include age and gender of the child and having Swiss citizenship. Household controls include household income, age of the mother, indicator variables for the mother having Swiss citizenship and being born in Switzerland, an indicator for mother and father education level, indicator variables for missing education level, and indicator variables for single-parent household, household that received financial aid, and household that experienced financial problems. Controls for baseline child SBQ measures include measures for anxiety and depressivity, ADHD, non-aggressive externalizing problem behavior, non-aggressive conduct disorder, opposition and defiance, prosociality, and three measures of aggressive behavior. Robust standard errors clustered at the school level are in parentheses. ${ }^{* * *} \mathrm{p}<0.01, * * \mathrm{p}<0.05, * \mathrm{p}<0.1$. 
Table A2: Main Results with Alternative Treatment Definition

\begin{tabular}{|c|c|c|c|c|c|}
\hline & (1) & (2) & (3) & (4) & (5) \\
\hline $\begin{array}{l}\text { Panel A: } \\
\text { Randomization } \\
\text { Controls }\end{array}$ & $\begin{array}{c}\text { Attending } \\
\text { Academic High } \\
\text { School Age } 13\end{array}$ & $\begin{array}{c}\text { Attending } \\
\text { Academic High } \\
\text { School Age } 15\end{array}$ & $\begin{array}{c}\text { Attending } \\
\text { Academic High } \\
\text { School Age } 17\end{array}$ & $\begin{array}{l}\text { Completed } \\
\text { Academic High } \\
\text { School (Self- } \\
\text { Reported) }\end{array}$ & $\begin{array}{c}\text { Enrolled in } \\
\text { University } \\
\text { (Self-Reported) }\end{array}$ \\
\hline PATHS Treatment & $\begin{array}{c}0.043 * * \\
(0.021)\end{array}$ & $\begin{array}{c}0.070 * * * \\
(0.021)\end{array}$ & $\begin{array}{c}0.058 * * \\
(0.024)\end{array}$ & $\begin{array}{c}0.074 * * \\
(0.032)\end{array}$ & $\begin{array}{l}0.039 * \\
(0.022)\end{array}$ \\
\hline $\begin{array}{l}\text { Observations } \\
\text { R-squared }\end{array}$ & $\begin{array}{c}819 \\
0.257\end{array}$ & $\begin{array}{c}798 \\
0.295\end{array}$ & $\begin{array}{c}674 \\
0.314\end{array}$ & $\begin{array}{c}616 \\
0.295\end{array}$ & $\begin{array}{c}613 \\
0.208\end{array}$ \\
\hline $\begin{array}{l}\text { Control Group Mean } \\
\text { Dependent Variable } \\
\text { Randomization }\end{array}$ & 0.182 & 0.213 & 0.294 & 0.295 & 0.191 \\
\hline Controls & Yes & Yes & Yes & Yes & Yes \\
\hline Additional Controls & No & No & No & No & No \\
\hline Child Age & 13 & 15 & 17 & 20 & 20 \\
\hline Survey Wave & Wave 5 & Wave 6 & Wave 7 & Wave 8 & Wave 8 \\
\hline $\begin{array}{l}\text { Panel B: Full Set of } \\
\text { Controls }\end{array}$ & $\begin{array}{c}\text { Attending } \\
\text { Academic High } \\
\text { School Age } 13\end{array}$ & $\begin{array}{c}\text { Attending } \\
\text { Academic High } \\
\text { School Age } 15\end{array}$ & $\begin{array}{c}\text { Attending } \\
\text { Academic High } \\
\text { School Age } 17\end{array}$ & $\begin{array}{l}\text { Completed } \\
\text { Academic High } \\
\text { School (Self- } \\
\text { Reported) }\end{array}$ & $\begin{array}{c}\text { Enrolled in } \\
\text { University } \\
\text { (Self-Reported) }\end{array}$ \\
\hline PATHS Treatment & $\begin{array}{c}0.068 * * \\
(0.027)\end{array}$ & $\begin{array}{c}0.089 * * * \\
(0.020)\end{array}$ & $\begin{array}{c}0.041 * * \\
(0.019)\end{array}$ & $\begin{array}{c}0.074 * * * \\
(0.021)\end{array}$ & $\begin{array}{c}0.025 \\
(0.027)\end{array}$ \\
\hline $\begin{array}{l}\text { Observations } \\
\text { R-squared }\end{array}$ & $\begin{array}{c}560 \\
0.358\end{array}$ & $\begin{array}{c}551 \\
0.379\end{array}$ & $\begin{array}{c}489 \\
0.435\end{array}$ & $\begin{array}{c}458 \\
0.404\end{array}$ & $\begin{array}{c}456 \\
0.333\end{array}$ \\
\hline $\begin{array}{l}\text { Control Group Mean } \\
\text { Dependent Variable } \\
\text { Randomization }\end{array}$ & 0.231 & 0.272 & 0.355 & 0.345 & 0.224 \\
\hline Controls & Yes & Yes & Yes & Yes & Yes \\
\hline Additional Controls & Yes & Yes & Yes & Yes & Yes \\
\hline Child Age & 13 & 15 & 17 & 20 & 20 \\
\hline Survey Wave & Wave 5 & Wave 6 & Wave 7 & Wave 8 & Wave 8 \\
\hline
\end{tabular}

Note: This table shows the treatment effect of the PATHS intervention on the probability of attending academic high school at ages 13,15, and 17 as well as on the probability of completing academic high school and being enrolled in university at age 20. All dependent variables are indicator variables and all specifications are estimated using linear probability models. The estimation sample in this table includes only the control group and the treatment group that received the PATHS intervention. All children who received the Triple P intervention are excluded. All models include strata fixed effects for the level of randomization. In Panel A, we include randomization controls for mother and father education level and indicator variables for missing education level. In Panel B, we include controls for baseline child, parental, and household characteristics and baseline child SBQ measures. Child controls include age and gender of the child and having Swiss citizenship. Household controls include household income, age of the mother, indicator variables for the mother having Swiss citizenship and being born in Switzerland, an indicator for mother and father education level, indicator variables for missing education level, and indicator variables for singleparent household, household that received financial aid, and household that experienced financial problems. Controls for baseline child SBQ measures include measures for anxiety and depressivity, ADHD, non-aggressive externalizing problem behavior, non-aggressive conduct disorder, opposition and defiance, prosociality, and three measures of aggressive behavior. Robust standard errors clustered at the school level are in parentheses. *** $\mathrm{p}<0.01, * * \mathrm{p}<0.05$, $* \mathrm{p}<0.1$. 
Table A3: Test for Selective Attrition

\begin{tabular}{lccccc}
\hline & $(1)$ & $(2)$ & $(3)$ & $(4)$ & $(5)$ \\
& $\begin{array}{c}\text { Observed at } \\
\text { Age 13 }\end{array}$ & $\begin{array}{c}\text { Observed at } \\
\text { Age 15 }\end{array}$ & $\begin{array}{c}\text { Observed at } \\
\text { Age 17 }\end{array}$ & $\begin{array}{c}\text { Observing } \\
\text { Completion of } \\
\text { Academic High } \\
\text { School }\end{array}$ & $\begin{array}{c}\text { Observing } \\
\text { Enrollment in } \\
\text { University }\end{array}$ \\
\hline PATHS Treatment & 0.017 & 0.011 & 0.001 & 0.012 & 0.012 \\
& $(0.011)$ & $(0.015)$ & $(0.021)$ & $(0.019)$ & $(0.019)$ \\
Observations & 1,675 & 1,675 & 1,675 & 1,675 & 1,675 \\
R-squared & 0.012 & 0.029 & 0.063 & 0.090 & 0.089 \\
$\begin{array}{l}\text { Control Group Mean } \\
\text { Dependent Variable }\end{array}$ & 0.94 & 0.91 & 0.783 & 0.711 & 0.707 \\
Randomization Controls & Yes & Yes & Yes & Yes & Yes \\
$\begin{array}{l}\text { Additional Controls } \\
\text { Child Age }\end{array}$ & No & No & No & No & No \\
Survey Wave & 13 & Wave 6 & Wave 7 & Wave 8 & Wave 8 \\
\hline
\end{tabular}

Note: This table shows the treatment effect of the PATHS intervention on the probability of observing a student's educational outcome at ages $13,15,17$, and 20 . We estimate linear probability models. The dependent variable is an indicator variable for observing the respective educational outcome. All models include strata fixed effects for the level of randomization. All models include randomization controls for mother and father education level and indicator variables for missing education level. The point estimates for the PATHS Treatment indicate whether the treatment has an effect on attrition. Robust standard errors clustered at the school level are in parentheses. $* * *$ $\mathrm{p}<0.01, * * \mathrm{p}<0.05, * \mathrm{p}<0.1$. 
Table A4: Main Results with Inverse Probability Weighting

\begin{tabular}{|c|c|c|c|c|c|}
\hline & $\begin{array}{c}(1) \\
\text { Attending } \\
\text { Academic High } \\
\text { School Age } 13\end{array}$ & $\begin{array}{c}(2) \\
\text { Attending } \\
\text { Academic High } \\
\text { School Age } 15\end{array}$ & $\begin{array}{c}(3) \\
\text { Attending } \\
\text { Academic High } \\
\text { School Age } 17\end{array}$ & $\begin{array}{c}(4) \\
\text { Completed } \\
\text { Academic High } \\
\text { School (Self- } \\
\text { Reported) }\end{array}$ & $\begin{array}{c}(5) \\
\text { Enrolled in } \\
\text { University } \\
\text { (Self-Reported) }\end{array}$ \\
\hline PATHS Treatment & $\begin{array}{c}0.044 * * \\
(0.020)\end{array}$ & $\begin{array}{c}0.061 * * * \\
(0.017)\end{array}$ & $\begin{array}{c}0.061 * * * \\
(0.019)\end{array}$ & $\begin{array}{c}0.066 * * * \\
(0.020)\end{array}$ & $\begin{array}{c}0.035 \\
(0.022)\end{array}$ \\
\hline Observations & 1,011 & 997 & 900 & 837 & 833 \\
\hline R-squared & 0.306 & 0.366 & 0.396 & 0.366 & 0.245 \\
\hline $\begin{array}{l}\text { Control Group Mean } \\
\text { Dependent Variable }\end{array}$ & 0.199 & 0.252 & 0.303 & 0.308 & 0.191 \\
\hline $\begin{array}{l}\text { Randomization } \\
\text { Controls }\end{array}$ & Yes & Yes & Yes & Yes & Yes \\
\hline Full Set of Controls & Yes & Yes & Yes & Yes & Yes \\
\hline Child Age & 13 & 15 & 17 & 20 & 20 \\
\hline Survey Wave & Wave 5 & Wave 6 & Wave 7 & Wave 8 & Wave 8 \\
\hline
\end{tabular}

Note: This table shows the treatment effect of the PATHS intervention on the probability of attending academic high school at ages 13, 15, and 17 as well as on the probability of completing academic high school and being enrolled in university at age 20. All dependent variables are indicator variables and all specifications are estimated using linear probability models. All models include strata fixed effects for the level of randomization. Models are identical to the regressions in Table VI, Panel C, but use inverse probability weighs to account for attrition. Inverse probabilities are based on predicted values from the model estimating attrition in Table A3. Robust standard errors clustered at the school level are in parentheses. $* * * \mathrm{p}<0.01, * * \mathrm{p}<0.05, * \mathrm{p}<0.1$. 
Table A5: Dosage Effects - Two Years vs. One Year of Treatment

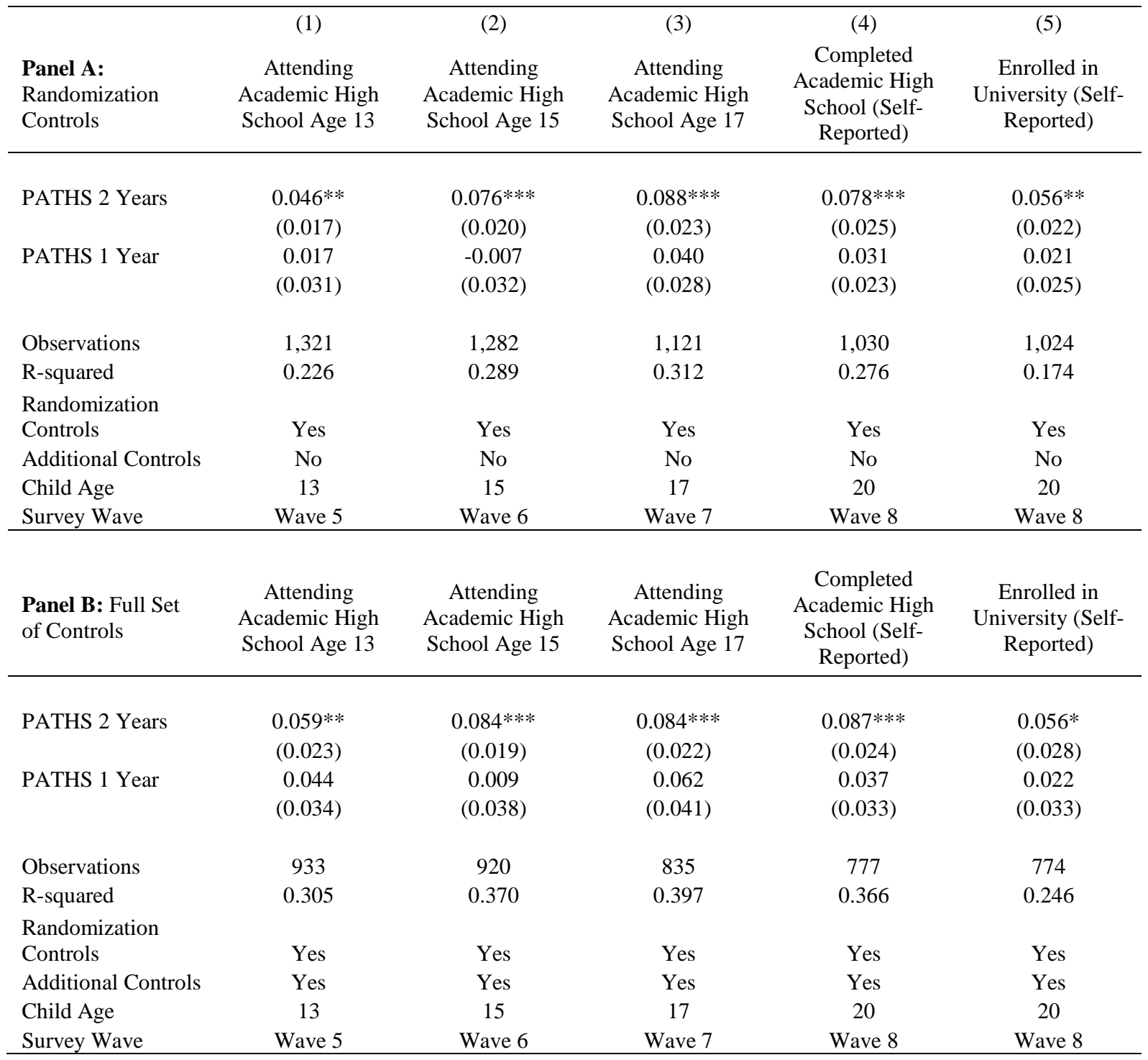

Note: This table shows treatment dosage effects of the PATHS intervention on the probability of attending academic high school at ages 13,15, and 17 as well as on the probability of completing academic high school and being enrolled in university at age 20. All dependent variables are indicator variables and all specifications are estimated using linear probability models. The PATHS treatment effect is separately shown for children who received the treatment for one (PATHS 1 Year) or two (PATHS 2 Years) years. All models include strata fixed effects for the level of randomization. In Panel A, we include randomization controls for mother and father education level and indicator variables for missing education level. In Panel B, we include controls for baseline child, parental, and household characteristics and baseline child SBQ measures. Child controls include age and gender of the child and having Swiss citizenship. Household controls include household income, age of the mother, indicator variables for the mother having Swiss citizenship and being born in Switzerland, an indicator for mother and father education level, indicator variables for missing education level, and indicator variables for single-parent household, household that received financial aid, and household that experienced financial problems. Controls for baseline child SBQ measures include measures for anxiety and depressivity, ADHD, non-aggressive externalizing problem behavior, non-aggressive conduct disorder, opposition and defiance, prosociality, and three measures of aggressive behavior. Robust standard errors clustered at the school level are in parentheses. $* * * \mathrm{p}<0.01, * * \mathrm{p}<0.05, * \mathrm{p}<0.1$. 
Table A6: Probability of Taking Academic High-School Admission Test

\begin{tabular}{|c|c|c|c|c|}
\hline \multirow[t]{2}{*}{ Panel A: Randomization Controls } & \multicolumn{4}{|c|}{ Taking Admission Test } \\
\hline & Any & Age 12 & Age 14 & Age 15 \\
\hline PATHS Treatment & $\begin{array}{c}0.027 \\
(0.022)\end{array}$ & $\begin{array}{l}0.041 * \\
(0.021)\end{array}$ & $\begin{array}{l}-0.001 \\
(0.013)\end{array}$ & $\begin{array}{c}0.006 \\
(0.012)\end{array}$ \\
\hline Observations & 1,675 & 1,675 & 1,675 & 1,675 \\
\hline R-squared & 0.153 & 0.153 & 0.009 & 0.013 \\
\hline Control Group Mean Dependent Variable & 0.316 & 0.262 & 0.096 & 0.055 \\
\hline Randomization Controls & Yes & Yes & Yes & Yes \\
\hline Additional Controls & No & No & No & No \\
\hline \multirow[t]{2}{*}{ Panel B: Full Set of Controls } & \multicolumn{4}{|c|}{ Taking Admission Test } \\
\hline & Any & Age 12 & Age 14 & Age 15 \\
\hline PATHS Treatment & $\begin{array}{c}0.002 \\
(0.025)\end{array}$ & $\begin{array}{c}0.020 \\
(0.025)\end{array}$ & $\begin{array}{l}-0.014 \\
(0.015)\end{array}$ & $\begin{array}{c}0.009 \\
(0.015)\end{array}$ \\
\hline Observations & 1,093 & 1,093 & 1,093 & 1,093 \\
\hline R-squared & 0.200 & 0.199 & 0.012 & 0.011 \\
\hline Control Group Mean Dependent Variable & .367 & .31 & .103 & .057 \\
\hline Randomization Controls & Yes & Yes & Yes & Yes \\
\hline Additional Controls & Yes & Yes & Yes & Yes \\
\hline
\end{tabular}

Note: The table shows the effect of the treatment on taking the academic high school admission test. We estimate linear probability models. Taking the admission test is possible at the three times. Column (1) shows the effect of ever taking the admission test. Columns (2) to (4) show the effect by grade. Panel A includes randomization controls for mother and father education level. Panel B includes controls for baseline child, parental, and household characteristics and the baseline child SBQ measures. All models include strata fixed effects. Robust standard errors clustered at the school level are in parentheses. *** $\mathrm{p}<0.01, * * \mathrm{p}<0.05, * \mathrm{p}<0.1$. 
Figure A1: Example Material from the Intervention I

\section{Training Self-Control with Control Signals}

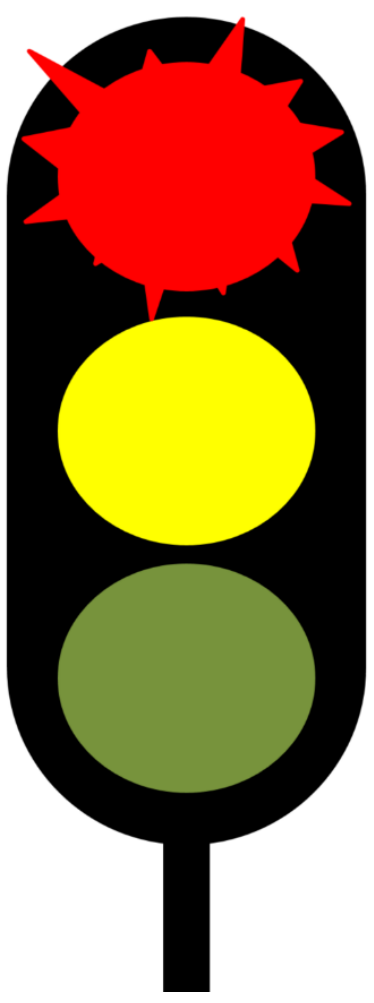

- Stop!

- Take a deep breath and calm down!

- Explain the problem and how you feel!

- What could you do?

- Would it work?

- What would happen?

- Try out your plan!

- Evaluate!

- Did your plan work out? 
Figure A2: Example Material from the Intervention II

\section{Understanding and Expressing Feelings}
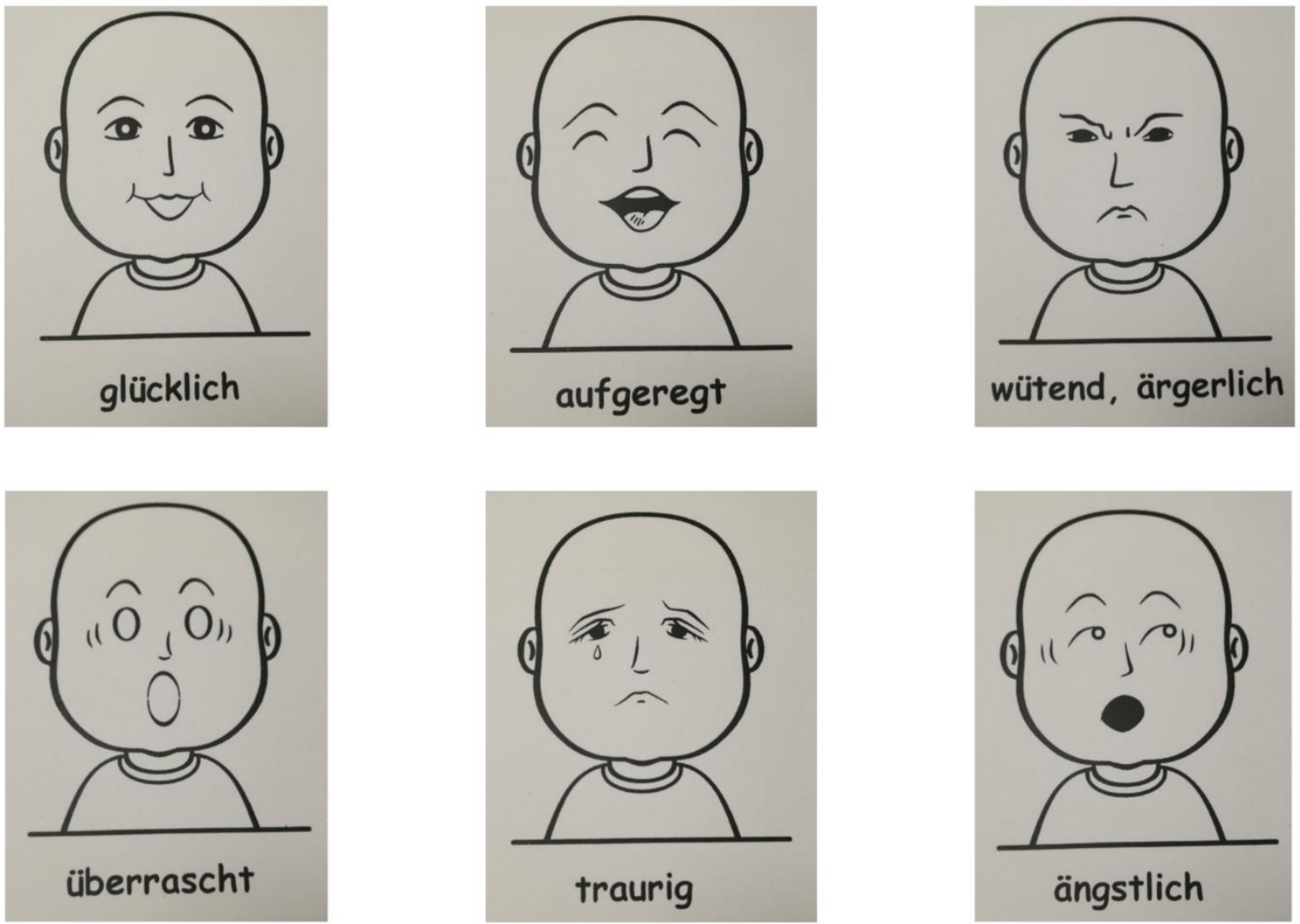

Note: Children use feeling cards to explain their own and other people's behavior, reactions, and feelings. Translation: happy, excited, angry, surprised, sad, worried. 
Figure A3: Example Material from the Intervention III

\section{Fairness and Rules: Recognizing Aggression \& Unacceptable Behavior}
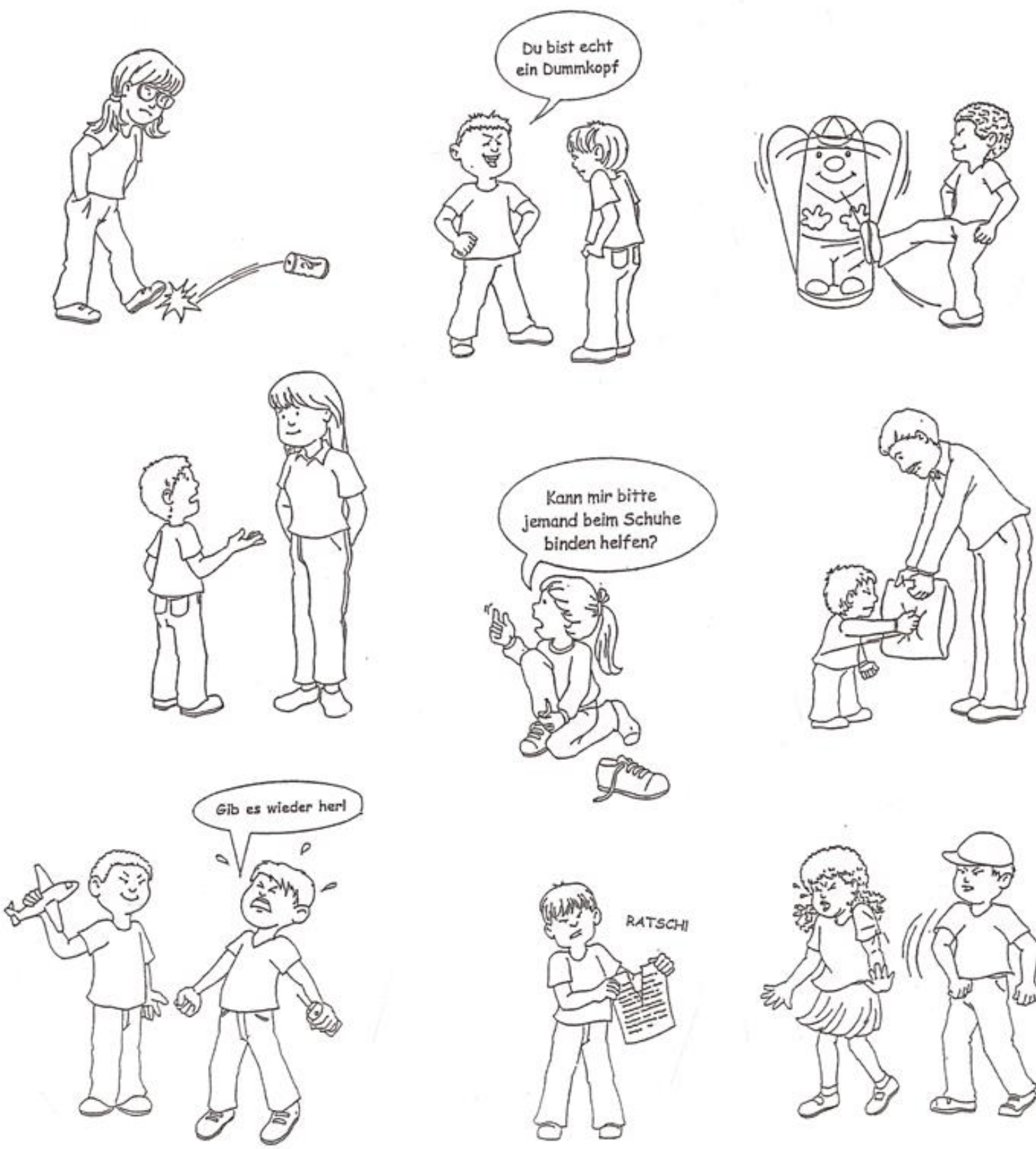

Note: Instructions for children: Color all pictures showing a behavior that is okay. 
Figure A4: Example Material from the Intervention IV

\section{Homework with parental involvement}

\section{Being proud of something}

Ask your mother, father or another adult about a situation, back where they were around your age, when they were very proud of an achievement.

Draw a picture about this:

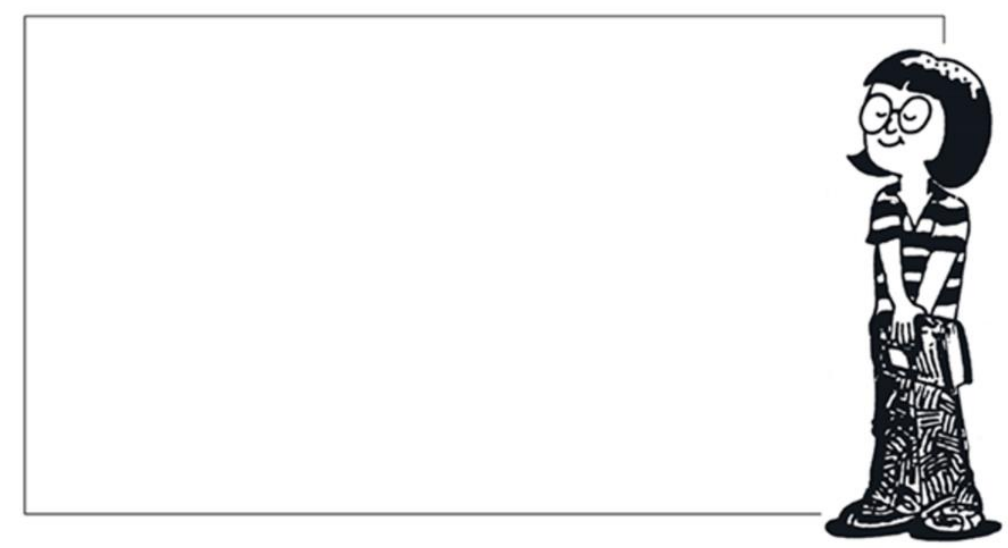

$\underline{\text { STOLZ sein }}$

Frage deine Mutter, deinen Vater oder eine andere erwachsene Person nach einer Situation, in der sie sich richtig stolz fühlte über etwas, das sie getan oder erreicht hatte, als sie ungefähr in deinem Alter war.

Zeichne ein Bild dazu: 
Figure A5: Example Material from the Intervention V

Information Leaflet for Parents (a)

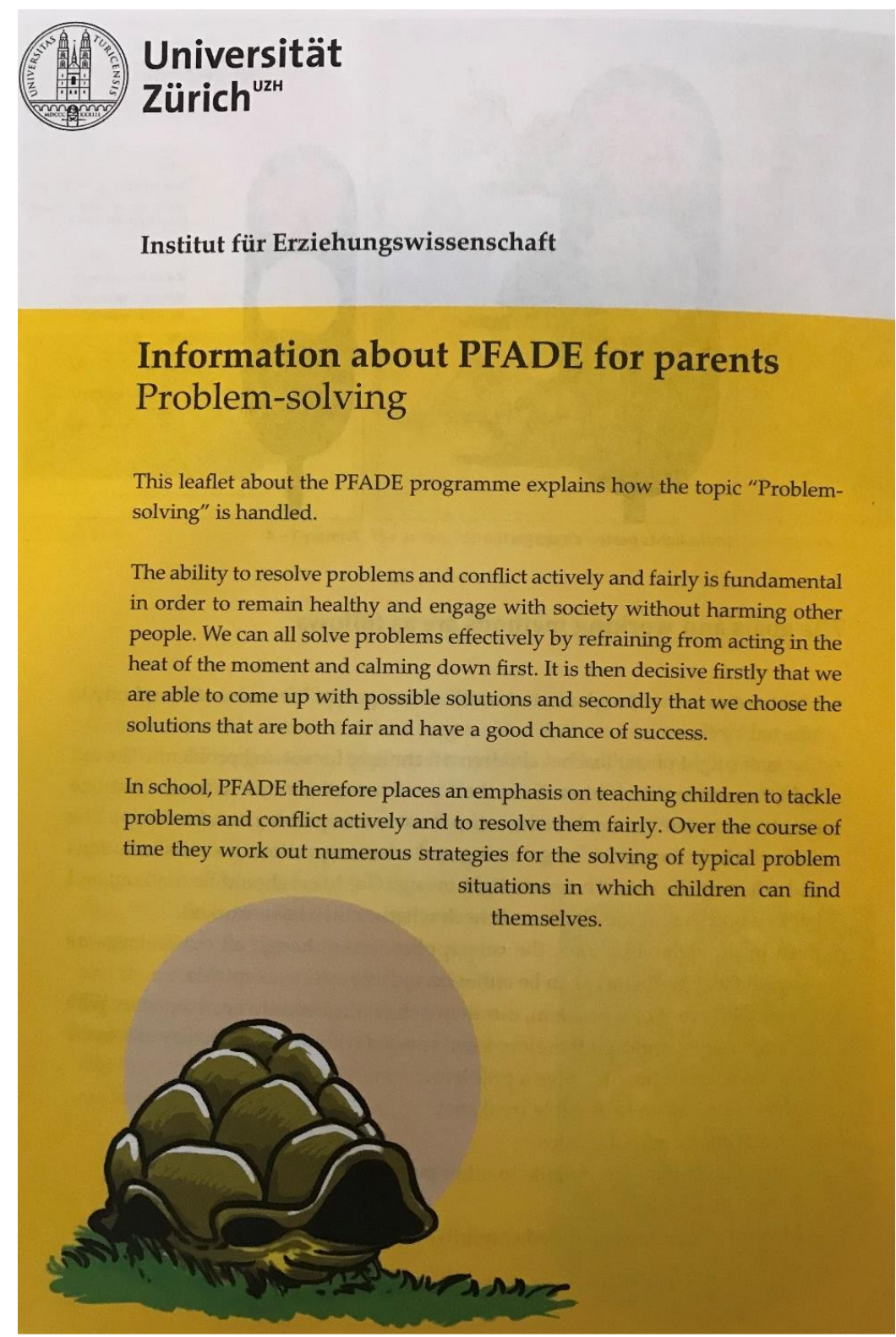




\section{Information Leaflet for Parents (b)}

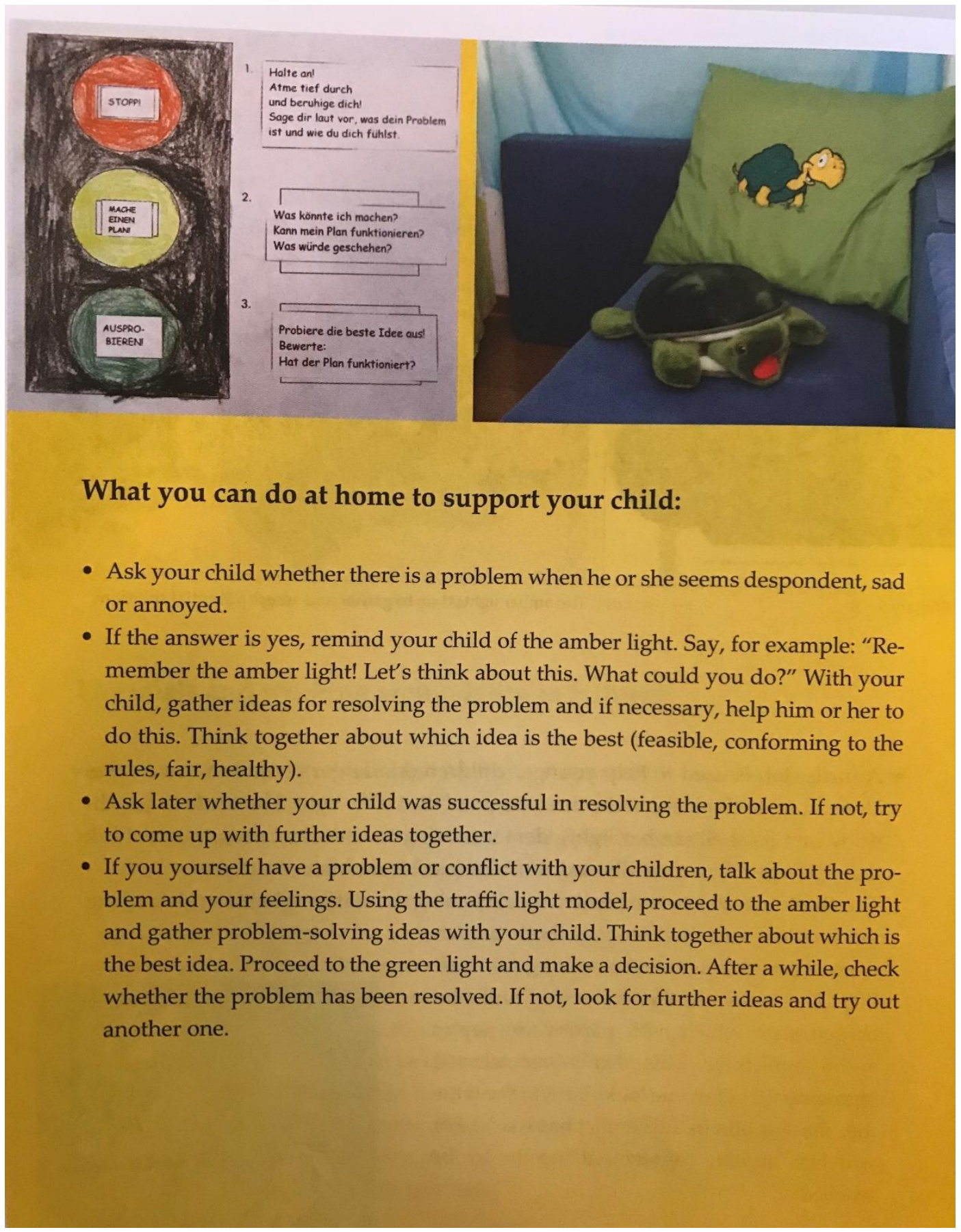




\section{Information Leaflet for Parents (c)}

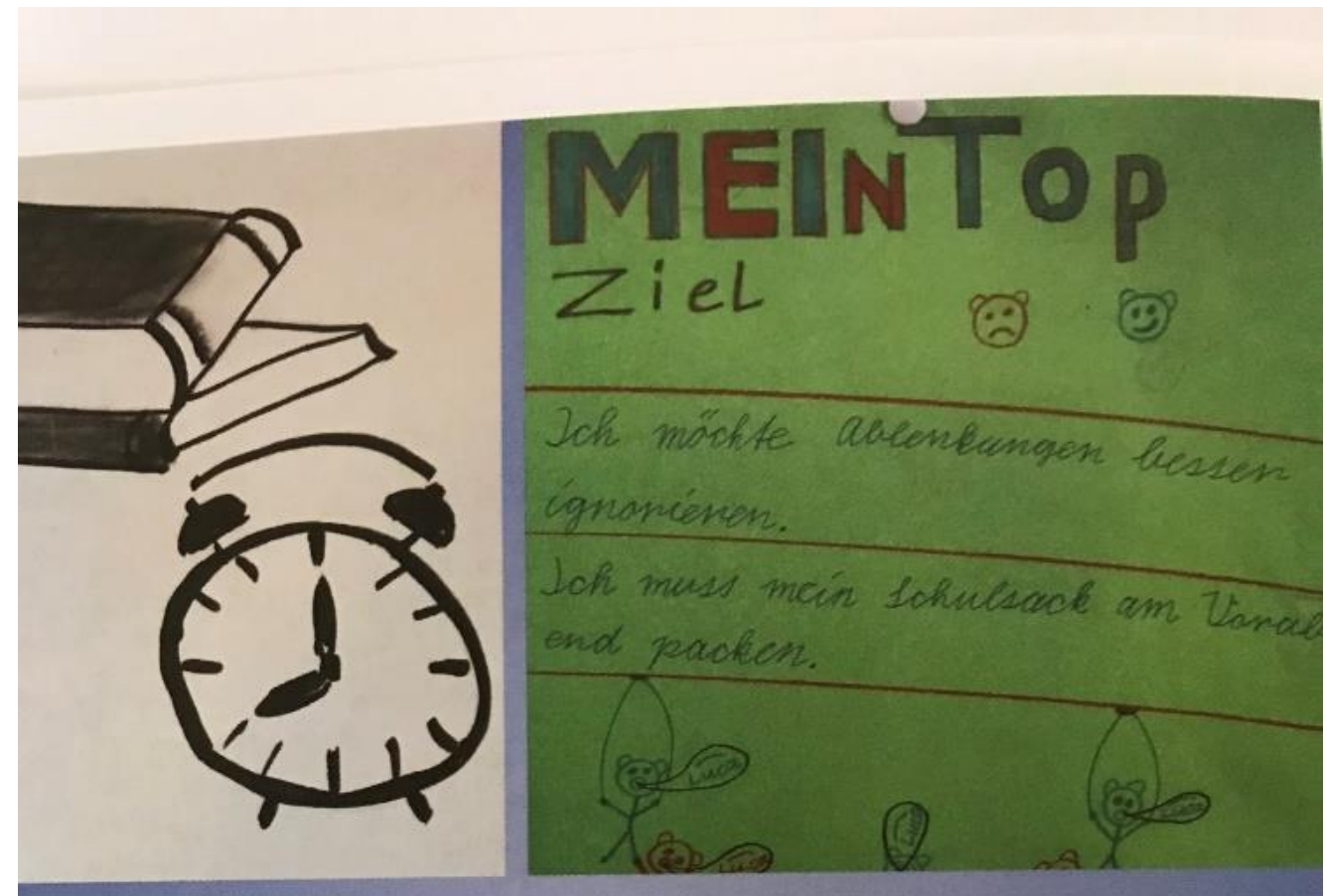

What you can do at home to support your child:

- Talk to your child about the TOP technique and ask what strategies he or she has learned through it.

- Organisation and planning also relate specifically to the time your child spends at home and in other places outside the classroom. Support your child in looking after the necessary materials and help him or her to have a tidy, quiet place for their school things and for studying.

- Help him or her to apportion their out-of-school time sensibly so that studying is completed in good time and where necessary in several sessions but also in order to ensure that relaxation has its place.

- Encourage your child to develop a strong motivation for school and schoolwork and to put in the appropriate amount of effort. 
Figure A6: Treatment Effects on Employment and Education Status at Age 20

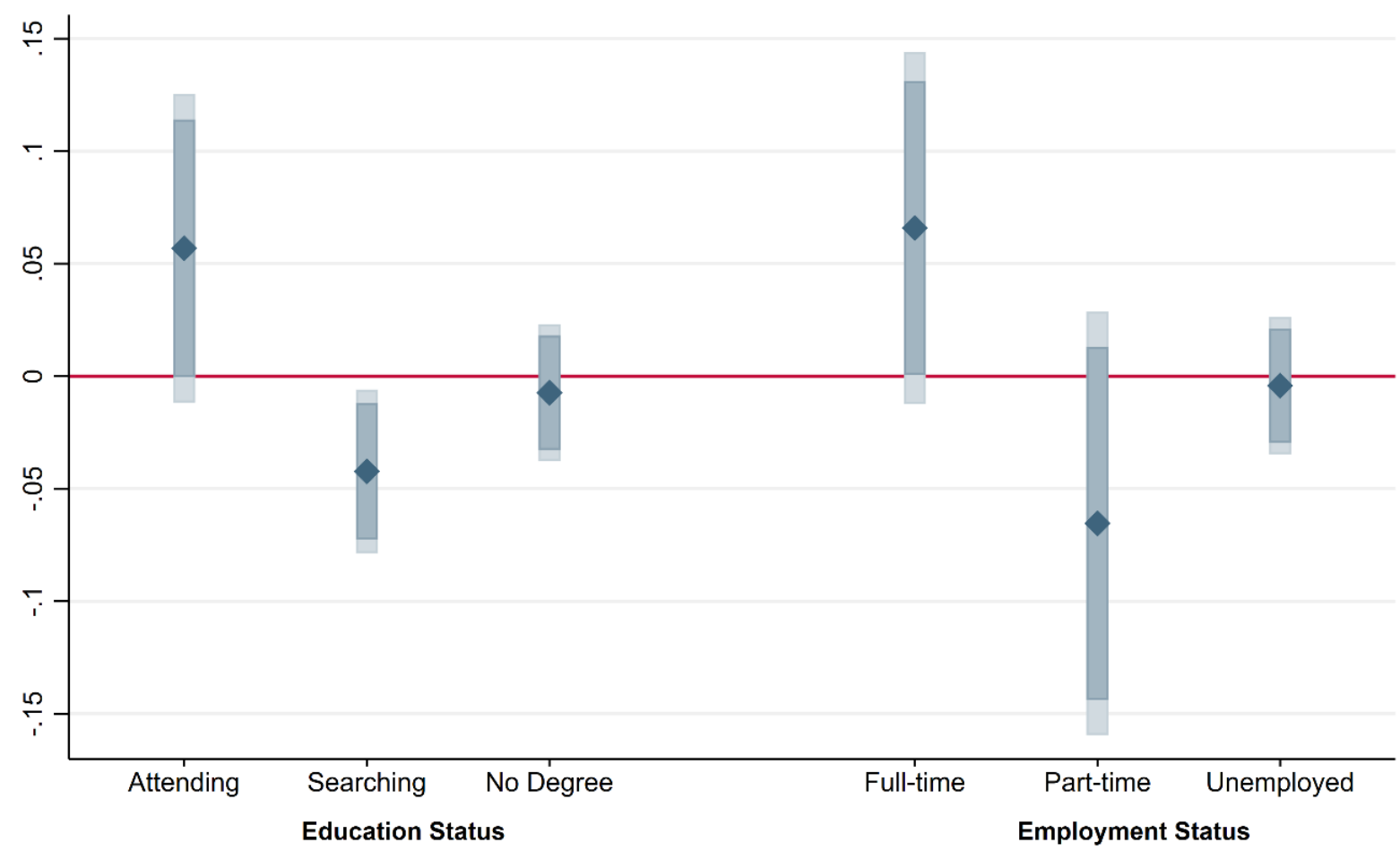

Confidence Interval:

$95 \%$
$\square$

Note: The figure shows the treatment effect of the PATHS intervention on employment and education status at age 20. Employment outcomes are conditional on not participating in any education or training. All dependent variables are indicator variables and all specifications are estimated using linear probability models. All models include strata fixed effects for the level of randomization. All models include randomization controls for mother and father education level and indicator variables for missing education level as well as controls for baseline child, parental, and household characteristics and the baseline child SBQ measures. Each point estimate is shown with the respective 90 and 95 percent confidence intervals calculated based on standard errors clustered at the school level. 


\section{Figure A7: Heterogeneous Treatment Effects for Academic High School Completion}

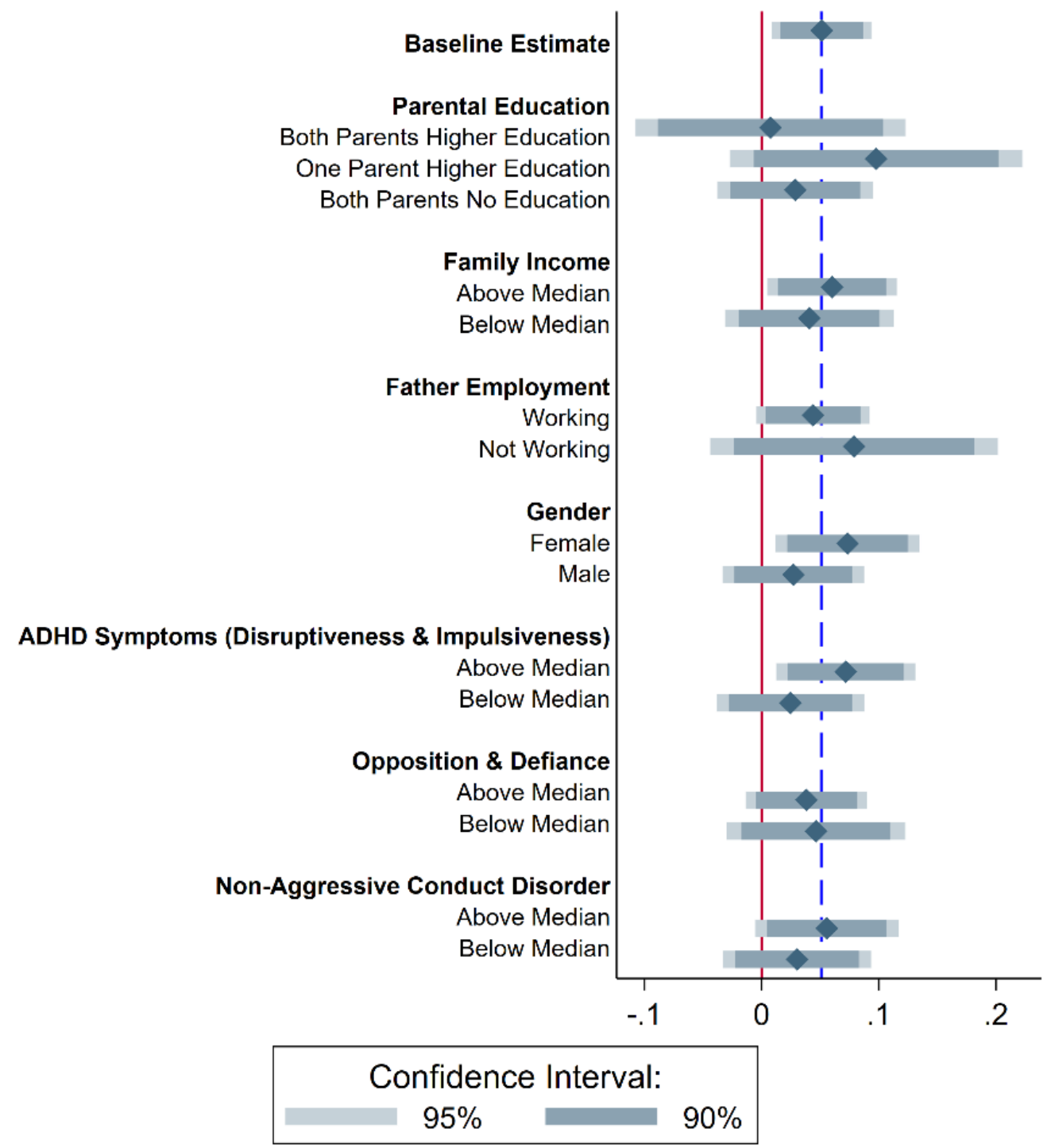

Note: This figure shows heterogeneous treatment effects for completion of academic high-school depending on parental education, family income, employment status of the father, the gender of the child, as well as on the baseline SBQ measure for ADHD symptoms (disruptiveness and impulsiveness), opposition and defiance, and non-aggressive conduct disorder. Estimates are based on models in Table VI, Panel B and include randomization controls. The dashed line indicates the overall treatment effect shown in Table VI, Panel B, column (1). All models include strata fixed effects for the level of randomization. Each point estimate is shown with the respective 90 and 95 percent confidence intervals calculated based on standard errors clustered at the school level. 


\section{Figure A8: Treatment Effects on Attention Deficit and Hyperactivity Symptoms}

(a) Disruptiveness

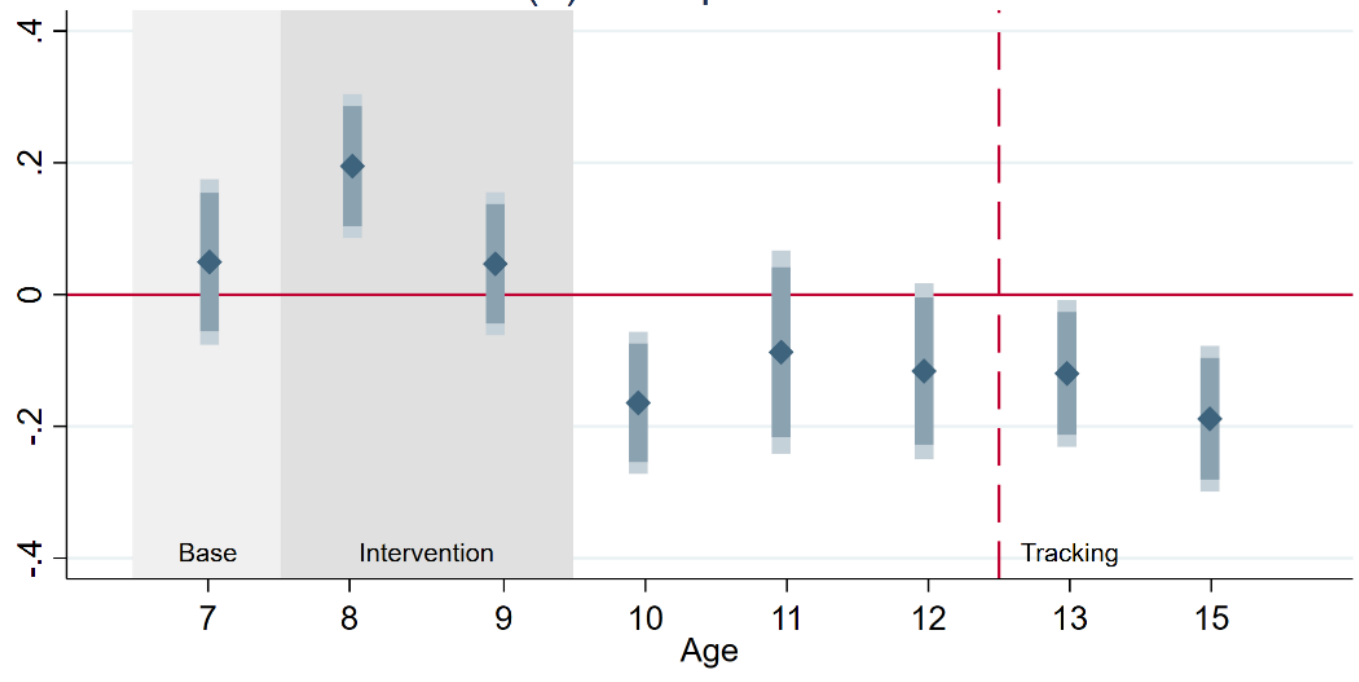

(b) Impulsiveness
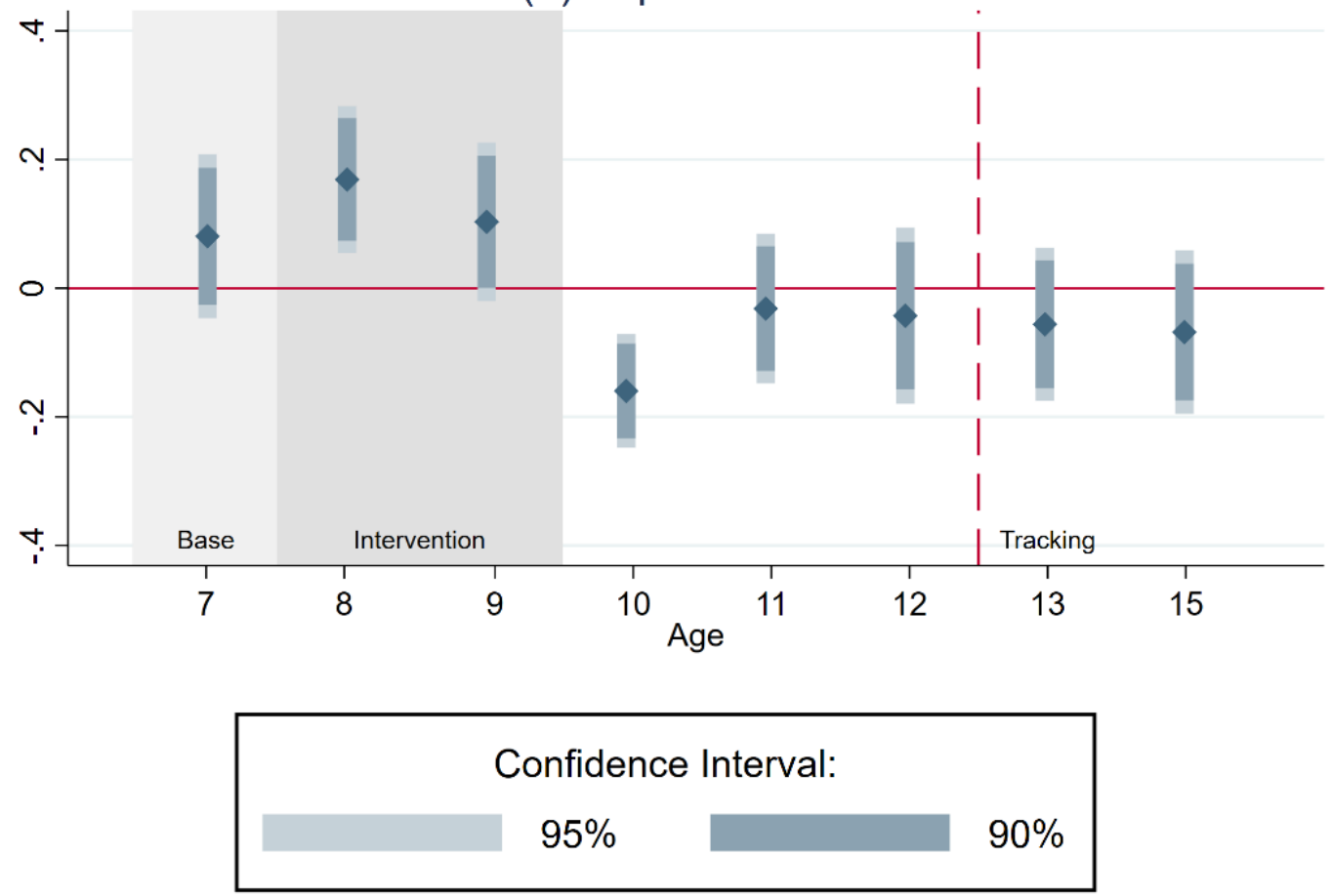

Note: This figure shows the treatment effect of the PATHS intervention on children's socio-emotional skills from ages 7 through 15. The dependent variable in Panel (a) is disruptiveness. The dependent variable in Panel (b) is impulsiveness. All dependent variables are indices standardized to mean zero and a standard deviation of one. All models include strata fixed effects for the level of randomization. All models include controls for baseline child, parental, and household characteristics and baseline child SBQ measures. To provide evidence on balance across the treatment and the control groups, we do not include individual controls in the estimation of the treatment effect at age 7. For each SBQ measure, we combine measures from teacher and parent reports by taking the average of the two standardized indices and standardizing the resulting index again. For measures at ages 10, 12, 13, and 15, we rely solely on teacher reports, as there are no parent surveys at these times. Details on the SBQ items and construct validity are provided in Appendix B2. Shaded areas indicate the baseline and the intervention periods. The dashed vertical line shows the time when tracking into secondary schools takes place. Each point estimate is shown with the respective 90 and 95 percent confidence intervals calculated based on standard errors clustered at the school level. 


\section{Appendix B1: Data Collection and Survey Procedures}

In each of the 56 selected schools, all children entering Grade 1 in 2004 were invited to participate in the first survey wave via their parents, providing a target sample of 1,675 children. For the data collection of waves 1 to 3 at ages 7, 8, and 9, we obtained informed consent from the parents of participating children, which we renewed for the data collection in wave 4 at age 11 . From wave 5 (age 13) onward, the participants themselves provided direct informed consent, though parents retained the right to opt their child out of the study. Informed consent by the youths was renewed at wave 7 (age 17) and wave 8 (age 20).

z-proso entails four main types of data collections, i.e., parent, teacher, child, and youth surveys. Parent interviews at child age 7, 8, 9, and 11 were usually carried out at the mothers' home using computer-aided personal interviews (CAPI). Given the highly multicultural population in Zurich, the standardized interviews were conducted by specially trained native speakers in nine different languages: German, Albanian, Bosnian/Croatian/Serbian, Portuguese, Spanish, Italian, Turkish, Tamil, and English. The interviews typically took about an hour and participating parents received vouchers worth USD 20-50 as participation incentives.

Teachers of all participating children were invited to complete postal surveys at ages 7 , $8,9,10,11,12,13,15$, and 17 . The teacher survey consisted of a one-page form related to each participant in the teacher's class that took five to ten minutes to complete, plus a questionnaire at the level of the class and of the schoolhouse, which took five to ten minutes to complete. In the first three years, participation was mandatory for all teachers. After that, teachers who had to complete more than seven questionnaires were offered book vouchers worth about USD 50 as a participation incentive. 
Specially trained interviewers conducted standardized computer assisted child interviews (CAPI) at ages 7, 8, and 9 during regular school lessons (45 minutes). These surveys were specially designed for the age group and were mostly play-based. At ages 11, 13, 15, and 17 we changed the methodology to classroom-based paper-and-pencil questionnaires. Two to three research assistants conducted the survey sessions, which lasted 60 to 90 minutes. At age 11, the surveys were conducted during regular school lessons. For later waves, surveys took place during leisure time and were incentivized with the equivalent of USD 30-60 in cash. At age 20, the survey was based on essentially the same instrument as in previous waves, but was administered in a central university computer lab using computer-assisted self-interview (CASI) methodology. The participation incentive increased to USD 75.

All data collections were in accordance with the Swiss data protection and human research acts. The most recent review by the Ethics Committee of the Faculty of Arts and Social Sciences of the University of Zurich took place in early 2018. 


\section{Appendix B2: Additional Information for SBQ and APQ Measures}

Table B1: Social Behavior Questionnaire Items (SBQ)

\begin{tabular}{|c|c|}
\hline Domain & Survey Items Examples \\
\hline $\begin{array}{l}\text { ADHD symptoms } \\
\text { (Disruptive and } \\
\text { Impulsive) }\end{array}$ & $\begin{array}{l}\text { Is impulsive, acts without thinking about it } \\
\text { Has difficulty awaiting turn in games or groups } \\
\text { Cannot sit still, is restless or hyperactive } \\
\text { Is squirmy, fidgety } \\
\text { Cannot settle to anything for more than a few moments } \\
\text { Is distractible, has trouble sticking to any activity } \\
\text { Can't concentrate, can't pay attention for long } \\
\text { Is inattentive }\end{array}$ \\
\hline $\begin{array}{l}\text { Opposition and } \\
\text { Defiance }\end{array}$ & $\begin{array}{l}\text { Is disobedient } \\
\text { Ignores teacher/parents }\end{array}$ \\
\hline $\begin{array}{l}\text { Non-Aggressive } \\
\text { Conduct Disorder }\end{array}$ & $\begin{array}{l}\text { Steals } \\
\text { Destroys things/belongings } \\
\text { Tells lies and cheats }\end{array}$ \\
\hline $\begin{array}{l}\text { Anxiety and } \\
\text { Depressivity }\end{array}$ & $\begin{array}{l}\text { Cries a lot } \\
\text { Is nervous, high-strung, or tense } \\
\text { Tends to be overly fearful and anxious } \\
\text { Seems worried and concerned } \\
\text { Seems sad, unhappy, or depressive } \\
\text { Is not as happy as other children } \\
\text { Has trouble enjoying himlherself } \\
\text { Stares into space } \\
\text { Appears miserable, depressed or unhappy }\end{array}$ \\
\hline Aggression & $\begin{array}{l}\text { When child has been teased or threatened, gets angry easily and strikes back } \\
\text { Gets aggressive when contradicted } \\
\text { Gets mad when not getting something } \\
\text { Gets aggressive when something is taken from him/her } \\
\text { Takes part in fights } \\
\text { Attacks others physically } \\
\text { Kicks, bites, or hits other kids } \\
\text { Tortures or tyrannizes others or is mean to others } \\
\text { Intimidates or bullies others in order to get his own way } \\
\text { Tries to dominate others } \\
\text { Threatens others } \\
\text { Humiliates others } \\
\text { Bosses others around } \\
\text { Encourages other children to pick on a particular child }\end{array}$ \\
\hline Prosocial Behavior & $\begin{array}{l}\text { Volunteers to help clear up a mess someone else has made } \\
\text { If there is a quarrel or dispute, will try to stop it } \\
\text { Will try to help someone who has been hurt } \\
\text { Will invite bystanders to join in a game } \\
\text { Spontaneously helps to pick up objects that another child has dropped (e.g. pencils, books, etc.). } \\
\text { Comforts a child who is crying or upset } \\
\text { Listens to others' points of view } \\
\text { Shows sympathy to someone who has made a mistake } \\
\text { Is good at understanding other people s feelings } \\
\text { Shares with others }\end{array}$ \\
\hline
\end{tabular}

Note: This table shows the survey items for each domain measuring social behavior, taken from the Social Behavior Questionnaire. Answers were given on a 5-point Likert scale (1 = "never," 5 = "always"). 
Table B2: Validity of SBQ Measures

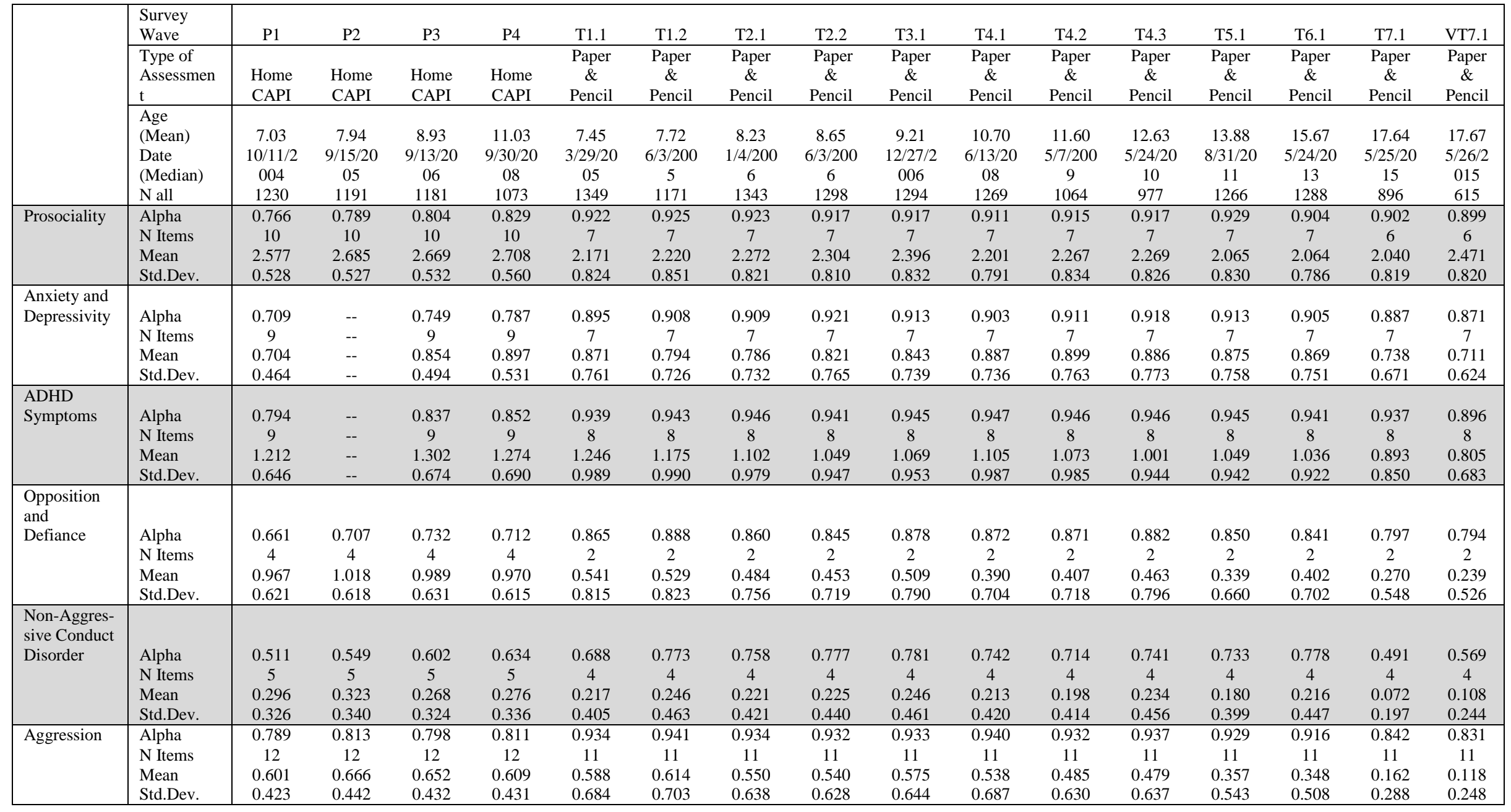

Note: This table provides information on the measurement of the SBQ inventory and Cronbach's Alpha of the respective subdomain. 
Table B3: Parenting Practices Survey Items (APQ)

\begin{tabular}{|c|c|}
\hline Domain & Survey Item \\
\hline Corporal Punishment & $\begin{array}{l}\text { You spank your child with your hand when he/she has done something wrong } \\
\text { You slap your child when he/she has done something wrong } \\
\text { You hit your child with a belt, switch, or other object when he/she has done something wrong }\end{array}$ \\
\hline $\begin{array}{l}\text { Parental Control and } \\
\text { Supervision }\end{array}$ & $\begin{array}{l}\text { Your child fails to leave a note or to let you know where he/she is going } \\
\text { Your child stays out in the evening past the time he/she is supposed to be home } \\
\text { Your child is out with friends you don't know } \\
\text { Your child goes out without a set time to be home } \\
\text { Your child is out after dark without an adult with him/her } \\
\text { You get so busy that you forget where your child is and what he/she is doing } \\
\text { You don't check that your child comes home at the time she/he was supposed to } \\
\text { You don't tell your child where you are going } \\
\text { Your child comes home from school more than an hour past the time you expect him/her } \\
\text { You don't know where your child is out }\end{array}$ \\
\hline Inconsistent Discipline & $\begin{array}{l}\text { You threaten to punish your child and then do not actually punish him/her } \\
\text { Your child talks you out of being punished after he/she has done something wrong } \\
\text { You feel that getting your child to obey you is more trouble than it's worth } \\
\text { You let your child out of a punishment early (like lift restrictions earlier than you originally said) } \\
\text { Your child is not punished when he/she has done something wrong } \\
\text { The punishment you give your child depends on your mood }\end{array}$ \\
\hline Parental Involvement & $\begin{array}{l}\text { You have a friendly talk with your child } \\
\text { You volunteer to help with special activities that your child is involved in (such as sports, } \\
\text { boy/girl scouts, church youth groups) } \\
\text { You play games or do other fun things with your child } \\
\text { You ask your child about his/her day in school } \\
\text { You help your child with his/her homework } \\
\text { You ask your child what his/her plans are for the coming day } \\
\text { You drive your child to a special activity } \\
\text { You talk to your child about his/her friends } \\
\text { Your child helps plan family activities } \\
\text { You attend PTA meetings, parent/teacher conferences, or other meetings at your child's school }\end{array}$ \\
\hline Positive Parenting & $\begin{array}{l}\text { You let your child know when he/she is doing a good job with something } \\
\text { You reward or give something extra to your child for obeying you or behaving well } \\
\text { You compliment your child when he/she does something well } \\
\text { You hug or kiss your child when he/she does something well } \\
\text { You tell your child that you like it when he/she helps out around the house }\end{array}$ \\
\hline
\end{tabular}

Note: This table shows the survey items for each domain measuring parenting style, taken from the Alabama Parenting Questionnaire (Shelton, Frick, and Wootton 1996). Answers were given on a 5-point Likert scale $(1=$ "never," 5 = "very often"). 


\section{Appendix B3: Performance Differences After Tracking}

One question that arises from our results is whether the treatment effect creates a potential mismatch between students and secondary schools. Marginal students who got pushed into academic high school by the treatment may perform relatively worse in the more challenging school track. We analyze this question by looking at students' grades in secondary school after tracking has taken place. While grades are determined on a curve and might not be comparable across schools' tracks, this analysis can still provide important information about the relative performance positions of treatment and control children in their respective school. If the treatment causes a mismatch between students and schools, we would expect these children to receive worse grades.

Figure B1 (Panel (a) and Panel (b)) shows the treatment effect for standardized math and language grades at ages 13,15 , and 17 . The figure shows the treatment does not affect math or language grades in secondary school. Treated and untreated children perform similarly during secondary school. This similarity seems to confirm that the intervention did not lead to a mismatch between students and secondary schools. The intervention caused children to enter more demanding school tracks without reducing their relative performance within these schools. Once tracked, they do not underperform in comparison to the control group. These results are consistent with the persistence of the treatment effect in secondary school documented in Figure 3. 


\section{Figure B1: Student-School Mismatch? Treatment Effects on Post-Tracking Performance}

(a) Math Grades

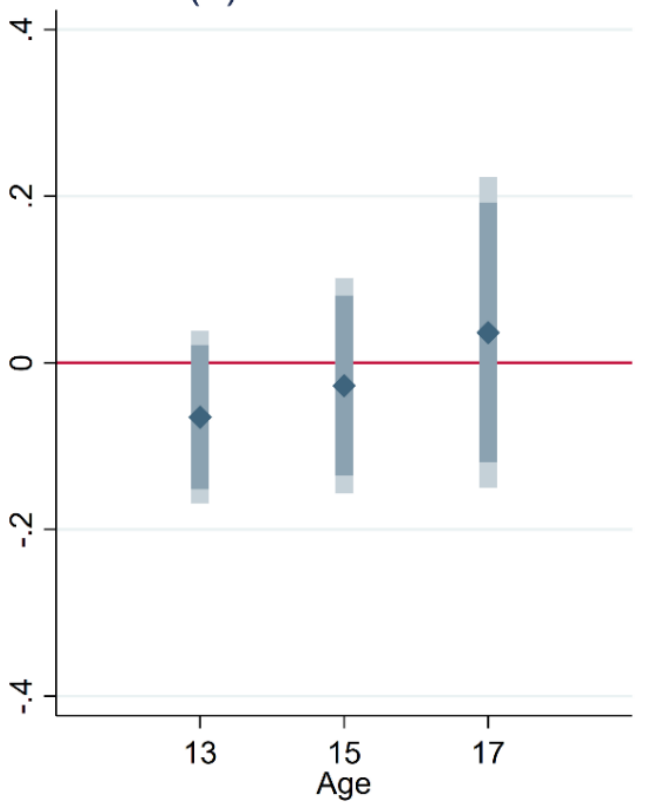

(b) Language Grades

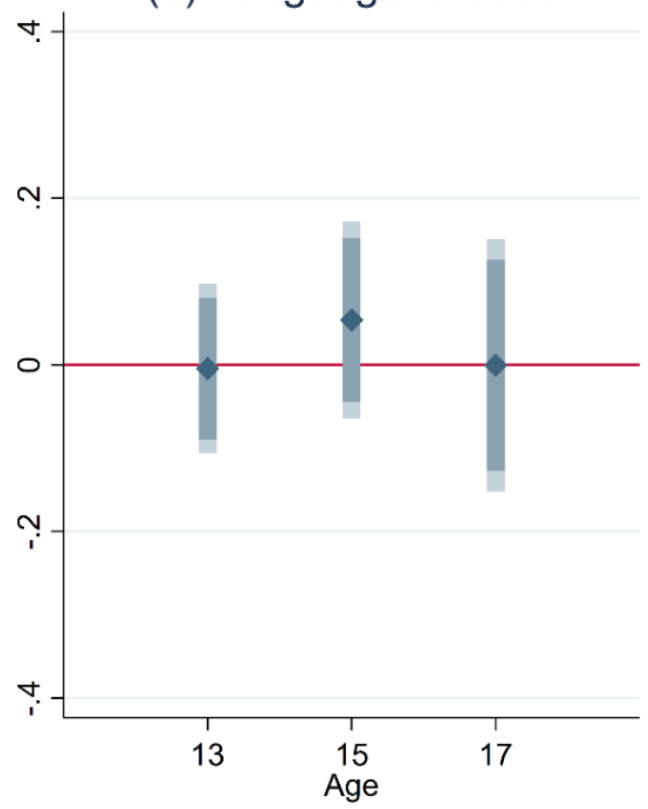

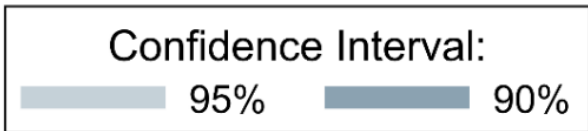

Note: This figure shows the treatment effect of the PATHS intervention on standardized post-tracking school grades from ages 13 through 17. The dependent variable in Panel (a) is a student's grade in mathematics. The dependent variable in Panel (b) is a student's grade in language. All dependent variables are indices standardized to mean zero and a standard deviation of one. All models include strata fixed effects for the level of randomization. All models include controls for baseline child, parental, and household characteristics and baseline child SBQ measures. Each point estimate is shown with the respective 90 and 95 percent confidence intervals calculated based on standard errors clustered at the school level. 